\title{
Mergers and Acquisitions (M\&As) in High-Tech Industries : measuring the post-M\&A innovative performance of companies
}

Citation for published version (APA):

Cloodt, M. M. A. H. (2005). Mergers and Acquisitions (M\&As) in High-Tech Industries : measuring the post-M\&A innovative performance of companies. [Doctoral Thesis, Maastricht University]. Datawyse. https://doi.org/10.26481/dis.20050408mc

Document status and date:

Published: 01/01/2005

DOI:

10.26481/dis.20050408mc

Document Version:

Publisher's PDF, also known as Version of record

Please check the document version of this publication:

- A submitted manuscript is the version of the article upon submission and before peer-review. There can be important differences between the submitted version and the official published version of record.

People interested in the research are advised to contact the author for the final version of the publication, or visit the DOI to the publisher's website.

- The final author version and the galley proof are versions of the publication after peer review.

- The final published version features the final layout of the paper including the volume, issue and page numbers.

Link to publication

\footnotetext{
General rights rights.

- You may freely distribute the URL identifying the publication in the public portal. please follow below link for the End User Agreement:

www.umlib.nl/taverne-license

Take down policy

If you believe that this document breaches copyright please contact us at:

repository@maastrichtuniversity.nl

providing details and we will investigate your claim.
}

Copyright and moral rights for the publications made accessible in the public portal are retained by the authors and/or other copyright owners and it is a condition of accessing publications that users recognise and abide by the legal requirements associated with these

- Users may download and print one copy of any publication from the public portal for the purpose of private study or research.

- You may not further distribute the material or use it for any profit-making activity or commercial gain

If the publication is distributed under the terms of Article $25 \mathrm{fa}$ of the Dutch Copyright Act, indicated by the "Taverne" license above, 


\section{MERGERS AND ACQUISITIONS (M\&As) IN HIGH-TECH INDUSTRIES}

MEASURING THE POST-M\&A INNOVATIVE PERFORMANCE OF COMPANIES 
Mergers and Acquisitions (M\&As) in high-tech industries:

Measuring the post-M\&A innovative performance of companies

C M.M.A.H. Cloodt, Maastricht 2005

Proefschrift Universiteit Maastricht

ISBN 90-5278-450-7

Niets uit deze uitgave mag worden verveelvoudigd en/of openbaar gemaakt door middel van druk, fotokopie, microfilm, of welke andere wijze dan ook, zonder voorafgaande, schriftelijke toestemming van de houder van het auteursrecht.

Foto omslagontwerp: De "Southern Crab Nebula" (Space Telescope Science Institute) Druk: Datawyse / Universitaire Pers Maastricht 


\section{MERGERS AND ACQUISITIONS (M\&AS) IN HIGH-TECH INDUSTRIES}

\section{MEASURING THE POST-M\&A INNOVATIVE PERFORMANCE OF COMPANIES}

\section{PROEFSCHRIFT}

TER VERKRIJGING VAN DE GRAAD VAN DOCTOR

AAN DE UNIVERSITEIT MAASTRICHT, OP GEZAG VAN DE RECTOR MAGNIFICUS, PROF. MR. G.P.M.F. MOLS VOLGENS HET BESLUIT VAN HET COLLEGE VAN DECANEN, IN HET OPENBAAR TE VERDEDIGEN OP VRJJDAG 8 APRIL 2005 OM 14.00 UUR

DOOR

MYRIAM MARIA ANNA HELENA CLOODT

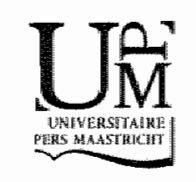


Promotor:

Prof. dr. J. Hagedoom

\section{Beoordelingscommissie:}

Prof. dr. J.G.A.M. Lemmink (voorzittert)

Prof. dr. G.M. Duysters

Prof. dr. E.H.J. Vaassen, RA 
Voor mijn ouders 


\section{Dankwoord (Acknowledgements in Dutch)}

Nog jongk en onbevange, bin ich op waeg gegaon.

Oet maonde woorte jaore, oet druime 'n bestjaon (Schintaler).

De voltooing van dit proefschrift was niet mogelijk geweest zonder de steun en vriendschap van velen. Allereerst wil ik mijn promotor John Hagedoorn bedanken, die zo"n belangrijke rol heeft gespeeld bij de totstandkoming van dit proefschrift. Ondanks zijn drukke agenda wist hij altijd tijd vrij te maken om bruikbare ideeën te ontwikkelen, mijn onderzoek te bespreken, met grote precisie de hoofdstukken te lezen en deze van waardevol commentaar te voorzien. Ik heb veel van hem geleerd en heb waardering voor zijn excellente academische vaardigheden en niet aflatend enthousiasme. John, ik heb bijzonder prettig met je samengewerkt en hoop dat ook in de toekomst te mogen doen.

Hans van Kranenburg wil ik bedanken voor zijn waardevolle adviezen en de plezierige samenwerking als co-auteur.

Eveneens een woord van dank voor Geert Duysters, Jos Lemmink en Eddy Vaassen vanwege hun vakkundige evaluatie van mijn proefschrift en hun waardevolle opmerkingen, Geert Duysters wil ik tevens bedanken voor de kans die hij me heeft gegeven om me verder te ontplooien als onderzoeker binnen een vriendelijke en stimulerende werkomgeving.

Ik bedank mijn voormalige collega's van de UM en in het bijzonder de collega's van Organisatie en Strategie voor de leuke en leerzame tijd in Maastricht. Ik wil vooral Kitty van Straaten, Eva Nelissen en Adela Buttolo bedanken voor hun uitstekende hulp bij het regelen van allerlei zaken; Marc van Ekert voor het bedenken van de meest ingewikkelde queries; Laura Willemsen en Kim Wolters voor hun helpende hand tijdens de data verzameling; Geke Blok, Henk Frederiks en Robert Pans voor de "slecht-nieuws" gesprekken tijdens mijn jaar als studie consulent; Judith Buddenberg, Ellen Krijnen, Ine Kuppen, Karen Temmink, Eveline van Caspel, Margje Heijmans en het MEV bestuur voor alle inspanningen op alumni-gebied en last but not least het champagne-comité voor de leuke vrijdagavonden, voorheen in d'Ouwe Klok en later in de Wekker.

Alle aio's van de NOBEM cursus wil ik bedanken voor de plezierige tijd in Rotterdam en Groningen. Waar is de volgende reünie?

Ook een woord van dank aan mijn collega's van de TU/e, in het bijzonder de afdeling Organisatiekunde \& Marketing voor de leuke manier waarop ze me hebben ontvangen als nieuwe medewerker. 
Mijn kamergenoot Maurice de Rochemont wil ik bedanken voor zijn interesse in mijn onderzoek en zijn steun tijdens de laatste loodjes van mijn proefschrift.

Alle mensen van de TAG groep en in het bijzonder Bonnie Beerkens, René Belderbos, Geert Duysters, Victor Gilsing, Charmianne Lemmens, Ard-Pieter de Man, Ad van den Oord, Gaby Rasters, Nadine Roijakkers, Wim Vanhaverbeke, Nicoline Verbeek en Vareska van de Vrande wil ik bedanken voor hun vertrouwen in onze (toekomstige) samenwerking.

Ik wil ook graag mijn vrienden en kennissen bedanken die, elk op hun eigen manier, kleur geven aan mijn leven. Margy Grispen, Mieke Hasman, Freek Hermkens, Simone Evans en Esther van der Zwet bedankt voor menig gezellig uurtje; Sarianna Lundan and Sara Villanueva many thanks for the enjoyable talks; Adela Buttolo, Mark Stallinga en Simone Franssen bedankt voor de leuke uitstapjes naar het Onze Lieve Vrouweplein en de Schintaler; Pascal Breuls, Nadine Roijakkers, Caren Schelleman, Wilfred Schoenmakers en Diana Smitsmans bedankt voor jullie vriendschap en vertrouwen; Mirella Kleijnen, bedankt dat je mijn paranimf wilt zijn. Je bent een echte vriendin! Het is moeilijk in woorden uit te drukken wat elk van bovenstaande personen voor mij betekent, vandaar de volgende quote: "Each friend represents a world in us, a world possibly not born until they arrive, and it is only by this meeting that a new world is born" (Anais Nin).

Tenslotte een woord van dank aan mijn familie en in het bijzonder oma Erven voor uw betrokkenheid en liefde en oma Cloodt voor de onbetaalbare tijd die we samen mochten hebben.

Daniëlle en Robert, ik wil jullie bedanken voor jullie eindeloze wriendschap, hulp en enthousiasme. Daniëlle, ik kan me geen betere zus wensen! Je hebt een speciaal plekje in mign hart.

Mijn grootste dank gaat uit naar mijn ouders aan wie ik dit boek opdraag. Mam en pap bedankt voor jullie onvoorwaardelijke liefde en ondersteuning. 't Geuf sjterre aan de hemel en sjterre hie op aerd, mèr geluif mich es ich zegk geer zeet mich 't mièste waert. Ik hou van jullie!

Maastricht, 2005 



\section{CONTENTS}

Acknowledgements (in Dutch)

1 Introduction 1

1.1 Introduction 1

1.2 Resource-based view, knowledge-based view, organizational learning 3

1.3 Research questions 4

1.4 Reasons for selecting the high-tech industries 5

$\begin{array}{ll}1.5 \text { Outline of the book } & 7\end{array}$

2 M\&A activity in high-tech industries 9

2.1 Introduction 9

2.2 Mergers \& Acquisitions: their rationale and some definitions 11

2.3 Historical importance of M\&As, 1900-1985 13

2.4 General patterns in M\&A activity, 1985-1994 15

2.5 International patterns in M\&A activity, 1985-1994 17

2.6 Product-market diversification patterns in M\&A activity, 1985-1994 23

2.7 Technological diversification patterns in M\&A activity, 1985-1994 24

2.8 Conclusions 26

3 Measuring innovative performance $\quad 29$

$\begin{array}{ll}3.1 \text { Introduction } & 29\end{array}$

3.2 Relationship between inventive, technological and innovative performance 31

3.3 Indicators of innovative performance $\quad 32$

$\begin{array}{ll}3.4 \text { Research questions } & 36\end{array}$

$\begin{array}{ll}3.5 \text { Research Methodology } & 37\end{array}$

$\begin{array}{ll}3.6 \text { Results } & 39\end{array}$

3.7 Discussion and Conclusions $\quad 44$

4 Mergers and Acquisitions: their effect on innovative performance $\quad 47$

4.1 Introduction $\quad 47$

4.2 Theory and hypotheses $\quad 49$

4.3 Methods $\quad 53$

4.4 Results $\quad 59$

4.5 Discussion and Conclusions 63 
5 The choice between related and unrelated technological M\&As $\quad 67$

5.1 Introduction $\quad 67$

5.2 Theory and hypotheses $\quad 69$

5.3 Methods $\quad 73$

5.4 Results $\quad 77$

$\begin{array}{lr}5.5 \text { Discussion } & 80\end{array}$

5.6 Conclusion $\quad 82$

6 Conclusions $\quad \mathbf{8 3}$

$\begin{array}{ll}6.1 \text { Introduction } & 83\end{array}$

6.2 Some major findings of this thesis $\quad 84$

6.3 Methodological, theoretical and managerial implications 90

6.4 Limitations and suggestions for future research 93

$\begin{array}{lr}\text { Appendices } & 95\end{array}$

A. The Securities Data M\&A database 95

B. The U.S. Patent and Trademark Office Database (USPTO) 96

C. Distribution of companies in the sample, for sectors and regions 97

D. Correlations 98

E. Results for the KMO measure and the MSA measure $\quad 100$

$\begin{array}{ll}F . \text { Communalities for North America and others } & 101\end{array}$

G. Results of the initial unrotated factor analysis $\quad 102$

H. Ratios for the different indicators in the sample 103

I. Distribution of companies in the sample, for sectors and regions 104

$\begin{array}{ll}\text { J. Means and standard deviations, for all variables } & 105\end{array}$

K. Distribution of companies in the sample, for sectors and regions 107

$\begin{array}{lr}\text { References } & 109\end{array}$

Summary in Dutch (Nederlandse samenvatting) 131

$\begin{array}{ll}\text { Curriculum Vitae } & 137\end{array}$ 


\section{LIST OF TABLES}

2.1 Relative international M\&A index per high-tech sector 19

2.2 Distribution of the share of M\&A deals per high-tech sector and per region 22

2.3 Relative diversification M\&A index per high-tech sector 24

2.4 Relative technological diversification M\&A index per high-tech sector 25

2.5 Important findings in M\&A activity for the period 1985-1994 26

3.1 Distribution of size classes of companies 38

$\begin{array}{ll}3.2 \text { Means and standard deviations } & 40\end{array}$

3.3 Correlations 41

3.4 Communality measures $\quad 43$

3.5 Results of the initial unrotated factor analysis 43

4.1 Distribution of size classes of companies 55

4.2 Negative binomial regression with distributed lag anallysis 60

5.1 Distribution of size classes of companies 75

5.2 Means, standard deviations, and correlations for all variables 78

$\begin{array}{ll}5.3 \text { Results for the Negative Binomial model } & 79\end{array}$

\section{LIST OF FIGURES}

1.1 Overview of the specific research questions 6

2.1 Number of M\&A deals in the period 1895-1985 14

2.2 Number of M\&A deals in the high-tech industry during the period 1985-1994 16

2.3 Number of M\&A deals per high-tech sector during the period 1985-1994 17

2.4 The share $(\%)$ of international M\&As in the total number of M\&A deals $\quad 18$

2.5 Distribution of number of M\&A deals for the high-tech industry 20

$\begin{array}{ll}2.6 \text { Distribution of number of M\&A deals, economic regions } & 21\end{array}$

3.1 Venn diagrams $\quad 32$

5.1. An overview of the contribution of our study to prior research 68 

. 


\section{CHAPTER 1}

\section{INTRODUCTION}

\subsection{Introduction}

During the last decades, we have seen an enormous growth in M\&A activity in general and more specific in the high-tech sector. Merger activity in the first half of 2004 consisted of 14.565 transactions and volume increased well over $42 \%$ (compared to the same period in 2003) to 892 billion dollar (Thomson Financial Statistics, 2004). The high-technology sector is nowadays the most active sector in M\&A activity with 727 completed deals in the first quarter of 2004 , or $15.3 \%$ of the total global market (Thomson Financial Statistics, 2004).

In 2003, the high-tech sector was characterized by large transactions with the top 10 deals representing 54\% of the total deal value (PriceWatherhouseCoopers, 2004). One of the top deals driving the market at that time was the acquisition by General Electric Co's of Amersham for 9.4 billion dollars (Mergerstat, 2004). In that same year, an important M\&A in the computers and office machinery sector was the acquisition of Rational Software by IBM for the amount of 3.2 billion dollars. Significant deals in the aerospace and defense industry include, for example, the acquisition of Honeywell's Australian Aerospace unit by Raytheon, and the acquisition of Orincon by Lockheed Martin. Volume-wise the year 2003 was a record year for M\&A activity in the pharmaceutical industry consisting of 568 transactions with a total value of 29 billion dollars (PriceWaterhouseCoopers, 2004). A striking deal in this sector was the 66 billion dollar hostile acquisition of Aventis by the French pharmaceutical company Sanofi (Thomson Financial Statistics, 2004).

This enormous increase in M\&A activity has not remained unnoticed and is probably also one of the reasons why mergers and acquisitions have attracted so much attention in the academic press. Although M\&As are very popular in business life, academic research about the impact of M\&As on the acquiring firm's performance remains inconclusive (King, Dalton, Daily and Covin, 2004). We will shortly summarize the findings of previous research covering different fields and concentrating on those articles that specifically address key issues. Industrial economists have focused on merger motives such as economies of scale and scope, market power, and the effects of mergers and acquisitions on efficiency and profitability (Olie, 1996). Research done by Caves (1989) shows that mergers may be profitable, however on average, empirical analyses show that improved post-M\&A performance is either non-existent or very limited. Meeks (1977) demonstrates that in the year of the M\&A the profitability improves slightly. All subsequent years report a decline from the pre-merger level. Studies done by Mueller (1986a, 1986b) and Ravenscraft and Scherer $(1987,1989)$ illustrate that in general mergers have a neutral 
or negative effect on profitability and growth (market share). Based on the abovementioned literature it can be said that in most of the cases the hypothesis that M\&As improve performance is not supported.

A number of studies argue that M\&As imply transaction costs, such as negotiating, bidding, monitoring, and enforcements costs, which can all be present during the takeover process (Williamson, 1975). Potential difficulties with respect to M\&As are for example the complexity of the acquisition process, information asymmetry and asset specificity of the two firms engaged in the M\&A negotiations (Hitt, Hoskisson, Johnson and Moesel, 1996; VanHaverbeke, Duysters and Noorderhaven, 2002). M\&A negotiations are often complex given the fact that there are multiple parties involved i.e. bankers, lawyers, and executives (Hitt et al., 1996). The information asymmetry argument addresses the problem of valuing a potential candidate for a merger or acquisition (VanHaverbeke et al., 2002). Asset specificity deals with the difficulties associated with separating needed assets from undesired assets (Duysters, 2001). To deal with these transaction dilficulties, M\&As require extensive managerial time and energy and the use of substantial resources, which complicate the realization of potential returns (Bamey, 1988; Hitt et al., 1996).

Financial economists typically have studied acquisition performance and have used stock market data to assess it. More in particular, they use the event study methodology to measure performance by examining changes in the (stock market) value of the acquiring and acquired companies. Most merger event studies conclude that the shareholders of the acquired firm experience positive returns while the returns for the shareholders of the acquiring firm are by and large small or insignificant. This means that on average mergers are value-enhancing (Healy, Palepu and Ruback, 1992; Jensen \& Ruback, 1983; Jensen, 1984; Jarell, Brickley and Netter, 1988).

Research in strategic management has focused on the role of strategic fit and the post-merger implementation process (Olie, 1996). Strategic fit is the degree to which the acquired or merged firms augment or complement the acquiring firm's strategy and the degree to which additional value is created (Jemison and Sitkin, 1986). A substantial part of the management literature expects that compared with unrelated M\&As, related M\&As should show superior performance because of value created by economies of scale, economies of scope, or market power (i.e. Singh \& Montgomery, 1987; Shelton, 1988). Others show that unrelated M\&As did not do worse than horizontally related or vertical M\&As (i.e. Datta, 1991; Lubatkin, 1987; Seth, 1990). "This inconclusive evidence may suggest that strategic fit by itself is not enough for increased post-M\&A performance (Olie, 1996).

Contributions of the organizational behavior theory, argue that the post-M\&A integration process is another important factor in the enhancement of a firm's postM\&A performance. Effective integration is defined by Olie (1996) as the combination of firms into a single entity in such a way that the goals of the new organization are fulfilled. However, effective integration is complex, time consuming and full of risks (Capron and Mitchell, 2000; Chakrabarti, Hauschildt and Sueverkruep, 1994; Haspeslagh and Jemison. 1991). Overall, firom the fields of strategic management and 
organizational behavior, one may conclude that the success of a merger or acquisition depends first on the strategic fit and second on the effective (post-merger) implementation.

Extending the discussion of different theoretical perspectives in the next section, we will describe the different academic approaches that help us to position the topic of this dissertation within the proper theoretical context. We will introduce the research questions that form the center of each of the core chapters in this thesis in section 1.3. Section 1.4 clarifies the most important reasons for selecting four hightech industries, as the primary industrial context of our analysis. Finally, in section 1.5 we will discuss the outline of the remainder of this thesis.

\subsection{Resource-based view, Knowledge-based view, Organizational Learning}

The conclusions of the various studies mentioned in section 1.1, present a mixture of results and often predict a negative effect of M\&As on a firm's post-M\&A performance. A reason for this finding is according to King et al. (2004) the short-term focus of most post-M\&A research and the fact that M\&A activity is often motivated by factors other than financial performance. A number of elements in the resourcebased view of the firm, in combination with some related contributions that stress the importance of organizational learning and innovation, provide some useful insights about the implications of M\&As on a longer term. The resource-based view of the firm describes the firm as a unique collection of difficult-to-imitate resources, competencies and capabilities (Barney, 1986; Grant, 1996; Wernerfelt, 1984). To create a competitive advantage and capture above-normal rate of returns (i.e. rents), these resources must, by definition, be scarce, valuable and reasonably durable (Barney, 1991.). The emerging knowledge-based view is an outgrowth of the resource-based view to the extent that it focuses upon knowledge as the strategically most important resource of the firm (Conner and Prahalad, 1996; Grant, 1996; Nonaka, 1991; Spender, 1989). Knowledge is also a central issue in several other research traditions that stress the importance of both organizational learning and the transfer and diffusion of innovative capabilities within the firm (e.g. Boisot, 1995; Grant, 1996; Huber, 1991; Levitt and March, 1988).

In the context of this thesis, the opportunities for organizational learning increase when a firm is exposed to new and diverse ideas based on differences in technological capabilities between the acquiring and the acquired firm (Goshal, 1987; Hitt et al., 1996). By making accurate use of the acquired knowledge base a firm can develop a strong and coherent technological profile. In addition, the firm should access and monitor all the necessary technologies embedded in a broad range of unrelated technological areas, thereby increasing its flexibility (Grant, 1996). Acquiring diverse external knowledge bases and making proper use of this new knowledge are found to be relevant contributions to a firm's post-M\&A innovative performance (Cohen and Levinthal, 1989; Pakes and Griliches, 1984). 


\subsection{Research Questions}

The main purpose of this thesis is to analyze if mergers and acquisitions in the hightech industry, on average, lead to higher innovative performance for the acquiring firm. When mergers and acquisitions became a focus of the academic literature, several definitions of M\&As were introduced. See Jarell et al. (1988); Jensen (1984) and Oster (1999) for a further discussion of the different forms of M\&As. We define a merger as a transaction whereby two or more equally valued firms become one. An acquisition occurs when there is a difference in equality between two or more firms, in which the dominant firm acquires the assets of the less dominant firm (Sutton, 1980). In this study, however, we will make no distinction between mergers and acquisitions and use the terms interchangeably. This is based on the idea that in reality most mergers are in fact acquisitions with one company controlling the other (World Investment Report, 2000).

Current meta-analyses of financial M\&A performance show that M\&A activity, does not positively contribute to the post-M\&A performance of acquiring firms (King et al., 2004). A reason for this finding is the short-term focus of most post-M\&A performance research and a shortage of multiple measures of firm performance in these studies (King et al., 2004). In addition, M\&A activity is often motivated by factors other than financial performance, such as the use of M\&As to manage technological uncertainties, which deserve additional theorizing and analyses. Therefore we decided to take the debate of the effect of M\&A activity somewhat further by studying the long-term implications of M\&As on high-tech firms' postM\&A innovative performance. In that way we can better exemplify the complete performance implications of M\&A activity. To achieve this goal, the general research question of this study is: to what extent contribute mergers and acquisitions (M\&As) in high-tech industries to the post-M\&A innovative performance of acquiring firms?

In order to obtain a better understanding of the phenomenon that is actually being studied, we first present a definition of $M \& A s$, their main rationales and an initial analysis of some major trends and patterns in M\&A activity for the period 1985 1994. Next, we study the innovative performance of a large international sample of nearly 1200 companies in four high-tech industries, using a variety of indicators. Based on this study we can decide which indicators we have to consider, either separately or in a composite construct, in order to measure the post-M\&A innovative performance of the acquiring firm. More in particular, we provide an empirical analysis of the post-M\&A innovative performance of acquiring firms by replicating and extending the analysis of Ahuja and Katila (2001). Our study is clearly linked to recent research that has already made some progress in analyzing critical success factors that have a significant influence on a firm's post-M\&A innovative performance. Thereby we follow the methodological suggestion of King et al. (2004) to use variables from existing M\&A research as a foundation for our model building. By replicating known effects instead of seeking 'new' effects, we hope to contribute to the overall knowledge accumulation of research activity in the M\&A area (King et al., 
2004). Finally, to answer the general research question we examine the direction of a firm's technological diversification by means of M\&As, which is very important for effective innovative performance of high-tech firms (Eisenhardt and Martin, 2000; Grant, 1996). Although the relationship between technological diversification and a firm's post-M\&A innovative performance is already analyzed (e.g. Hagedoorn and Duysters, 2002a), few studies have examined the determinants of the choice between technologically related and technologically unrelated M\&As. In sum, the main research question can be divided into four more specific research questions (see figure 1.1):

1. What are the major trends and patterns in M\&A activity for the manufacturing industry in general and the high-tech industry in particular?

2. How to measure innovative performance; is there an advantage in using multiple indicators?

3. What is the effect of (nontechnological and technological) mergers and acquisitions on the post-M\&A innovative performance of high-tech firms?

4. What is the effect of internal learning, external learning, and technological M\&A experience on the choice between related and unrelated technological M\&As?

\subsection{Reasons for selecting the high-tech industries}

From a theoretical and empirical perspective it is necessary to create a better understanding of the characteristics of M\&As and their post-M\&A performance, i.e. their rationales, trends and patterns of M\&A activity, the measurement of post-M\&A innovative performance, the impact of $M \& A s$ on the acquiring firms' post-M\&A innovative performance, and the determinants of the choice between related and unrelated technological M\&As. Four high-tech industries are selected as the primary context of our analysis: aerospace and defense (SIC-codes 372 and 376), computers and office machinery (SIC-code 357), pharmaceuticals (SIC-code 283), and electronics and communications (SIC-code 36). There are several reasons to select these high-tech industries, defined by the OECD (1997), as the focus of our study.

First, Link (1988) argues that M\&As are important sources of innovation for all key players in the most technologically oriented industries. Even more so, the importance of M\&As is greater for firms in industries were competition is technology based than in industries where competition is not technology based (Link, 1988).

Second, these high-tech industries are primarily knowledge-driven industries (OECD, 1997). Firms operating in this high-tech environment use aggressive acquisition behavior and extensive knowledge recombination, in order to improve their innovative performance and survive in a rapidly changing and technologically complex environment (Bierly and Chakrabarti, 1996; Capron and Mitchell, 2000).

Third, these high-tech sectors are selected because it is known that particularly in these industries R\&D expenditures, patents, patent citations and new products play a 


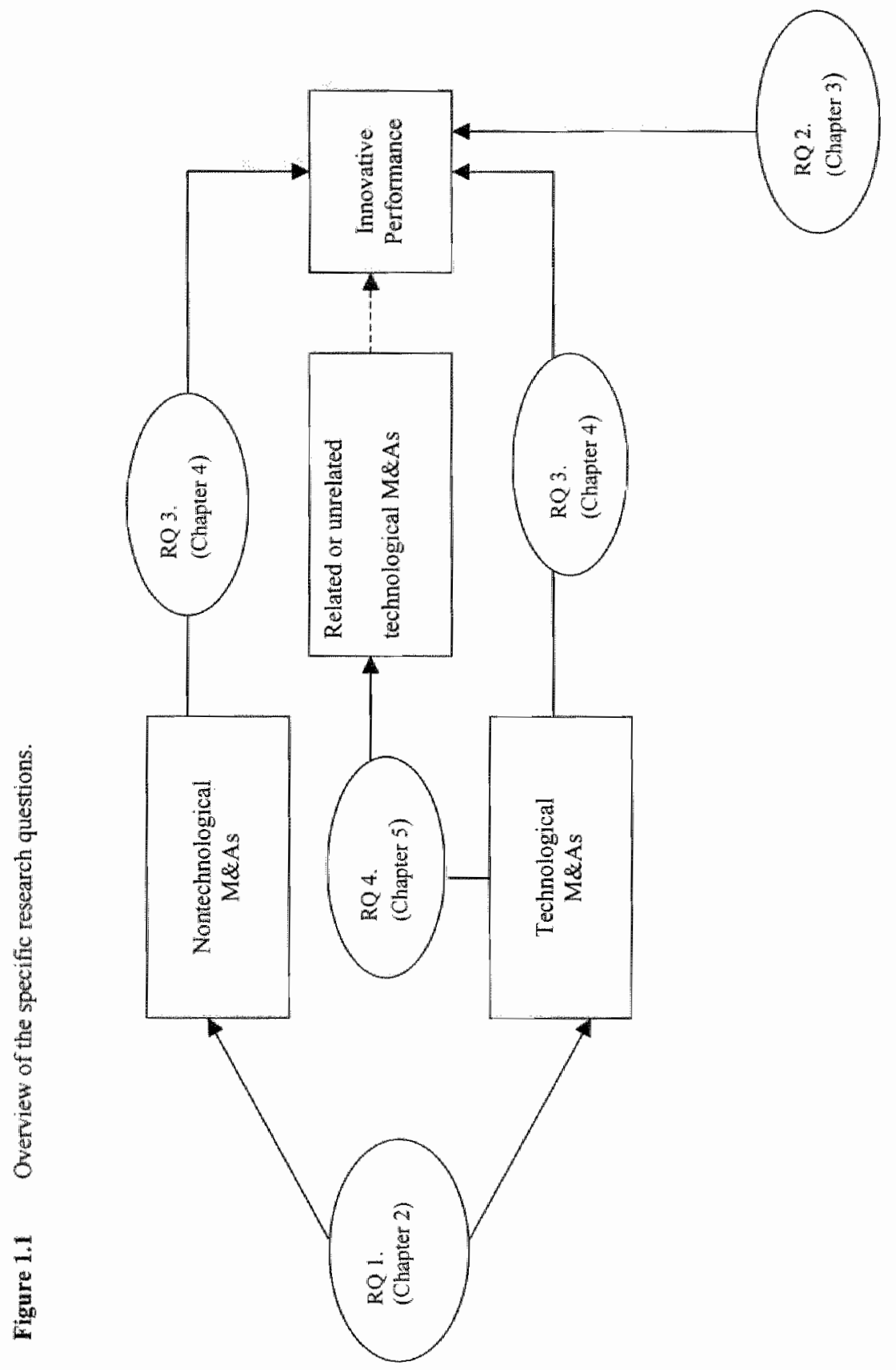

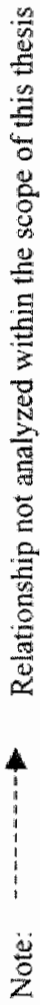


significant role in indicating important aspects of innovative performance (Hagedoorn and Cloodt, 2003; OECD, 1997). This means that we have an abundance of reliable innovation indicators within the high-tech sectors. Innovation in low-tech sectors is often 'hidden' in new products and processes resulting from other activities than formal. R\&D and for which patenting is not necessarily a major means to protect the innovation (Nelson, 1987; Hagedoorn \& Duysters, 2002a).

Finally, the high-tech enviromment is also a field, which has become highly internationalized and characterized by global competition (OECD, 1992). Several changes in the business environment, i.e. the liberalization of foreign direct investment, discriminatory regional agreements, privatization, and deregulation of industries, stimulate high-tech firms to undertake more and more international M\&As (Kang and Johansson, 2000; Kleinert and Klodt, 2002). This allows us to study the impact of M\&As on a firm's innovative performance within an international setting.

\subsection{Outline of the book}

Chapter 2 introduces an historical analysis of the major trends and patterns in M\&A activity for firms in the manufacturing high-tech sectors during the so-called "merger mania" of 1985-1994. It discusses the historical importance and magnitude of M\&A activity from the beginning of the previous century, together with some main rationales of M\&As to understand the phenomenon that is actually being studied. Thereafter, we investigate the general growth patterns and sectoral growth patterns in M\&A activity related to developments in the business environment during the period 1985-1994. Using country-level data, we analyze the growth pattern in the number of international M\&A deals and the role that the different international economic and trading blocks play in all of this (Europe, North-America, Asia, and all other regions). Besides an international expansion in M\&A activity, we discuss the general and sectoral changes in the direction of M\&A activity in terms of product-markets. The chapter ends with a general overview of the distribution between technological - and nontechnological M\&As.

Chapter 3 provides an analysis of the measurement of innovative performance of companies, considering the possible use of both a number of single indicators or various combinations of multiple indicators in a composite measure of performance. Based on our understanding of previous literature on innovation indicators, three research questions are formulated. First, is there a systematic disparity between different indicators such as R\&D inputs, patent counts, patent citations, and new product announcements? Second, is there a statistical communality between two or more indicators, indicating that a composite construct could capture a latent variable? Third, is the statistical association between two or more indicators of such a nature that each of these indicators can be applied as a representative indicator of innovative performance? Factor analysis is used to understand innovative performance in terms of 
the possible causal structure among a number of indicators, considering a set of common underlying dimensions or factors.

Chapter 4 investigates the post-M\&A innovative performance of acquiring firms in four major high-tech sectors (aerospace and defense, computers and office machinery, pharmaceuticals, and electronics and communications). A panel negative binomial regression model with distributed lags is used to analyze the effects of nontechnological M\&As and technological M\&As in terms of the absolute size and relative size of the acquired knowledge base and the overlap in knowledge bases between the acquiring firm and the acquired firm. The results of this analysis are discussed within the theoretical context of important streams of literature and enable us to replicate and falsify some of the findings of previous empirical research.

Chapter 5 discusses three important determinants of the direction of a firm's technological diversification by means of M\&As. Particularly in rapidly changing environments, such as high-tech industries, technological diversification is important for effective innovative performance and the creation of a sustainable competitive advantage (Eisenhardt and Martin, 2000; Grant, 1996). However, to our knowledge, technological diversification by means of M\&As and its determinants are rather underrepresented in the literature and only a few authors have put this topic on the research agenda. We attempt to fill the existing gap in the literature and use a negative binomial model to investigate the effect of a firm's internal learning process, its external learning process and technological $M \& A$ experience on its choice for undertaking related or unrelated technological M\&As.

Chapter 6 presents the conclusions of this thesis and provides an answer to the overall research question: "to what extent contribute mergers and acquisitions (M\&As) in high-tech industries to the post-M\&A innovative performance of acquiring firms?". In addition, chapter 6 will state the limitations of our study and offer some suggestions for future research. 


\section{M\&A ACTIVITY IN HIGH-TECH INDUSTRIES: AN OVERVIEW OF MAJOR TRENDS AND PATTERNS (1985-1994)}

\subsection{Introduction}

In today's business world, most of the firms engage in a broad number of inter-firm business modes ranging from standard market transactions to mergers and acquisitions (M\&As). During the last decades, we have seen an enormous growth in one of these business modes namely the total number of M\&As, both international and domestic, which have grown at an annual rate of 42 percent in the 1980 s and 1990 s (World Investment Report, 2000, page 106). This enormous increase in M\&A activity has not. remained unnoticed and is probably also one of the reasons why mergers and acquisitions have attracted so much attention in the academic press from the $1980 \mathrm{~s}$ and early 1990s (Clark, Chakrabarti and Chiang, 1988; Jarell et al. 1988; Jensen, 1984; Lubatkin, 1987; Mueller, 1986a, 1986b; Ravenscraft and Scherer, 1987; Seth, 1990; Shelton, 1988; Shugart and Tollison, 1984).

In this chapter we will attempt to contribute to the understanding of mergers and acquisitions with an initial analysis of some major trends and patterns in M\&A activity for the period 1985-1994. These years lay according to Farell (2000, July 7): "The foundation for the longest economic expansion in the US history". The beginning of the period 1985-1994 reflects the so-called "merger mania" that begins in 1984 and sweeps through the business world until the early 1990s (Adams, 1998, DiBartolomeo, 2000). The merger mania is characterized by colorful hostile deals and record-breaking mergers (Gaughan, 2001). The two largest transactions during this time are the $\$ 13$ billion takeover of Gulf Oil by Standard of California (1984) and the $\$ 25$ billion "leveraged buyout" of RJR Nabisco (1988) (DuBoff and Herman, 2001). The "urge to merge" ends with the collapse of the junk bond markets and the savings and loan crisis during the recession of 1990-1991 (DuBoff and Herman, 2001; Gaughan, 2002). By choosing the period 1985-1994 as the period of our analysis, we have the opportunity to examine the beginning and the ending of a very lively merger and acquisition wave.

According to Kleinert and Kllodt (2002, page 4) the driving forces of the 1985 1994 merger wave are: "The synergies which are expected from melting production activities with related technologies". Consequently, merger and acquisition activities during this period tend to cluster in technology-intensive industries (Kleinert and Klodt, 2002). Hence, we will limit our analysis to acquiring firms in the manufacturing industry and more in particular to firms in the high-tech manufacturing industry based 
on the definition of the OECD (1997) . The above implies that we analyze the M\&A activity of high-tech firms whereas the M\&As in which these companies are involved might of course be related to a variety of manufacturing industries.

Naturally, we witness the same "merger mania" in the manufacturing high-tech industries. There is an increasing trend towards mergers in the pharmaceutical industry in the 1980 s and early 1990s (Di Pede, 2001). For example, in 1989 , Beecham Group PLC merges with Smithkline Beckman Co. to create the then second largest pharmaceutical company in the world (Di Pede, 2001). In the early 1990s, the US aerospace industry enters a period of profound change characterized by merger mania and extensive horizontal and vertical consolidation (Lorell, Lowell, Moore, Greenfield and Vlachos, 2002). In 1984, IBM buys Rolm a pioneer of digital office telecommunications system technology, reflecting the accelerated technological convergence between the computer and telecommunication market during the mid 1980 s and early 1990s (Duysters and Hagedoorn, 1998).

The growth in M\&A activity during the period 1985-1994 can be seen as a reaction to several changes in the business environment. For example, the liberalization of foreign direct investment, the ongoing regional economic integration, the change in world capital markets, the deregulation of several industries, and significant changes in technology, all increase the uncertainty in a firm's business environment. M\&As are an important element in the overall strategy of companies to deal with this uncertainty that is present in the economy at large, their industry, or particular technological fields (Hagedoom, 1993; Hoskisson and Hitt, 1994; Oster, 1999). By means of M\&As, firms can either takeover companies in the region(s), sector(s) or technological field(s) in which they are already present or diversify to decrease the dependency on their existing environment (Hagedoorn and Duysters, 2002a; MacDonald, 1985; Pfeffer, 1972). By choosing the four high-tech sectors as the primary group of our analysis we are not only able to analyze the patterns in international - and product-market $M \& A s$, but we can also analyze some general trends in the technological M\&As undertaken by the high-tech companies.

In the next section, we briefly present a definition of M\&As and their main rationales to understand the phenomenon that is actually being studied. In section 2.3 , we will present and explain the historical importance and magnitude of M\&A activity from 1900 till 1985. In the next section, we analyze the general pattern in M\&A activity over the period 1985-1994, followed by an analysis of the sectoral patterns in the number of M\&A deals, as they appear in the Securities Data database (see Appendix A). Section 2.5 is devoted to a discussion of the international patterns of M\&As in terms of changes in the distribution of domestic and international M\&As. In section 2.6 we will pay attention to the analysis of changes in the direction of productmarket M\&As undertaken by high-tech companies. The M\&A data in combination with patent data from the US Patent \& Trademark Office (see appendix B) allow us to

\footnotetext{
Following the OECD (1597) sectoral RQD intensities (the share of total R\&D expenses in total turnover). Aerospace and defense. Computers and office machinery, Pharmaceuticals, and Electronics and communications are classified as high-tech sectors.
} 
introduce in section 2.7 a general overview of the distribution of technological - and nontechnological M\&As. The closing section presents some conclusions that can be drawn from this contribution.

\subsection{Mergers \& Acquisitions: their rationale and some definitions}

When mergers and acquisitions began to attract attention in the academic literature, severall definitions of M\&As were introduced. See Jarell et al. (1988); Jensen (1984) and Oster (1999) for a further discussion of the different forms of M\&As. We define a merger as a transaction whereby two or more equally valued firms become one. This transaction is negotiated with the target's management and, when approved by its board of directors, the terms of the offer are submitted to a vote of the shareholder (Jarell et al., 1988; Jensen, 1984). An acquisition occurs when there is a difference in equality between two or more firms, in which the dominant firm acquires the assets of the less-dominant target firm (Sutton, 1980). In contrary to a merger, negotiation with and approval of the target firm's management is not always necessary, depending on the type of acquisition. In the following, however, we will make no distinction between mergers and acquisitions and use the terms interchangeably. This is based on the idea that in reality most mergers are in fact acquisitions with one company controlling the other (World Investment Report, 2000). For example, the number of international mergers is less than 3 per cent of all international M\&As for the period 1987-1999 (World Investment Report, 2000, page 99).

Following the literature, M\&As can be classified in terms of their international nature (Hitt, Hoskisson and Kim, 1997), in terms of the product-markets involved (Hay and Morris, 1991) and in terms of the technological fields involved (Hagedoorn and Duysters, 2002a). Empirical evidence shows that due to changes in the business environment, international M\&As have become a feasible alternative to domestic M\&As (Caves, 1989; Cooke, 1988; Ikeda and Doi, 1983). Nowadays, many leading companies are expanding internationally by means of M\&As to exploit emerging opportunities for international business (Kranenburg van, Cloodt and Hagedoorn, 2001; Ravenscraft and Scherer, 1989). For that reason, it seems important to look at the international nature of mergers and acquisitions, and analyze the changes in distribution of domestic and international M\&As.

In addition, M\&As are a viable mode to provide a quick and seemingly easy route to achieving product-market diversification objectives (Datta, 1991). In this context, it is interesting to analyze the direction of diversification by means of M\&As. With regard to the product-markets involved in an M\&A transaction, we can make a distinction between a horizontal M\&A, a vertical M\&A and a conglomerate M\&A. When firms operating in the same product-market, are joined, we classify the M\&A as a horizontal one. A vertical M\&A is one in which a firm acquires another firm that is in a different stage of production within a particular market. Finally, conglomerate or 
unrelated M\&As are unions of firms between which there is no horizontal or vertical relationship (Hay and Morris, 1991; Oster, 1999; Ross, Westerfield and Jaffe, 1996).

To create and sustain a competitive advantage a firm should not only decide which particular regions or product markets it should target, but also in which technological fields it should make future investments (Geringer, Beamish and daCosta, 1989). In high-tech industries, characterized by complex technologies, internal development of technological knowledge is a time consuming activity and M\&As can serve as an instrument to quickly enter a new technological field (Chakrabarti et al., 1994). We classify a merger or acquisition as a technological M\&A when the transaction enables the acquiring firm to access relatively broad categories of technological disciplines and engineering capabilities (Hagedoorn and Duysters, 2002a).

An interesting subject in this context refers to the motivation of companies to enter into one or several of the abovementioned types of mergers and acquisitions. It should be noted that although we discuss the different motives in isolation, it is important to realize that when analyzing M\&A activity, several of the motives for undertaking M\&As are at work simultaneously (Mueller, 1980; Scherer and Ross, 1990).

Compared to domestic M\&As, international M\&As offer several additional incentives to merge or acquire another firm. Organizations possessing ownership specific capabilities often prefer to exploit these capabilities in new cross-border locations and in addition get quick access to knowledge about local market conditions (Cooke, 1988; World Investment Report, 2000). A second motive for firms to undertake international M\&As is firm growth. Because of the saturation of their home market a lot of firms can only grow by acquiring other firms in overseas markets (Cooke, 1988; Ikeda and Doi, 1983). The growth motive can be of a defensive nature as greater size of a company makes it more difficult to be taken over, or it can be undertaken in order to expand aggressively (Cooke, 1988). A last important incentive to undertake international M\&As is the reduction of risk by geographical market diversification (Cooke, 1988; World Investment Report, 2000). By merging or acquiring a non-domestic target, firms can exploit differences between business cycles and stock markets across the world (Oster, 1999). For example, during the 1997 Asian crisis many US firms purchased firms in the countries affected by the financial crisis, laking advantage of the depressed stock market (Oster, 1999).

Besides international diversification, M\&As are often undertaken to diversify into related or unrelated product-markets. A substantial part of the management literature expects that compared with unrelated M\&As, related M\&As should show superior performance because of value created by economies of scale, economies of scope, or market power (Healy et al., 1992; Porter, 1987; Shelton, 1988; Singh and Montgomery, 1987). Economies of scale and scope are created when the value of the combined firm after the M\&A is greater than the sum of the values of the separate firms (Cooke, 1988; Seth, 1990). Examples include, using each others' distribution networks, economies of scale in production leading to cost reductions, exploiting the 
relationships among business segments, or sharing distinctive firm capabilities (Hitt et al., 1997; World Invesiment Report, 2000)). In general, synergy gains can be divided into two categories based on the fact if they are static (cost reduction or revenue enhancing at a given point in time) or dynamic (e.g. innovation-enhancing) in nature (Dunning, 2000; World Investment Report, 2000). Especially dynamic synergies play a crucial role in high-tech industries such as aerospace and defense, computers and office machinery, pharmaceuticals, and electronics and communications.

The pursuit of market power is mainly an important incentive for firms operating in concentrated industries where existing rivals are few (Hay and Morris, 1991; Oster, 1999). Only in these instances one can eliminate one of the competitors in the industry by undertaking a horizontal M\&A and influence price, quantity, or the nature of the product in the market place (Carlton and Perloff, 1990; Oster, 1999; Singh and Montgomery, 1987).

The abovementioned considerations mainly motivate firms to undertake nontechnological acquisitions that, as explained in chapter 4, are less likely to provide technological knowledge to the acquiring firm. However, firms are also often undertaking M\&As to gain access to new technological knowledge and engineering capabilities (Chakrabarti et al., 1994; Cooke, 1988; Freeman and Hagedoorn, 1995; Hitt et al., 1997; Ikeda and Doi, 1983; Oster, 1999; World Investment, Report 2000). Especially in industries with complex technologies the investment of resources can be a time consuming activity. In that case M\&As can serve as an instrument to enter a new technological field quickly and gain access to technology and technical knowhow (Chakrabarti et al., 1994). Although research in the area of technological M\&As is rather limited, most of the studies argue that technological related M\&As outperform technological unrelated M\&As (Gerpott, 1995; Hagedoorn and Duysters, 2002a). The positive effect of relatedness in technological knowledge on the success of M\&As is based on the effects of economies of scale and scope of R\&D, such as sharing the costs of innovation, a shorter innovation lead-time and the possibility to engage in larger combined projects (Gerpott, 1995, Hagedoorn and Duysters, 2002a; Ikeda and Doi, 1983; Mowery, Oxley and Silverman, 1996).

\subsection{Historical importance of M\&As during the period 1900-1985}

To obtain a good overview of the historical importance and magnitude of M\&A activity one needs a long and consistent set of time-series data on mergers and acquisitions. Unfortunately, the early data series are not completely comprehensive since the available data on the number of M\&As concentrate mainly on the activity in the United States and much less on the activity in other regions (Carlton and Perloff, 1990). In addition, small transactions are mostly eliminated from the analysis thereby biasing the measurement of M\&A activity (Carlton and Perloff, 1990; Golbe and White, 1988). 
Starting at the beginning of the previous century, Nelson collected data covering the manufacturing and mining sectors in the US for the period 1895-1920, Thorpe compiled a quarterly series on M\&A activity for the period 1919-1939, and the U.S. Federal Trade Commission composed a dataset for the period 1948-1979 (Golbe and White, 1988; Nelson, 1959). From 1967 onwards, the quarterly issues of the periodical mergers and acquisitions (M\&A) publish the M\&A activity for all sectors present in the US economy (Golbe and White, 1988). Figure 2.1 provides a historical perspective on M\&A activity based on these time-series data.

Figure 2.1 Number of M\&A deals in the period 1895-1985.

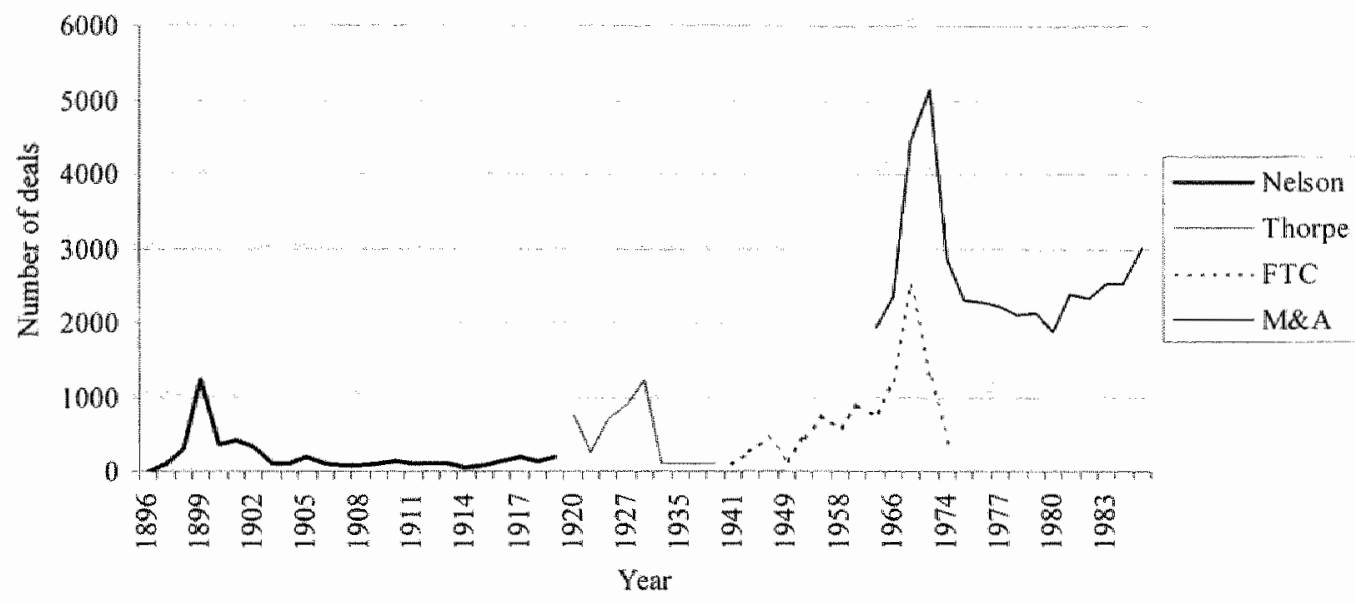

Nelson: Data derived by Nelson (1959) for manufacturing and mining.

Thorpe: Datta derived by Thorpe for manufacturing and mining.

PTC: Continuation of Thorpe series by Federal Trade Commission.

M\&A: Data fron Mergerstat, includes all sectors of econony (Carlton and Perloff, 1990) page 163).

Source: Golbe and White, 1988 in: Alan J. Auerbach, ed. Mergers and Acquisitions.

The historical data on M\&A activity in the US reveal four important merger waves from the turn of the century up till 1985. The explanation for this seemingly cyclical movement is generally related to several important developments in the business environment during that time, which 'triggered' companies to undertake M\&As (Golbe and White, 1988). For example, the completion of the transnational railroads and the development of communications, that established the US as the first large common market in the world, were during the first merger wave a huge stimulation for firms to undertake M\&As (Carlton and Perloff, 1990; Weston and Chung, 1990). More in particular, the establishment of a large common market triggered firms to undertake mainly horizontal M\&As with the main reason to achieve market domination (Oster, 
1999; Weston, Chung and Hoag, 1990). This strive for market domination transformed regional firms into national firms and formed the large industrial concerns we still witness today (Carlton and Perloff, 1990; Oster, 1999; Weston et al., 1990).

A stimulating event that led to an increase in mainly vertical M\&As and product-line extensions during the second merger wave (1920s), was the development of the automobile (Weston and Chung, 1990). This development enabled firms to extend their sales areas and to create more effective geographic sales and distribution systems (Weston et al., 1990; Weston and Chung, 1990), especially in industries such as food processing and chemicals (Weston et al., 1990).

The third merger wave (1960-1973) represented an era of tougher US antitrust policies, in which horizontal and vertical M\&As were replaced by unrelated mergers and acquisitions. The enforcement of antitrust restrictions turned out to be very effective. For the period 1948-1977 unrelated mergers and acquisitions represented 75 percent of the total assets acquired (Weston and Chung, 1990, page 6). However this takeover of mainly unrelated business activities had severe consequences for the survival of the merged firms, whereby almost half of the acquisitions were divested within several years after the original M\&A (Katz, Simanek and Townsend, 1997).

One possible explanation for the increase in M\&A activity during the fourth merger wave (1980s) was the globalization of markets and a changing antitrust environment (Weston and Chung, 1990), which led to an expansion of markets with increased international competitive pressures (Weston and Chung, 1990; World Investment Report, 2000). Speed became the main incentive for survival and M\&As are often the fastest means of potential inter-corporate arrangements. By merging or taking over an existing firm one can respond quickly to business opportunities and preferably before competitors do (World Investment Report, 2000).

\subsection{General patterns in M\&A activity during the period 1985-1994}

In order to assess the importance and magnitude of $M \& A$ activity after the fourth merger wave we examined the number of M\&A deals as they appear in the Securities Data database (See Appendix A). Overall the period 1985-1994 shows a relatively large increase in the number of M\&A deals as shown in figure 2.2. During the second half of the 1980 s until the beginning of the 1990 s the number of M\&A deals rose from 263 deals in 1985 to around 1103 deals in 1991. Overall, those years mark a rather steep growth with an average increase in M\&A activity of $28 \%$ each year. After 1991, the number of M\&As show a dramatic drop to around 544 deals, a decline of $50 \%$ compared to the year before. At the end of the period of our analysis this number takes off again to over $1273 \mathrm{M} \& \mathrm{~A}$ deals in 1994 . In other words, there is a clear pattern of growth in the number of M\&A deals since 1985, with the exception of a drop in M\&A activity in the year 1992 . 
Figure 2.2 Number of M\&A deals in the high-tech industry during the period 1985-1994.

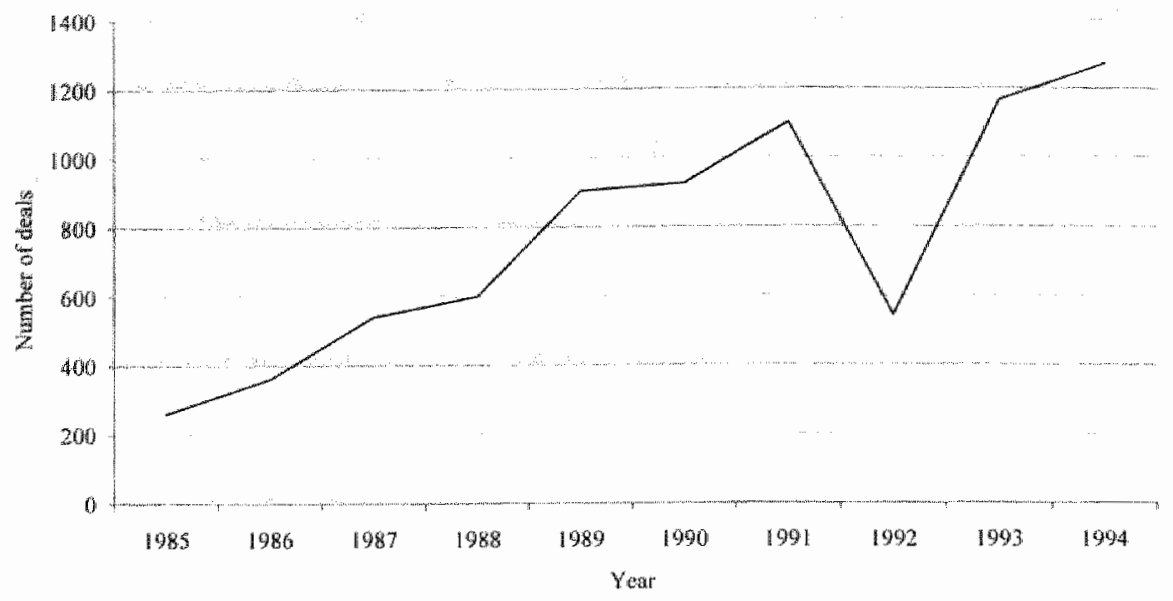

In the literature, the explanation for this overall growth pattem in M\&A activity is related to the motives that stimulate companies to undertake M\&As. A major factor mentioned in that context is the rapid pace of technical change taken place in the business environment at that time (World Investment Report, 2000). This rapid pace of technical change, leading to an increased complexity of R\&D projects, riskier R\&D projects, increasing costs of R\&D projects, and shorter innovation cycles (Hagedoorn, 2002; OECD, 1992; World Investment Report, 2000), stimulates M\&As to become an integral part of the strategic initiatives of many firms. A second important change in the environment during this period is the liberalization of foreign direct investment and the ongoing regional economic integration (World Investment Report, 2000). The main means of achieving liberalization such as the GATT or the WTO and discriminatory regional agreements such as the EU and the NAFTA all stimulate the opening of markets and directly raise the possibility of a large increase in the number of mergers and acquisitions. In addition, many M\&As have occurred in industries that recently were deregulated such as the telecommunications industry, which start to open up and attract foreign acquirers (Kang and Johansson, 2000). A final stimulus for an increase in the number of M\&As is the change in world capital markets (World Investment Report, 2000). Unrestricted facilities for cross-border loans and credits, foreign currency deposits and portfolio investment facilitate the growth of especially international M\&As (World Investment Report, 2000).

We also looked at the trends in the share of individual high-tech sectors (see figure 2.3). All sectors follow more or less the same pattern as the overall pattern of M\&A activity in the high-tech industry. However, the computer and office machinery sector shows a slightly more dymanic M\&A activity than the rest. 
Figure 2.3 Number of M\&A deals per high-tech sector during the period 1985-1994.

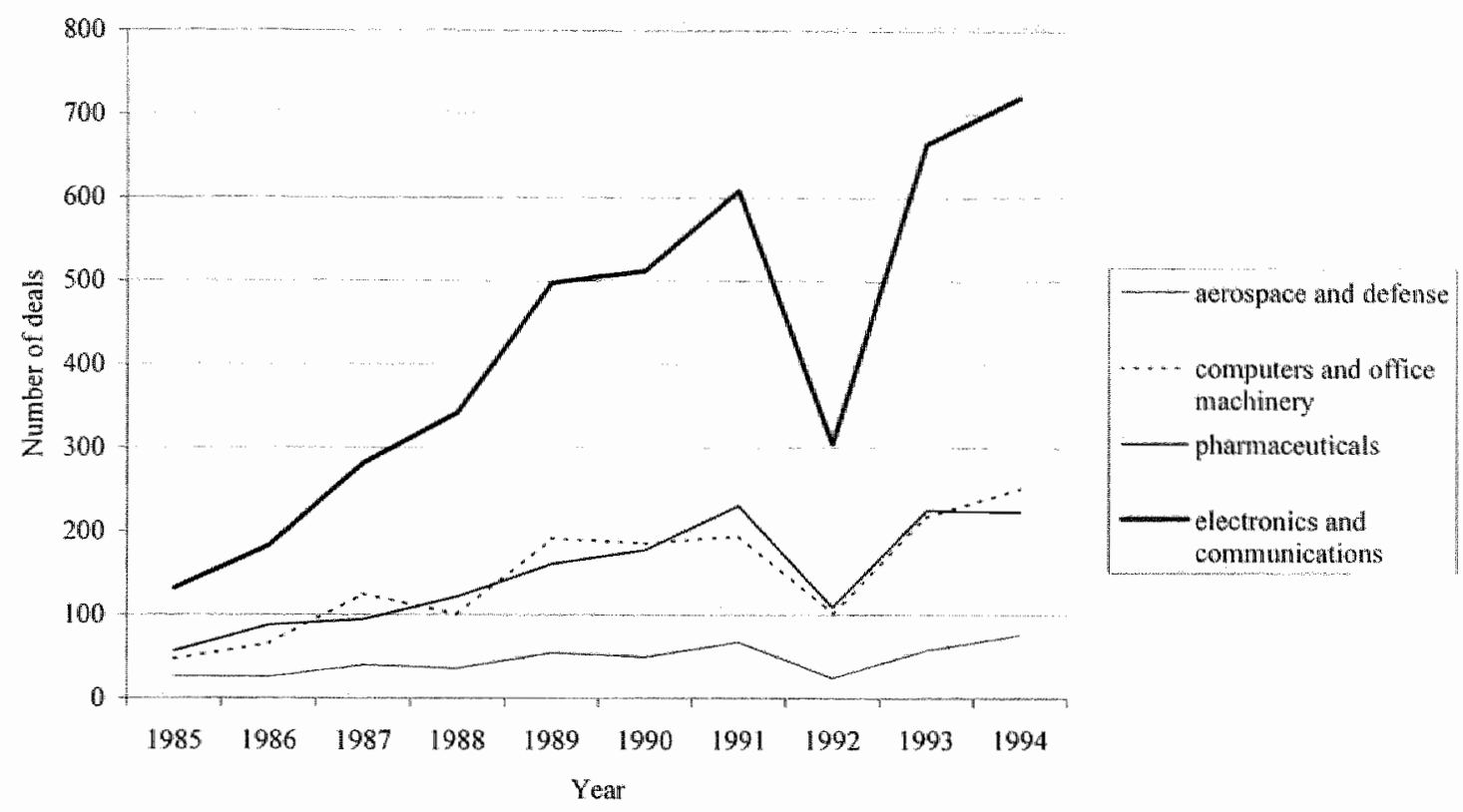

The electronics and communications sector has by far the largest share in the sectoral distribution of high-tech M\&A activity (55\%). This reflects the importance of the electronics and communications industry in terms of its contribution to the total industrial R\&D efforts, new products and services (Hagedoorn, 2002). The share of the number of M\&A deals in the computer and office machinery sector and the pharmaceutical industry by and large is almost the same (around 20\%). As the electronics and communications sector, the computer and office machinery sector and the pharmaceutical sector have become so dominant in the M\&A activity in high-tech industries, the share for the last high-tech sector (aerospace and defense) has remained relatively small.

\subsection{International patterns in M\&A activity during the period 1985-1994}

The period 1985-1994 has not only seen an explosion in M\&A activity in general but also a large increase in the number of international M\&A deals (Kang and Johansson, 2000). As mentioned before, changes in the business environment intensified competitive pressures and speed became the most important factor for survival. International M\&As provide firms with a fast entrance into new markets and a fast way to react to intensified competition (Kang and Johansson, 2000). In addition, 
policies such as the liberalization of FDI, discriminatory regional agreements, privatization, and deregulation of industries are a stimulus for companies to undertake international M\&As by opening up markets and regions and increasing the availability of favorable M\&A targets (Kang and Johansson, 2000).

The total number of international M\&As, undertaken between domestic and foreign firms increased rapidly during this period from 69 deals in 1985 to 452 deals in 1991. In 1992 we witnessed a significant drop to 193 deals but a year later the number of M\&A deals recovered to a number of 452 . Also the importance of international M\&As compared to the total number of M\&As increased rapidly from $26 \%$ in 1985 to $41 \%$ in 1990 (see figure 2.4). From 1991 onwards the share of international M\&As remained more or less stable at an average of $36 \%$.

For a further analysis of the sectoral differences that might have occurred in the importance of undertaking international M\&As, I calculated a 'relative international $M \& A$ ' index per high-tech sector based on the 'relative international partnering' index defined by Hagedoon (2002, page 486). This index is calculated by setting the ratio of international M\&As versus domestic M\&As for each sector against the overall international $M \& A /$ domestic $M \& A$ ratio. Despite the fact that the overall 'relative international $M \& A^{\prime}$ ' index is close to one, the 'relative international $M \& A$ ' indexes for each individual high-tech sector show an unevenly distribution across industries (see table 2.1).

Figure 2.4 The share (\%) of international M\&As in the total number of M\&A deals for the hightech industry (1985-1994).

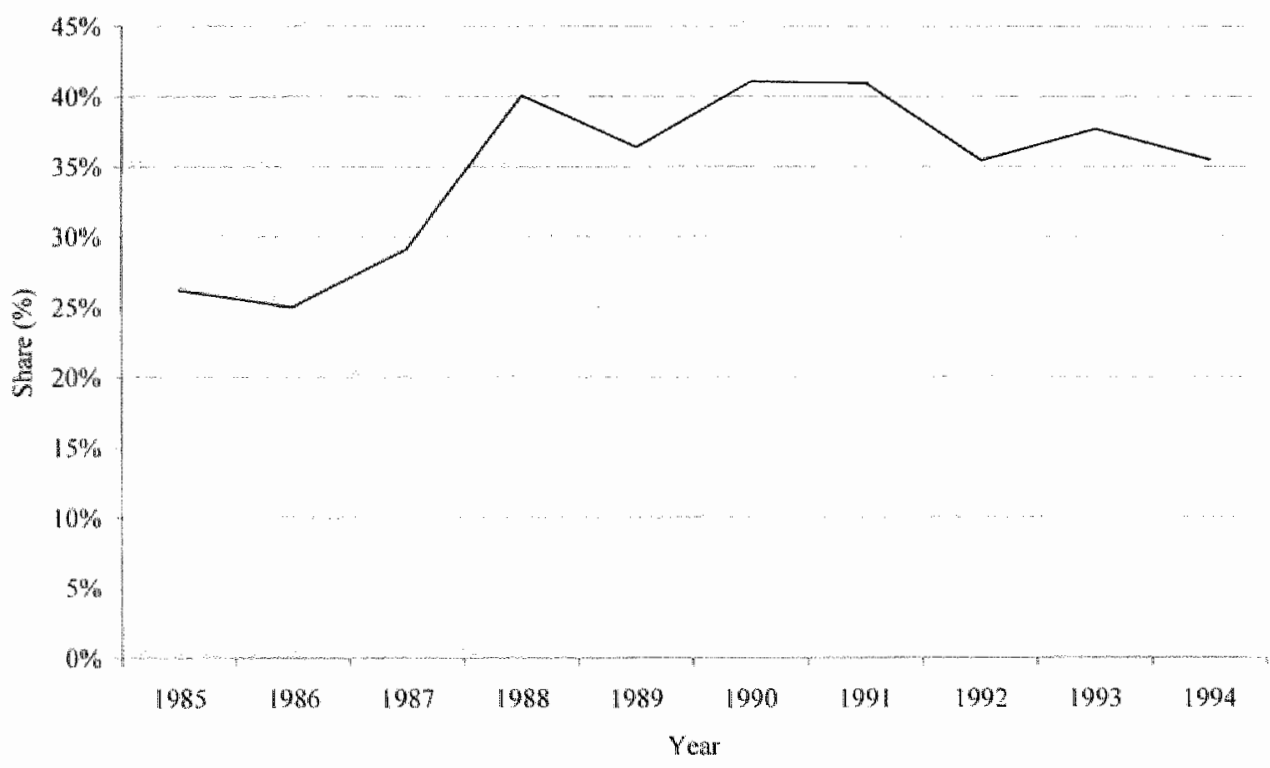


Table 2.1 Relative international M\&A index per high-tech sector for the period 1985-1994.

\begin{tabular}{lc}
\hline Sector & Index \\
\hline Aerospace and defense & 0.84 \\
Computers and office machinery & 0.61 \\
Pharmaceuticals & 1.57 \\
Electronics and communications & 1.02 \\
\hline
\end{tabular}

High-tech industries such as aerospace and defense and computers and office machinery are clearly below the industry-wide average of international M\&As during the period 1985-1994. The need for military independence and national prestige are an important characteristic of the aerospace and defense sector in Europe, in the United States and more recently in some Asian countries (Texier, 2000) and explain the preference for domestic M\&As in this sector. Regarding the computers and office machinery industry this effect is at first sight somewhat awkward. However, during the period 1985-1994 we witnessed a rapid maturation of the computer industry with slower growth rates, declining profit margins, an increased sophistication of users and the standardization of products (Duysters, 1995). In addition, the leading companies at that time in the computer and office machinery sector were all coming from the US (Duysters, 1995). After analyzing the data it shows that more than $82 \%$ of the domestic M\&As in the computers and office machinery industry took place between US companies. The consolidation pressures in combination with the large presence of US companies in this sector lead to a relative overrepresentation of domestic M\&As.

The 'relative international M\&A' index in the electronics and communications industry is very close to the industry-wide average. This finding is somewhat surprising given that we are dealing with a high-tech sector in which rapid technological change and deregulation (e.g. telecommunications market) force companies to look for new partners across borders (Kang and Johansson, 2000). However, our finding is consistent with the result of Kang and Johansson (2000) who witnessed that the number of M\&As across borders has remained relatively low in this sector. For the pharmaceuticals industry, international M\&As are of a disproportionate importance. Especially, long lead times of products, high risks, the financing of R\&D required to develop new generations of drugs, and the threat of new entrants in the pharmaceuticals industry are driving the spate of cross-border M\&A activity (Dimasi, 1995; Fildes, 1990; Kang and Johansson, 2000; Pisano and Wheelwright, 1995; Sharp, Patel and Pavitt, 1997).

In addition, we decided to take a closer look at the role that the different international economic and trading blocks play in all of this. In the following we will differentiate between M\&As and companies from Europe, North America (US and Canada), Asia and all other regions (Africa, Central and South America, New Zealand and Australia). If one looks at the overall pattern in M\&A activity for the period 1985- 
1994, it becomes clear that Europe and North America are the dominant economic regions with $87 \%$ of the number of M\&As taking place within or between the regions. Especially North America dominates the activity in M\&As given that almost $69 \%$ of the M\&As concerned at least one North American company. M\&As within North America account for $48 \%$ of all M\&A activity (see figure 2.5 ).

Additional analysis of these data for each high-tech sector individually reveals that the dominance of North-America becomes even more important (see figure 2.6). The share of M\&As that concerns at least one North American company is almost $70 \%$ for the acrospace and defense industry, $83 \%$ in the computers and office machinery industry, $70 \%$ for the pharmaceuticals industry, and $65 \%$ in the electronics and communications industry.

Figure 2.5 Distribution of number of M\&A deals for the high-tech industry, economic regions (1985-1994).

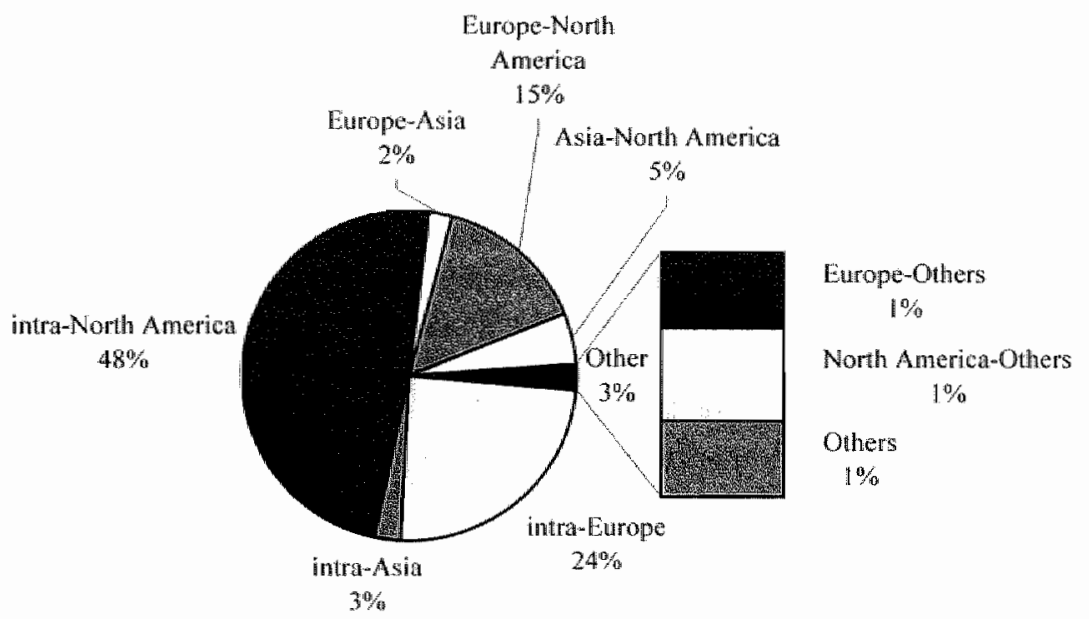

The dominance of North America reflects the leading role that this continent plays in R\&D and production in major high-tech industries (OECD, 1992). This dominance has not only led to a large share of inter-North American M\&As, it also led to a situation where most of the M\&A deals in the high-tech sectors are undertaken between companies within North-America. More in particular, the dominance of intra-North American M\&As is particularly strong in the aerospace and defense industry and the computers and office machinery industry. As mentioned before, national prestige and military independence are an important reason for US companies to acquire domestic companies in the aerospace and defense industry. 
Figure 2.6 Distribution of number of M\&A deals, economic regions (1985-1994).

Aerospace and defense sector

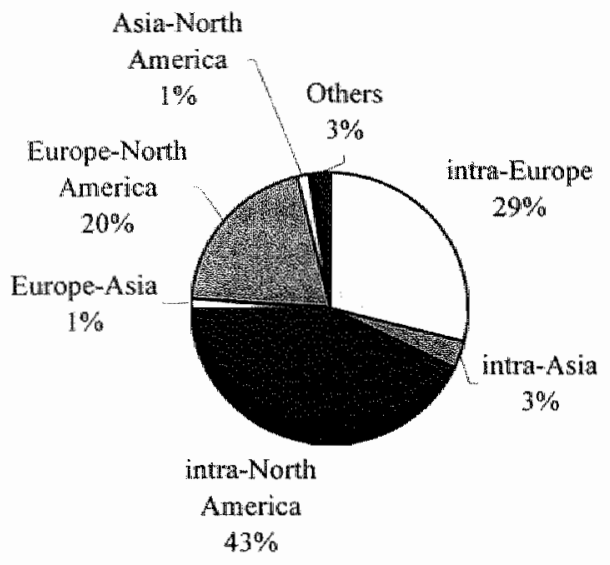

Pharmaceuticals sector

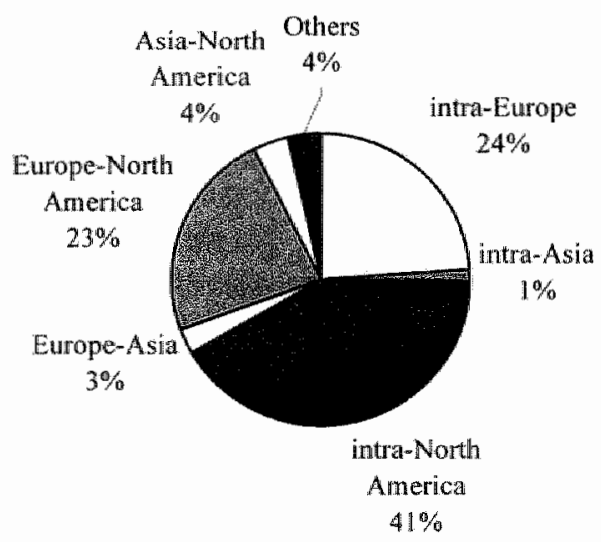

Computers and office machinery sector

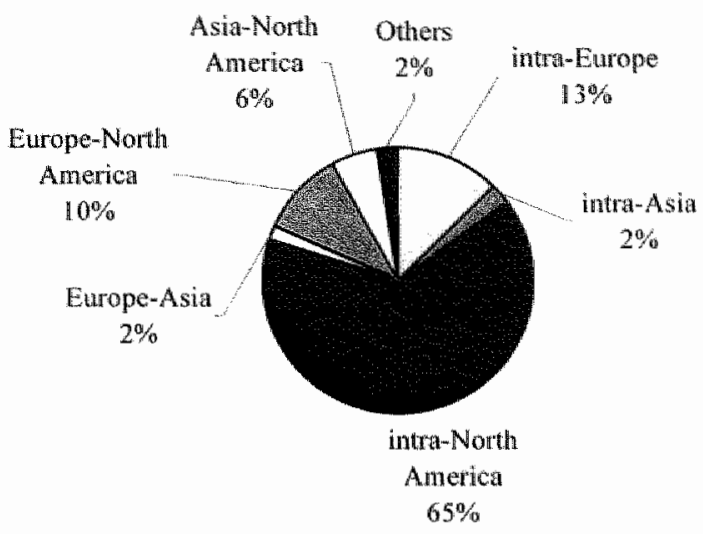

Electronics and communications sector

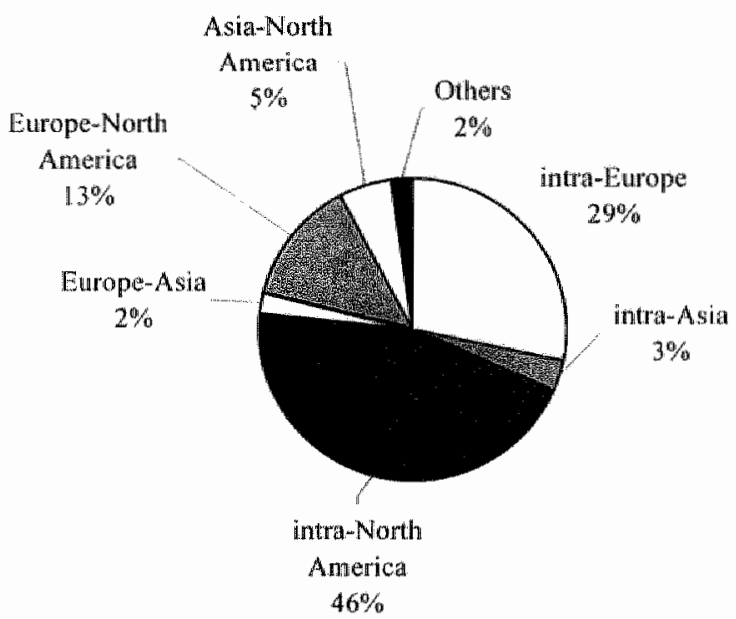


The share of European-North American M\&As is greatest for the pharmaceuticals industry. This can largely be explained by the fact that during the early 1980 s large established firms from the US and Europe started to invest heavily in biotechnology research (Rojjakkers and Hagedoorn, 2003), which led to an increase in M\&A activity between these two regions.

In addition, we witness that the dominance of intra North-American M\&As is larger in the first period of our analysis (1985-1989) than in the second period of our analysis (1990-1994), while the M\&A activity within Europe increased in the latter period (see table 2.2). One reason for the fact that the dominance of intra NorthAmerican M\&As decreases while the importance of intra-European M\&As increases, is that in contrast to the US and Canada, the consolidation wave in Europe only just

Table 2.2 Distribution of the share of M\&A deals per high-tech sector and per region.

\begin{tabular}{|c|c|c|c|c|c|c|c|}
\hline Sector / Period & $\begin{array}{l}\text { Intra- } \\
\text { North } \\
\text { Anerica }\end{array}$ & $\begin{array}{l}\text { Intra- } \\
\text { Europe }\end{array}$ & $\begin{array}{l}\text { Intra- } \\
\text { Asia }\end{array}$ & $\begin{array}{l}\text { Europe- } \\
\text { North } \\
\text { America }\end{array}$ & $\begin{array}{c}\text { Europe- } \\
\text { Asia }\end{array}$ & $\begin{array}{l}\text { Asia- } \\
\text { North } \\
\text { Americal }\end{array}$ & Others \\
\hline $\begin{array}{l}\text { Total High-tech } \\
1985-1989\end{array}$ & $55 \%$ & $22 \%$ & $1 \%$ & $15 \%$ & $1 \%$ & $5 \%$ & $2 \%$ \\
\hline $\begin{array}{l}\text { Total High-tech } \\
1990-1994\end{array}$ & $45 \%$ & $25 \%$ & $4 \%$ & $15 \%$ & $3 \%$ & $5 \%$ & $3 \%$ \\
\hline $\begin{array}{l}\text { Aerospace and } \\
\text { defense } \\
1985-1989\end{array}$ & $62 \%$ & $22 \%$ & $0 \%$ & $13 \%$ & $1 \%$ & $1 \%$ & $1 \%$ \\
\hline $\begin{array}{l}\text { Aerospace and } \\
\text { defense } \\
1990-1994\end{array}$ & $43 \%$ & $29 \%$ & $3 \%$ & $20 \%$ & $1 \%$ & $1 \%$ & $3 \%$ \\
\hline $\begin{array}{l}\text { Computers and } \\
\text { office machinery } \\
1985-1989\end{array}$ & $71 \%$ & $12 \%$ & $1 \%$ & $9 \%$ & $1 \%$ & $5 \%$ & $1 \%$ \\
\hline $\begin{array}{l}\text { Computers and } \\
\text { office machinery } \\
\text { 1990-1994 }\end{array}$ & $62 \%$ & $13 \%$ & $3 \%$ & $11 \%$ & $2 \%$ & $6 \%$ & $3 \%$ \\
\hline $\begin{array}{l}\text { Pharmaceuticals } \\
\text { 1985-1989 }\end{array}$ & $45 \%$ & $19 \%$ & $1 \%$ & $27 \%$ & $1 \%$ & $5 \%$ & $2 \%$ \\
\hline $\begin{array}{l}\text { Pharmacenticals } \\
\text { 1990-1994 }\end{array}$ & $39 \%$ & $27 \%$ & $2 \%$ & $21 \%$ & $3 \%$ & $3 \%$ & $5 \%$ \\
\hline $\begin{array}{l}\text { Electronics and } \\
\text { communications } \\
1985-1989\end{array}$ & $49 \%$ & $26 \%$ & $1 \%$ & $14 \%$ & $2 \%$ & $6 \%$ & $2 \%$ \\
\hline $\begin{array}{l}\text { Electronics and } \\
\text { communications } \\
1990-1994\end{array}$ & $43 \%$ & $30 \%$ & $4 \%$ & $13 \%$ & $3 \%$ & $5 \%$ & $2 \%$ \\
\hline
\end{tabular}


begins during the period of our analysis (Translink, 2003). Other important factors driving the increase in European M\&As in the period 1990-1994 are the fall of the wall in Germany, the official ending of the Soviet Union, and the establishment of the single European market. In November of 1989, the border separating Western from Eastern Germany disappeared and on 31 December 1991 the Soviet Union officially came to an end. The opening of the East European markets increased the number of available target companies and boosted the intra-European M\&A activity. Furthermore, opportunities to undertake M\&As between companies operating inside Europe increased with the establishment of the single market in 1992. Regulations such as internal trade barriers and national protectionism largely disappeared leading to increased competition and driving the urge of M\&As.

\subsection{Product-market diversification patterns in M\&A activity during the period 1985-1994}

The continuing popularity of mergers and acquisitions during the 1980s and $1990 \mathrm{~s}$ is an indication of the belief that M\&As are a viable mode to provide a quick and seemingly easy route to achieving diversification objectives (Datta, 1991). In this context, it is interesting to analyze the direction of diversification of M\&As based on their existing product-markets. We measured the product-market relatedness of M\&As in terms of the (dis)similarity of the three-digit SIC code of the sectors of the M\&A partners (Hagedoorn and Duysters, 2002a).

For the period 1985-1994, on average $67 \%$ of all M\&A deals were so called unrelated M\&As en $33 \%$ of the M\&A activity took place in related product-markets. This large number of unrelated M\&As can partly be explained by an accelerated technological convergence apparent on the product-market level during the mid $1980 \mathrm{~s}$ and early 1990s (Duysters and Hagedoorn, 1998). The boundaries between the hightech sectors, and more in particular between the computer, telecommunications \& semiconductor markets became blurred and this created opportunities for a large continuum of combined products (Duysters and Hagedoorn. 1998). The literature suggests that firms react to these new opportunities by entering each other's markets (Jonquières de, 1989). As mentioned before, M\&As are an attractive and fast option for companies to enter unrelated product-markets and deal with the opportunities created by convergent technologies. Another explanation for the large amount of unrelated M\&As in the high-tech industry can lie in the fact that the R\&D expenditures of high-tech firms often produce unexpected by-products. These products create a basis for new diversification opportunities in other markets (Sutton, 1980).

In order to measure the sectoral differences in diversification we calculated a 'relative diversification M\&A' index, which is somewhat similar to the 'relative international M\&A' index, as it indicates the degree to which related or unrelated diversification is more important in some sectors than in others. This index can be calculated by setting the ratio of unrelated M\&As versus related M\&As for each sector 
against the overall unrelated $M \& A s /$ related $M \& A s$ ratio. The 'relative diversification M\&A" indexes for each individual high-tech sector show an unevenly distribution across industries (see table 2.3 ).

Table 2.3 Relative diversification M\&A index per high-tech sector for the period 1985-1994.

\begin{tabular}{lc}
\hline Sector & Index \\
\hline Aerospace and defense & 1.08 \\
Computers and office machinery & 1.02 \\
Pharmatceuticals & 0.72 \\
Electronics and conmunications & 1.14 \\
\hline
\end{tabular}

The sectors aerospace and defense, computers and office machinery, and electronics and communications all have a slight above-average propensity to undertake unrelated M\&As, but the difference with the industry-wide average is negligible. Interestingly the 'relative diversification $M \& A$ ' index for the pharmaceuticals industry is around 0.7 . This indicates that firms in the pharmaceutical sector have a preference for undertaking relatively more related M\&As in terms of product-markets than firms in the other high-tech sectors. An explanation for this phenomenon probably lies in the fact that pharmaceutical firms are confronted with a dramatic increase of $R \& D$ costs and have to reposition themselves to achieve greater economies of scale and scope in R\&D (Roijakkers and Hagedoom, 2003). The pharmaceutical firms can achieve these economies of scale and scope best by undertaking related M\&As that should generate more synergetic benefits than in the case of undertaking unrelated M\&As where the partners have no significant relationship with each other (Healy et al., 1992; Kranenburg van et al. 2001; Singh and Montgomery, 1987).

\subsection{Technological diversification patterns in M\&A activity during the period 1985-1994}

To create and sustain a competitive advantage a firm should not only decide which particular regions or product markets it should target, but also in which technological fields it should make future investments (Geringer et al., 1989). In other words, it is the firm's ability to acquire additional knowledge bases and capabilities, its integration skills, and its capacity to generate new knowledge through M\&As that create a sustainable competitive advantage (Barney, 1986). Therefore, one of the main objectives of M\&As, from an innovation perspective, is to transfer and integrate the acquired firm's knowledge base into the knowledge base of the acquiring firm.

We do, however, realize that not all acquisitions are undertaken for technological reasons with the sole intent to learn (Hamel, 1991). M\&As might also be motivated by market-entry and market-structure related considerations. Firms can 
enter an international market or attempt to create new markets by merging with another firm. Furthermore, acquisitions can be motivated by the desire to expand the firm's product range internationally (Berkovitch and Narayanan, 1993; Chakrabarti et al., 1994; Hagedoorn and Sadowski, 1999; Trautwein, 1990). These considerations motivate firms to undertake non-technological acquisitions that are less likely to provide technological knowledge to the acquiring firm (see chapter 4).

To distinguish between technological and nontechnological M\&As, we anallyzed if the target firm had any patenting activity in the 5 years preceding the M\&A (Ahuja and Katila, 2001). For the period 1985-1994, firms in the high-tech industry undertake on average as many technological M\&As as nontechnological M\&As. Over the years, we do however see a slight increase in the number of technological M\&As and a slight decrease in the number of nontechnological M\&As, although the difference is marginal.

When analyzing the sectoral differences by means of a 'relative technological diversification M\&A' index, indicating the ratio of technological M\&As versus nontechnological M\&As for each sector against the overall technological M\&A/nontechnological M\&A ratio, we see a diverse picture (see table 2.4). With the exception of the year 1987, firms in the pharmaceutical industry and the electronics and communications sector participate in technological - and nontechnological M\&As with the same propensity as the high-tech industry as a whole. We see a downward sloping trend in the 'relative technological diversification M\&A' index for the aerospace and defense industry until 1990, thereafter there is a large increase of technological M\&As undertaken by aerospace and defense firms leading to an above industry ratio of around 2 at the end of our period. On average, firms in this sector

Table 2.4 Relative technological diversification M\&A index per high-tech sector for the period $1985-1994$.

\begin{tabular}{lc} 
Sector & Index \\
\hline Aerospace and defense & 1.23 \\
Computers and office machinery & 0.89 \\
Pharmaceuticals & 0.96 \\
Electronics and communications & 1.06 \\
\hline
\end{tabular}

reveal an above-average propensity to participate relatively more in technological M\&As. This could be related to the fact that the aerospace and defense industry has the highest R\&D intensity of all four high-tech industries (OECD, 1992), which suggests that fast access to R\&D capabilities are very important for the further growth and survival of aerospace and defense firms (Freeman and Soete, 1997).

The "relative technological diversification M\&A" index for the computer and office machinery industry during the period of our analysis is constantly below the average-industry index, with the exception of the years 1987 and 1990. So, compared to the other high-tech industries, firms in the computer and office machinery industry 
undertake relatively less technological M\&As and more nontechnological M\&As. Given the rapid maturation and slow growth rates of the computer industry, marketstructure related motives to undertake $M \&$ As are probably more important during the period of our analysis than technological related motives. In addition, we also witnessed a standardization of products in the computer industry during the period 1985-1994, which could make it less necessary for firms to acquire technological knowledge externally.

\subsection{Conclusions}

The most important findings regarding M\&As found in the high-tech industry in general and each high-tech sector individually are summarized in table 2.5. The rapid pace of technological change, the liberalization of $\mathrm{FDI}$, the regional economic integration, and the privatization and deregulation of several industries augmented inter-firm competition and triggered high-tech firms to increasingly undertake M\&As during the period 1985-1994.

Table 2.5 Important findings in M\&A activity for the period 1985-1994.

\begin{tabular}{|c|c|}
\hline Sector & Findings \\
\hline \multirow[t]{4}{*}{ High-tech industry in general } & Large increase in the total number of $M \& A s$ \\
\hline & Large increase in the importance of international M\&As \\
\hline & $\begin{array}{l}\text { About } 67 \% \text { of the M\&As are unrelated in terms of product- } \\
\text { markets and } 33 \% \text { is related }\end{array}$ \\
\hline & $\begin{array}{l}\text { About } 50 \% \text { of the M\&As can be classified as technological } \\
\text { M\&As, the other half are nontechnological M\&As }\end{array}$ \\
\hline \multirow[t]{2}{*}{ Aerospace and defense } & $\begin{array}{l}\text { Relatively less international M\&As than the other high-tech } \\
\text { sectors }\end{array}$ \\
\hline & $\begin{array}{l}\text { Relatively more technological M\&As than the other high-tech } \\
\text { sectors }\end{array}$ \\
\hline \multirow[t]{2}{*}{ Computers and office machinery } & $\begin{array}{l}\text { Relatively less international M\&As than the other high-tech } \\
\text { sectors }\end{array}$ \\
\hline & $\begin{array}{l}\text { Relatively less technological M\&As than the other high-tech } \\
\text { sectors }\end{array}$ \\
\hline \multirow[t]{2}{*}{ Pharmaceuticals } & $\begin{array}{l}\text { Relatively more international M\&As than the other high-tech } \\
\text { sectors }\end{array}$ \\
\hline & $\begin{array}{l}\text { Relatively larger preference for related M\&As in terms of } \\
\text { product-markets }\end{array}$ \\
\hline Electronics and connumications & $\begin{array}{l}\text { Largest share in the total number of M\&As undertaken in the } \\
\text { high-tech industry }\end{array}$ \\
\hline
\end{tabular}


In addition, these developments not only increased the total number of M\&As, they also led to an overall enlarged importance of international M\&As in the high-tech industry. Especially, the pharmaceuticals sector showed a relative over-representation of firms undertaking international M\&As, driven by long lead times of products, high risks and costs surrounding R\&D projects, and the threat of new entrants in the pharmaceutical industry. Although international M\&As increased in importance for all four high-tech industries, firms in the aerospace- and defense sector and computers and office machinery sector preferred to undertake relatively more domestic M\&As. The most important reason for this is the drive of national prestige in the first case and consolidation pressures in the latter.

When analyzing the different international economic and trading blocks, we can conclude that M\&As are part of a "game' played mainly by companies from North America and Europe. As companies from these two regions participate in $87 \%$ of the number of M\&As, little appears left for companies from other regions. Especially North America dominates the activity in high-tech M\&As, which reflects the leading role that this continent plays in $R \& D$ and production in major high-tech industries (OECD, 1992). Furthermore, this dominance has not only led companies from other countries, particularly Europe, to undertake M\&As with North-American companies, the North-American dominance of technological development has also led to a situation whereby a large percentage of M\&As are undertaken between companies within the US. However, the difference between the number of intra North-American M\&As and intra European M\&As is getting smaller. Reasons for this convergence can be found in a later start of the consolidation wave in Europe compared to North America (Translink, 2003), the opening up of the Eastern European market, and the establishment of the single European market in 1992.

Another important development in the business environment not mentioned above, was the accelerated technological convergence on the product-market level during the mid 1980s and early 1990s. For example, in 1984, IBM buys Rolm a pioneer of digital office telecommunications system technology, reflecting the technological convergence between the computer and telecommunication market (Duysters and Hagedoom, 1998). This convergence created new opportunities for high-tech firms to enter previously unrelated product-markets by means of M\&As and partly explains the large amount of unrelated M\&As during the period 1985-1994. Interestingly, the technological convergence is less apparent in the pharmaceutical industry and firms in this sector show a strong preference for undertaking relatively more related M\&As than firms in the other high-tech sectors. This can be explained by the previously mentioned drive for pharmaceutical firms to decrease their R\&D costs by means of related M\&As in order to reach economies of scale and scope in R\&D.

Although we see a large increase in the number of international M.\&As and unrelated M\&As in terms of products-markets, the balance between technological M\&As and nontechnological M\&As is equally divided and unchanged for the period of our analysis. This suggests that in the high-tech industry, nontechnological motives to acquire a target firm are as important as the technological motive to get access to 
new technological knowledge and engineering capabilities. Firms in the high-tech sectors are often rapidly growing, which creates a shortage of managerial and/or financial resources (McGowan, 1971). This motivates firms to acquire targets that can offer these resources, even if they cannot make a significant contribution to the existing knowledge base of the acquiring firm. However, technological M\&As are important as well since they provide a viable alternative to the long and costly process of internal development of technological knowledge and capabilities (see chapter 5). So high-tech firms probably strive towards a proper balance between M\&As that are static in nature and enhance revenue or reduce costs and M\&As that are dynamic in nature and enhance a firm's innovation. 


\section{MEASURING INNOVATIVE PERFORMANCE: IS THERE AN ADVANTAGE IN USING MULTIPLE INDICATORS?}

\subsection{Introduction}

Once we have obtained a better understanding of the definition of M\&As, their main rationales and some major trends in patterns in M\&A activity, we can examine the impact of mergers and acquisitions on the post-M\&A innovative performance of hightech firms. However, before we are able to analyze the effect of M\&As on a firm's innovative performance, we first have to establish a better understanding of the concept and measurement of innovative performance. Based on the results presented in this chapter we can decide which indicators we have to consider, either separately or in a composite construct, in order to measure the post-M\&A innovative performance of the acquiring firm.

The management and applied economics literature on innovation and related topics has a long history of struggling with the measurement of the innovative performance of companies. Both generally available measures such as R\&D inputs, patent counts, patent citations, or counts of new product announcements, and more specific survey-based measurements of this particular performance by companies have been used in trying to capture this innovative performance of companies. ${ }^{2}$ Many studies use a single-indicator (R\&D, patents, patent citations, or new product announcements) arguing that the specific indicator that is applied has fewer shortcomings than the other indicators. Some studies use two or more indicators to generate one construct. Given the variety in constructs, measurements, samples, databases, industries and country settings and inconsistency in definitions, it is no surprise that there appears to be hardly any clear understanding of the concept and measurement of innovative performance.

The main purpose of this chapter is to establish a better understanding of the innovative performance of companies, considering the possible use of both a number of single indicators or various combinations of multiple-indicators in a composite measure of performance. This exercise implies that we attempt to measure "the" quality of performance by means of a latent variable and that we analyse the

\footnotetext{
${ }^{1}$ This chapter is based on Hagedoorn J. and M. Cloodt, 2003, Measuring innowative performance: is there an advantage in using multiple indicators?, Research Pollicy, 32, pp. 1365-1379.

${ }^{2}$ In the following we will mainly consider these generally available innovation measures found in the public domain or in large databases and not those obtained from survey-research. Bibliometric indicators could also be used for measuring research output in terms of the yield of scientific papers. However, there are sone serious methodological problems in relating classifications of fields of scientific output to teclnology and industry classifications. Moreover, this paper focuses on the measurement of innovative performance and not on scientific performance.
} 
usefulness of multiple indicators, constructing a composite measure of the innovative performance of companies (see also Lanjouw and Schankerman, 1999). The advantage of such a multi-indicator approach is that, instead of assuming the 'correctness' of a single indicator, probably taken for reasons of convenience, an analysis of multiple indicators might allow us to measure innovative performance through a more complex, more informative, composite measure. In addition to this, a composite measure can be analysed in detail, in terms of the individual indicators and with reference to the contribution of each indicator to the latent variable "innovative performance'. This particular approach enables us to measure the information gains from using particular indicators. This latter aspect of the analysis also indicates that our research does not imply that a multiple-indicator approach is by definition superior. In case of strong statistical association between indicators, each indicator could replace any other measure used in the analysis.

Given the purpose of this chapter, it should be clear that this study is methodological in nature as it presents an analysis of the measurement of innovative performance. It does not outline a theory or a model analysing and explaining differences in the innovative performance of companies. In that sense, the following analysis is self-referential, i.e. innovative performance is exclusively defined in terms of individual measures or the common factor linking the different indicators used in the analysis. The main objective of this chapter, therefore, is to better understand the possible advantages of specific single indicators or of composite measures, using multiple indicators related to latent variables, that conditional on the observed characteristics of these indicators, might generate greater insight.

In the following we will first discuss a number of concepts that are relevant in the context of measuring innovative performance and that also enable us to picture the possible relationships between the different indicators of this performance. Section 3.3 presents an overview of the literature on indicators such as R\&D input, patent counts, patent citations and new product announcements. In that context it turns out that $R \& D$ inputs could be a reasonable indicator of innovative effort, patents could be a more than acceptable indicator of innovative output, patent citations could be used to measure the quality of innovative output and new product announcements could indicate the level of product innovation. We will also discuss the possible statistical relationship between these indicators as found in a number of studies. Based on our understanding of previous research we will formulate three research questions in section 3.4 . This is followed in section 3.5 by a description of the large international sample of companies in four high-tech sectors and a description of the specific variables that we will analyse. We also offer a brief explanation of the rationale behind the choice of industries. The four high-tech studies for which we will investigate the appropriate measures of innovative performance are aerospace and defense, computer and office machinery, pharmaceuticals and electronics and communications. The empirical analysis of the different indicators of innovative performance, based on factor analysis, will be presented in section 3.6. This is followed by a discussion of the results and the conclusions that can be drawn from this study (section 3.7). 


\subsection{The relationship between inventive, technological and innovative performance}

Concepts such as invention, technology and innovation and the related performance of companies have to be clearly defined in order to improve our comprehension of some technical issues related to the measurement of innovation. Therefore, we will briefly outline our understanding of each of these concepts.

We define inventive performance as the achievements of companies in terms of ideas, sketches, models of new devices, products, processes and systems (Ernst, 2001; Freeman and Soete, 1997). As discussed further below, inventive performance is frequently measured in the context of patents where both raw counts of patents and patent citations are taken as the actual measures. Following Griliches (1998), technological performance can be defined as the accomplishment of companies with regard to the combination of their R\&D input, as an indicator of their research capabilities, and their R\&D output in terms of patents. We can also differentiate between innovative performance in the narrow and in the broad sense. Innovative performance in the narrow sense refers to results for companies in terms of the degree to which they actually introduce inventions into the market, i.e. their rate of introduction of new products, new process systems or new devices (Freeman and Soete, 1997). In that case new product announcements can be applied as an indicator of innovative performance.

A broader understanding of innovative performance encompasses the three previous measures of performance as it indicates the achievement in the trajectory from conception of an idea up to the introduction of an invention into the market (Ernst, 2001). This broad innovative performance therefore overarches the measurement of all stages from $R \& D$ to patenting and new product introduction. In other words, this definition of innovative performance in the broad sense focuses on both the technical aspects of innovation and the introduction of new products into the market, but it excludes the possible economic success of innovations as such (see also Acs and Audretsch, 1989; Ahuja and Katila, 2001; Archibugi, 1992; Ernst, 2001; Freeman and Soete, 1997; Grupp, 1994; Lanjouw and Schankerman, 1999; Stuart, 2000; Trajtenberg, 1990).

Our understanding of the different measures, which might interact in the innovative performance of companies, can be explained further using Venn diagrams. These Venn diagrams picture the possible overlap between R\&D, patents (both counts and citations) and new product announcements as indicators of innovative performance, see figure 3.1. It is well known that the overlap between R\&D, patents and new products is not necessarily complete. Full (100\%) overlap is usually not expected because not all patents are directly related to R\&D and the same applies to new products of which only a part of the total number are protected by patents. Also, the space in the squares that surround the Venn diagrams can represent nonmeasurable technological change or technological change not accounted for by these measures. 
Figure 3.1 Venn diagrams.

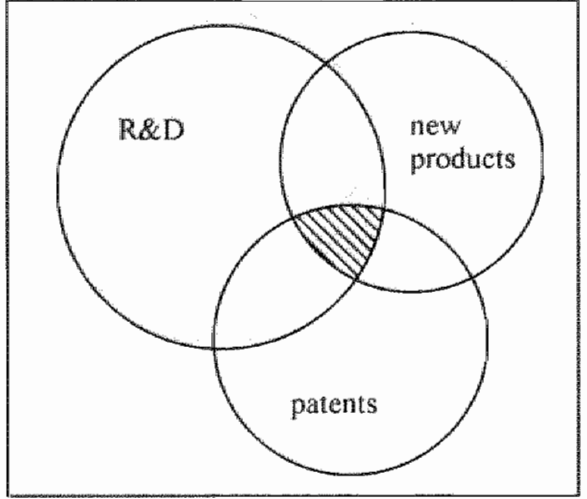

A

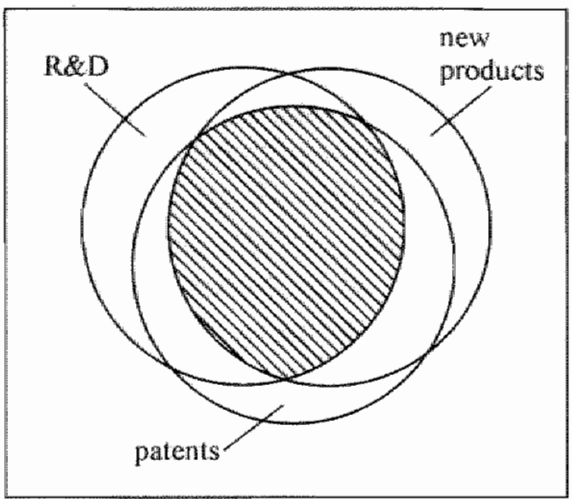

B

Note: Venn diagrams representing the relationship between R\&D, patents and new products in two hypothetical industries or two industry-average companies (A and B) with different degrees of overlap (see also Basberg, 1987)

The actual intersection between R\&D, patents and new products in the Venn diagrams depends on the specific nature of the industry. We submit that the degree of overlap between R\&D, patents and new product announcements determines the usefulness of single or multiple indicators. The more an industry or its average company is characterized by a high R\&D intensity, high patenting intensity and a high ratio for new product introduction, the larger the intersection in the Venn diagram. In case the overlap is complete or almost complete, i.e. in case of (nearly) complete association of measures, the assessment of innovative performance can probably be limited to one of the overlapping indicators (see figure 3.1B). In case the overlap is very small, one has to clearly differentiate between inwentive performance, technological performance and innovative performance in the narrow sense (see figure 3.1A). In other cases with varying degrees of overlap between $R \& D$, patents and new products, the use of multiple indicators might provide a better understanding of the actual innovative performance of companies.

\subsection{Indicators of innovative performance}

As discussed briefly in the above, we can analyse technological performance, inventive performance, and innovative performance in the narrow sense in terms of R\&D inputs, patent counts, patent citations, and new product announcements. These indicators can be used individually or combined in a multi-dimensional setting to measure innovative performance in the broader sense. 
The current literature on the measurement of innovation points towards some interesting perspectives on using these different indicators. In the following we will present a brief overview of this literature that will be helpful in providing some background to our research questions.

\subsubsection{R\&D inputs}

The literature usually takes $R \& D$ expenditures primarily as an input indicator of the efforts that companies make in establishing R\&D that might eventually lead to output. However, apart from the actual correlation of R\&D input with R\&D output through patents (Griliches, 1998), R\&D efforts can also indicate the innovative competences of companies that are found to affect the performance of companies, particularly in hightech industries (Duysters and Hagedoorn, 2001; Henderson and Cockburn, 1994). In that context, R\&D inputs of companies are part of the broader routines that companies follow in their innovative efforts, where previous R\&D expenditures affect subsequent R\&D inputs (Nelson and Winter, 1982). Successful R\&D input at a previous stage will increase the commitment to the allocation of future R\&D resources. In other words, within the routines that most companies have developed in managing their $R \& D$ inputs, the actual R\&D efforts not only reflect current input but also their previous successes that are an integral part of the skills that companies develop in creating an R\&D strategy with a stable set of long-term projects (Hagedoorn, 1989). We expect that, particularly in high-tech industries, $R \& D$ inputs are as much affecting future output as they are part of the current technological performance of a company in terms of generating new ideas, new blue prints and new models, part of which will eventually lead to new patents and new products (Griliches, 1998).

\subsubsection{Patents}

As most of the other indicators, the patent measure, in particular the use of raw patent counts, is subject to a longstanding debate regarding its bias and shortcomings (Archibugi, 1992; Cohen and Levin, 1989, Griliches, 1998). International and sectoral differences in patenting behaviour, differences in patenting between large companies and smaller firms, the identical weight given to some very important patents as well as to run-of-the-mill patents, the fact that patents only cover a part of the overall trajectory from R\&D to innovation, all of these 'shortcomings' feature in the literature that discusses the use of patents.

However, it appears that, certainly in large parts of the economics literature, raw patent counts are generally accepted as one of the most appropriate indicators that enable researchers to compare the inventive or innovative performance of companies in terms of new technologies, new processes and new products (Acs and Audretsch, 1989; Aspden, 1983; Bresman, Birkenshaw and Nobel, 1999; Cantwell and Hodson, 1991; Freeman and Soete, 1997; Griliches, 1998; Napolitano and Sirilli, 1990; Patel 
and Pavitt, 1995; Pawit, 1988). Even authors who are somewhat criticall of the overall use of patents as a performance indicator, such as Arundel and Kabla (1998) and Mansfield (1986), admit that patents can be an appropriate indicator in the context of many high-tech sectors. These literatures also suggest that the less patents are used for broad cross-sectional analysis that ignores inter-sectoral differences in the propensity to patent, the better patents reflect the performance of companies in one or a few sectors (see also Ernst, 2001).

\subsubsection{Patent citations}

Increasingly researchers are using patent citations as an indicator of inventive performance of companies. Compared to raw counts of patents, which generate a purely quantitative measure, patent citations also include a measure of the quality of patents. The basic assumption in using this indicator is that there is a positive relationship between the importance of a patent and the degree to which a patent is cited in later patents. This information on previous patents can be traced in each patent application as it is required that each patent cites earlier patents with somewhat similar or related technical claims, also known as the relevant prior art. The number of patent citations for a particular patent indicates its importance or impact.

Patent specialists are somewhat sceptical about the counting of patent citations without the necessary in-depth knowledge necessary to interpret the underlying citation reports that accompany each patent (Michel and Bettels, 2001). However, quantitative analysis of large numbers of patents and patent citations is frequently used in economics (for instance Harhoff, Narin, Scherer and Vogel, 1999; Jaffe, Trajtenberg and Henderson, 1993; "Trajtenberg, 1990) and the management literature (for instance Rosenkopf and Nerkar, 2001 ; Stuart, 2000).

Evidence of the validity of patent citations as an indicator of the quality of inventions or innovations, in terms of the correlation between the inter-subjective assessment of the importance of patents by technical specialists and the number of citations, is found in a number of studies (Albert, Avery, Narin and McAllister, 1991; Carpenter, Narin and Woolf, 1981; Karki, 1997; Narin, Noma and Perry, 1987; Pavitt, $1988)$.

\subsubsection{New product announcements}

Some contributions use new product announcements, traced through various sources and databases, as an indicator of the innovative performance of companies. In their study on two hundred and fifty US companies, Hitt et al. (1996) apply the degree to which new product announcements of companies were found in Dialog's NPA/plus database as a part of a combined indicator of the innovativeness of companies. Devinney (1993) shows that the positive relationship between the number of patents 
and new product announcements is primarily found at the level of industries and not at the level of individual companies, where less than $3 \%$ of the variance in individual firm new product announcements is explained by patent intensity.

One of the main problems with using new product announcements, as for instance found in various databases, is that these announcements are based on the press releases of the marketing departments of companies and little or no screening appears to be undertaken by the database operators themselves. In other words, new product announcements by companies themselves are simply accepted as long as companies identify them as such. Patents, on the other hand, in particular those registered in an advanced: economy such as the USA, are screened for their original contribution both during the pre-application period and during the actual application period by incompany engineers, patent lawyers and by patent office officials. Therefore, more than with some of the other indicators, careful screening of the data might be necessary with new product announcements in order to avoid major problems with the validity of the results.

\subsubsection{The statistical association of $R \& D$, patents and new product announcements}

As so many studies apply different indicators, it appears interesting to get a better understanding of the likely statistical association between these different indicators. The majority of studies use only one single indicator but a number of studies use multiple indicators or report on the correlation between some of the indicators mentioned in the above. However, the literature reporting more than one indicator appears to present a somewhat diverse picture when it comes to the possible relationship between $R \& D$ inputs, patent counts and citations, and new products.

Seminal studies by Pakes and Griliches (1984) and Bound, Cummins, Griliches, Hall and Jaffe 1984) find a rather strong relationship between R\&D and the number of patents across firms and industries. Ahuja and Katila's (2001) study of the international chemical industry reports a correlation of nearly 0.9 between R\&D inputs and patent counts. In their analysis of the international computer industry, Hagedoom and Duysters (2002a) mention a correlation of over 0.5 between the R\&D intensity of companies and their patent counts. However, in their study of US companies involved in nearly two hundred acquisitions, Hitt, Hoskisson, Ireland and Harrison (1991) show a low correlation of only about 0.2 between the R\&D intensity of these companies and their patent intensity.

In one of their early small-scale studies, Narin et al. (1987) find that the quality of research inputs of companies is highly correlated with raw patent counts and patent citations. Trajtenberg (1990) demonstrates that citation-weighted patent numbers of companies are more closely correlated with theür output measures of innovation, whereas unweighted patent counts are more closely related to R\&D expenditures of companies. Stuart (2000) reports a very high correlation of over 0.8 between raw patent counts and patent citations, the actual measure of innovation in a sample of 
hundred and fifty semiconductor firms. However, Rosenkopf and Nerkar (2001), who studied a smaller sample of optical disk manufacturing companies, find a relatively low correlation of about 0.3 between number of patents and patent citation indicators.

In a study of a sample of two hundred and fifty US companies, Hitt et al. (1996) establish a substantial correlation of 0.5 between the R\&D intensity of companies and their new product intensity, i.e. the number of new product announcements controlled for size of companies. Brouwer and Kleinknecht (1999) indicate some correlation between patenting and sales of innovative products, although this correlation is far from perfect. As already indicated in the above, Devinney (1.993) shows that the specific relationship between the patenting of companies and their new product announcements turns out to be quite weak.

\subsection{Research questions}

It is obvious from the above that the literature generates a rather mixed bag of findings, to say the least. Some studies suggest that, given the rather high correlation between some indicators, any of these correlated measures could be used as a partial or overall indicator of performance. Yet, the lack of any statistical association found for the same indicators in other studies, appears to suggest that the results from studies using any of these particular measures could be indicator-driven. However, the level of intermediate statistical association between a number of measures, as found in yet another set of studies, indicates that one composite construct with various measures could capture a latent variable that expresses the degree of innovative performance in the broader sense. The somewhat unclear nature of the measurement of innovative performance and other performance indicators, as found in large parts of the literature, appears influenced by a lack of systematic research in multiple industries, while frequently using only relatively small samples of companies in a domestic context.

Our understanding of the literature, as outlined in the above, suggests a number of research questions. In order to overcome the major shortcomings of previous research, we will investigate these questions empirically in an international, largescale, multi-sectoral setting. These research questions are:

1. Is there a systematic disparity between different indicators such as R\&D inputs, patent counts, patent citations and new product announcements?

2. Is there a statistical communality between two or more indicators, indicating that a composite construct could capture a latent variable?

3. Is the statistical association between two or more indicators of such a nature that each of these indicators can be applied as a representative indicator of innovative performance? 


\subsection{Research Methodology}

\subsubsection{Sample}

Our large, international sample of companies covers four high-tech industries: aerospace and defense (SIC-codes 372 and 376), computers and office machinery (SIC-code 357), pharmaceuticals (SIC-code 283) and electronics and communications (SIC-code 36). These high-tech sectors are selected because it is known that particularly in these industries R\&D expenditures, patents and new products play a role in indicating important aspects of innovative performance (OECD, 1997). Our sample consists of 1194 companies of which $51.17 \%$ is found in the electronics and communications industry, $23.45 \%$ is in computer and office machinery, $20.44 \%$ is in pharmaceuticals, and $4.94 \%$ belongs to the aerospace and defense sector.

The literature (Brouwer and Kleinknecht, 1999; Devinney, 1993; Ernst, 2001; Griliches, 1998) suggests that sectoral differences can play a role in explaining the various outcomes with respect to different indicators of innovative performance. Therefore, we will present the results of our analysis for the sample of companies as a whole as well as for each of the sub-samples for the different industries. As suggested by Ernst (2001), we also differentiate internationally between a North American subsample (70.02\%) and companies from other countries, mainly in Europe and Asia $(29.98 \%)$. Some details regarding the sectoral and international breakdown of this sample are presented in Appendix C.

Our sample is also diverse in terms of the distribution of the size of companies, representing many size-categories of innovating firms (see table 3.1). Most of the companies in our sample $(66.67 \%)$ are relatively small with annual revenues of up to a maximum of $\$ 100$ millions. A substantial number of companies $(14.74 \%)$ can be characterized as very large with annual revenues of over $\$ 1$ billion. Nearly one quarter of the sample $(18.59 \%)$ can be found in an intermediate size-class. Obviously, there are differences between the industry sub-samples but for each sector we do find a diverse picture in terms of the size-categories for companies.

It is well-known that there is no 'official' database with a world-wide, industrylevel list of all companies from which one can draw a random sample. Our sample is taken from the Securities Data databank on international companies, which provides information on companies in various industries, including those that were selected for this study. We concentrated on manufacturing sectors because some of the indicators more effectively capture aspects of technical innovation rather than of service innovation (Kleinknecht, 1999). Additional information on revenues and R\&D expenditures of companies in this sample was identified through various other datasets such as Amadeus, Compustat, the Fortune 500 list, and Worldscope. Companies entered the sample if the value of at least one of the variables used in the analysis had a value higher than zero. In other words, companies with zero R\&D, zero patents, zero patent citations and zero new products were excluded. 
Table 3.1 Distribution of size classes of companies in the total sample and for industry subsamples (1998 annual revenues in USS millions).

\begin{tabular}{llllll}
\hline $\begin{array}{l}\text { Size } \\
\text { classes }\end{array}$ & Total & $\begin{array}{l}\text { Aerospace } \\
\text { and defense }\end{array}$ & $\begin{array}{l}\text { Computers } \\
\text { and office } \\
\text { machinery }\end{array}$ & $\begin{array}{l}\text { Pharmaceu- } \\
\text { ticals }\end{array}$ & $\begin{array}{l}\text { Electronics } \\
\text { and } \\
\text { commu- } \\
\text { mications }\end{array}$ \\
\hline $\begin{array}{l}\text { and } \\
100<100\end{array}$ & $66.67 \%$ & $61.01 \%$ & $69.64 \%$ & $70.49 \%$ & $64.32 \%$ \\
$>1000$ & $18.59 \%$ & $16.94 \%$ & $17.14 \%$ & $13.94 \%$ & $21.28 \%$ \\
Total & $14.74 \%$ & $22.05 \%$ & $13.22 \%$ & $15.57 \%$ & $14.40 \%$ \\
& $100 \%$ & $100 \%$ & $100 \%$ & $100 \%$ & $100 \%$ \\
& $N=1194$ & $\mathrm{~N}=59$ & $\mathrm{~N}=280$ & $\mathrm{~N}=244$ & $\mathrm{~N}=61 \|$ \\
\hline
\end{tabular}

\subsubsection{Variables and data sources}

R\&D expenditures of companies are measured annually and standardized by converting the financial data from national currencies to US dollars. Data on R\&D expenditures were obtained through the well-known databases mentioned in the previous section and through additional internet searches.

We utilize the yearly number of all patents granted to each company as a second indicator. The data on patents are taken from the US Patent and Trademark Office (USPTO) database. We use US patent data for both US and non-US firms. Although these US data could imply a bias in favour of US companies against non-US firms, it is mentioned in the literature that given the importance of the US market, the 'real' patent protection offered by US authorities, and the level of technological sophistication of the US market, it is often compulsory for non-US companies to file patents in the US (Patel and Pavitt, 1991). Furthermore, to maintain a certain level of consistency, reliability and comparability it is necessary to choose one patenting system instead of several patenting systems across nations (Ahuja and Katila, 2001). ${ }^{3}$

Patent citations for each firm are counted as the yearly patent citations of their patents in all patent classes. Data on patent citations are also taken from the USPTO database.

New products or new product announcements are counted annually for each company in sectors such as aerospace and defense, computers, office equipment, pharmaceuticals, semiconductors and telecom, as found in the RDS Business \& Industry databank owned by the Gale Group. This database contains the full text of

\footnotetext{
With hindsight it turned out that there is little indication of major differences between North American (largely US) and non-North American companies, see the correlation for patents and other measures in Appendix D.
} 
press releases from all industries covering announcements related to products, with a focus on new products and services. In addition to product descriptions, the press releases generally contain key details about new products and technologies, including technical specifications, availability, uses, licensing agreements, distribution channels, and prices. The database covers more than 1500 technical and non-technical journals and can be found on www.gale.com. For this study we separated announcements of product development projects and new services from new product introduction and only use the latter information in the analysis.

For annual $R \& D$ expenditures and yearly patent counts data are obtained for the period 1992-1999, annual patent citations are registered for the years 1992-1998, and yearly new product announcements are counted for the period 1997-2000. We measured the performance of companies in the sample as a whole and for each subsample on each indicator with alternating time periods. The first period covers the years 1997 and 1998 for all indicators without any time lags between various indicators. All indicators in the data set share the years 1997 and 1998. The second time period (1995 - 1999) has an average lag of one year between indicators and the third time period $(1992-1999)$ has an average lag of two years between indicators. The fourth period is based on different time lags as mentioned in the literature (Cincera, 1997; Hall, Griliches and Hausman, 1986; Hall, Jaffe and Trajtenberg, 2000; Kondo, 1999; Napolitano and Sirilli, 1990; Pakes, 1985; Pakes and Griliches, 1984; Scherer, 1984). For this period we took lags of three years between R\&D and patents granted, two years between patents granted and patent citations, and one year between patent citations and new products.

\subsection{Results}

Our research questions suggest that we are basically making an attempt to understand innovative performance in terms of the possible causal structure among a number of indicators (variables), considering a set of common underlying dimensions or factors. Therefore, factor analysis is applied to examine our research questions. The results of this analysis will only be reported for the overall sample and its sub-samples for the period 1997-1998. The results for the analyses with different time lags turned out to be almost identical with no significant differences. Some descriptive data on the means and standard deviations for the overall sample and sub-samples are presented in table 3.2. Some additional descriptive data on the relationship between indicators for the overall sample and the sub-samples are given in Appendix $H$. These data suggest that there are inter-sectorall differences between the ratios for the different indicators. In that sense, despite the fact that all four sectors are high-tech industries, there are differences with regard to the degree to which, for instance particular levels of $R \& D$ lead to patents and new products. This phenomenon stresses the importance of understanding inter-sectoral differences, it does not question the use of this particular group of indicators. 
Table 3.2 Means and standard deviations for the sample as a whole and sub-samples.

\begin{tabular}{lll}
\hline Variables & Mean & Standard deviation \\
\hline Total & & \\
R\&D expenditures & 216016.4 & 619104.549 \\
Patent counts & 46.702 & 181.554 \\
Patent ciftations & 231.519 & 1007.653 \\
New products & 13.399 & 49.276
\end{tabular}

Aerospace and defense

R\&D expenditures

Patent counts

Patent citations

New products

Computers and office machinery

R\&D expenditures

Patent counts

195251.1

606422.472

63.847

251.625

Patent citations

343.435

1482.674

New products

24.528

76.719

Pharmaceuticals

R\&D expenditures

Patent counts

Patent citations

New products

Electronics and communications

R\&D expenditures

198493.6

662087.785

Patent counts

51.255

263.267

186.088

Patent citations

11.942

989.636

New products
291918.6

25.187

74.869

177.736

14.792

Note: R\&D expenditures are in thousands of US\$

In order to discover the usefulness of these different indicators we will first have to consider the outcomes of the factor analysis, presented below. 
Obviously a factor modlel can only be appropriate if variables are to some extent related to each other. If correlations between variables are lower than 0.30 , it is unlikely that they share common factors. In our sample and sub-samples correlations are greater than 0.30 , suggesting that a factor analysis is appropriate (see table 3.3 ). Similar correlations are found for the sub-samples for North American companies and other companies (see Appendix D). An exception is found for the aerospace and defense industry in non-North American countries. The irregular pattern of correlations, found for this industry and these countries, is probably caused by the relatively small number of twenty-one companies.

Table $3.3 \quad$ Correlations.

\begin{tabular}{|c|c|c|c|c|c|}
\hline Variables & Total & $\begin{array}{l}\text { Aerospace } \\
\text { and defense }\end{array}$ & $\begin{array}{l}\text { Computers } \\
\text { and office } \\
\text { machinery }\end{array}$ & $\begin{array}{l}\text { Pharma- } \\
\text { ceuticals }\end{array}$ & $\begin{array}{l}\text { Electronics } \\
\text { and commum- } \\
\text { cations }\end{array}$ \\
\hline $\begin{array}{l}\text { Patents and } \\
\text { patent citations }\end{array}$ & 0.941 & 0.805 & 0.973 & 0.777 & 0.925 \\
\hline $\begin{array}{l}\text { Patents and } \\
\text { R\&D expenditures }\end{array}$ & 0.783 & 0.874 & 0.931 & 0.704 & 0.812 \\
\hline $\begin{array}{l}\text { Patents and } \\
\text { new products }\end{array}$ & 0.798 & 0.475 & 0.793 & 0.589 & 0.830 \\
\hline $\begin{array}{l}\text { Patent citations and } \\
\mathbb{R} \& D \text { expenditures }\end{array}$ & 0.709 & 0.856 & 0.891 & 0.704 & 0.748 \\
\hline $\begin{array}{l}\text { Patent citations } \\
\text { and new products }\end{array}$ & 0.808 & 0.741 & 0.789 & 0.382 & 0.851 \\
\hline $\begin{array}{l}\mathbb{R} \& \mathbb{D} \text { expenditures } \\
\text { and new products }\end{array}$ & 0.734 & 0.666 & 0.907 & 0.817 & 0.763 \\
\hline
\end{tabular}

\footnotetext{
Some of the variables (i.e patent counts and patent citations) could be too strongly dependent on each other if a large number of companies have only zero patents which, ignoring time, will by definition lead to zero patent citations. This will have an upward elfect on the correlations. However, within a given period of time (e.g. 1997* 1998) or even in each of the other lagged periods, patent citations do not mecessarily refer to the patent counts from the same or lagged periods. Furthermore, $47.65 \%$ of the companies in the sample do not have patents whereas $38.11 \%$ of the companies have no patent citations. Or to put it differently, $36.38 \%$ of the companies in this sample that do not have patents in any of these periods, still have patent cilations.

'As noted in the literature (Hair et al, 1995) factor analytical methods are not well suited in case of a small sample and a low ratio of observations to variables. Even seemingly meaningful results, obtained from such samples, should be interpreted cautiously.
} 
A somewhat more advanced method of determining the appropriateness of factor analysis is the Kaiser-Meyer-Olkin (KMO) measure. The KMO measure is an index for comparing the magnitudes of the observed correlation coefficients to the magnitudes of the partial correlation coefficients (Norusis, 1993). It is defined as:

$\mathrm{KMO}=\left(\Sigma_{i+j} \Sigma_{r_{i j}}^{2}\right) /\left(\Sigma_{i \neq j} \sum r_{i j}^{2}+\Sigma_{i \neq i} \Sigma p_{i j}^{2}\right)$

where $r_{i j}$ is the simple correlation coefficient between variables $i$ and $j$, and $p_{i j}$ is the partiall correlation coefficient between variables $i$ and $j$. Higher values for this measure indicate the degree of appropriateness of using factor analysis. In addition to this we can also calculate a measure of sampling adequacy (MSA) for each individual variable.

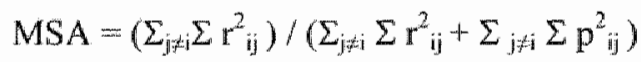

Again, values for this measure indicate whether factor analysis is appropriate or not. For our sample, both the KMO and the MSA measures indicate that factor analysis is an appropriate method to test if R\&D expenditures, patent counts, patent citation counts, and new products share one or more common factors (see Appendix E). This implies that we can continue with the second stage of the statistical analysis, i.e. exploratory factor analysis by means of principal component analysis (Hair, Anderson, Tatham and Black 1995).

The results of the initial unrotated factor analysis are presented in tables 3.4 and 3.5 and Appendices $\mathrm{F}$ and $\mathrm{G}$. Table 3.4, labelled communality measures, is an indication of the strength of the linear association among variables. Squaring the correlation coefficient shows the amount of the variable's total variance accounted for by the factor (Norusis, 1993). Small squared multiple correlation coefficients suggest that the variable should be eliminated from the analysis..

Over $75 \%$ of the communalities are greaten than 0.80 , suggesting that $80 \%$ or more of the variable"s total variance is accounted for by the factor. In general there are not many differences between the communalities calculated for the sample as a whole and the industry sub-samples (see table 3.4). The relatively largest differences involve the variables $R \& D$ expenditures and new products. The variable $R \& D$ expenditures has somewhat lower communalities for the sample as a whole, for the pharmaceutical industry and for the electronics and communications industry. The variable new products has lower communalities for the aerospace and defense industry and for the pharmaceuticals industry. An interesting finding is that, compared with the other industries, the communalities for the pharmaceutical industry show relatively low values. As indicated by Appendix $F$ the results for companies from North America and for those from other countries are not significantly different.

Table 3.5 and Appendix $G$ present the results of the factor analysis. Each row in the table and the appendix contains a factor loading indicating the correlation of that specific variable and the factor. High loadings make the variable representative of the factor. The signs of the factor loadings are all positive and the factor loadings are all 
statistically significant. $90 \%$ of the factor loadings are above 0.80 , while the lowest factor loading is still 0.774 , indicating that each of the four variables is representative of the factor. Not surprisingly, the factor loadings exhibit the same overall pattern as the communalities with respect to the sample as a whole, the sample with North American companies, and the sample consisting of companies from other countries. Furthermore, the factor loadings reveal the same pattern as the communalities for the variables patent citations and new products in the pharmaceutical industry and for the variable new products in the aerospace and defense industry.

Table 3.4 Communality measures.

\begin{tabular}{lcclll}
\hline Variables & Total & $\begin{array}{c}\text { Aerospace } \\
\text { and defense }\end{array}$ & $\begin{array}{l}\text { Computers } \\
\text { and office } \\
\text { machinery }\end{array}$ & $\begin{array}{l}\text { Pharma- } \\
\text { ceuticals }\end{array}$ & $\begin{array}{l}\text { Electronics } \\
\text { and } \\
\text { communi- } \\
\text { cations }\end{array}$ \\
\hline R\&D expenditures & 0.761 & 0.906 & 0.955 & 0.802 & 0.791 \\
Patent counts & 0.920 & 0.787 & 0.941 & 0.819 & 0.921 \\
Patent citations & 0.888 & 0.905 & 0.918 & 0.600 & 0.900 \\
New products & 0.822 & 0.627 & 0.831 & 0.676 & 0.856 \\
\hline
\end{tabular}

Table 3.5 Results of the initial unrotated factor analysis.

Component 1

\begin{tabular}{llllll}
\hline Variables & Total & $\begin{array}{l}\text { Aerospace } \\
\text { and defense }\end{array}$ & $\begin{array}{l}\text { Computers } \\
\text { and } \\
\text { office machinery }\end{array}$ & $\begin{array}{l}\text { Pharma- } \\
\text { ceuticals }\end{array}$ & $\begin{array}{l}\text { Electronics } \\
\text { and conmu- } \\
\text { vications }\end{array}$ \\
\hline $\begin{array}{l}\text { R\&D expenditures } \\
\text { Patent counts }\end{array}$ & 0.872 & 0.952 & 0.977 & 0.896 & 0.889 \\
$\begin{array}{l}\text { Patent citations } \\
\text { New products }\end{array}$ & 0.959 & 0.887 & 0.970 & 0.905 & 0.960 \\
& 0.907 & 0.951 & 0.958 & 0.774 & 0.949 \\
Total Eigenvalue & 3.391 & 3.224 & 3.644 & 0.822 & 0.925 \\
\% variance & 84.77 & 80.60 & 9.912 & 2.897 & 3.467 \\
explained & & & & & \\
\hline
\end{tabular}

Table 3.5 and Appendix $\mathrm{G}$ also give the total variance explained by each factor. For the sample as a whole nearly $85 \%$ of the total variance is explained by one component, that we label as innovative performance in the broad sense based on its 
appropriateness for representing the underlying dimension of this particular factor. In the computers and office machinery sector more than $90 \%$ of the total variance is explained by this component. The pharmaceutical industry has the lowest percentage explained by the component, namely $72.43 \%$. The difference of $19.5 \%$ between the average of both the computers and office machinery sector and the pharmaceutical industry is mainly based on the lower factor loadings for patent citations and new products in the pharmaceutical industry. Results for companies from North America and from other countries are almost identical (see Appendix $G$ ).

\subsection{Discussion and Conclusions}

Our study covers a large sample of nearly 1200 companies found in four high-tech industries. About $70 \%$ of these companies are registered in the US and Canada, most of the others are from Europe, Japan, South Korea and some South East Asian Newly Industrialized Countries. Our findings regarding the different indicators of innovative performance in this sample are rather unambiguous, leaving very little space for "subtle' re-interpretations of the pros and cons of the individual indicators. Also, using different time lags or no time lag at all does not affect the outcome of the analysis. Hence, we can present a set of clear-cut conclusions regarding the possible advantage of multiple indicators for measuring innovative performance in high-tech industries.

First, our research suggests that there is no major systematic disparity amongst R\&D inputs, patent counts, patent citations and new product announcements (research question 1). A systematic disparity was found for neither the sample as a whole, nor for individual sectors, or when taking the international distribution into account.

Second, the statistical communality of the four indicators of innovative performance is high for the sample as a whole and for all but one sub-sample (aerospace and defense outsicle North America). This indicates that a composite construct based on these indicators catches a latent variable "innovative performance" that measures the performance of companies in high-tech industries (research question 2). The latent variable innovative performance measures the overall, broad interpretation of innovative performance of companies in terms of their research input, the size of their inventive activities, the quality of their inventive output and their level of new product introduction (see also Mohnen and Dagenais, 2002 and Mairesse and Mohnen, 2002).

Third, the results of the analysis, however, also indicate that the overlap between each of these four indicators is that great (similar to Figure 3.1B) that in hightech sectors any of these four indicators could be taken as a measure of innovative performance in the broad sense (research question 3). Certainly in the electronics industry at large, with sub-sectors such as computers, office machinery and electronics and communications, and also in the aerospace and defense sector, each indicator appears to capture the innovative performance of companies. Although the results of our statistical analysis certainly do not dictate that a single indicator approach is 
invalid for the pharmaceutical industry, a composite construct that overarches all stages of the innovation process could be used for the measurement of innovative performance of companies in this particular sector. The factor loadings in the analysis of this sector specify a slightly higher degree of multidimensionality where R\&D inputs and patent counts represent somewhat different aspects of innovative performance than patent citations and new products (see also Trajtenberg, 1990).

Finally, our findings do not imply that there is no need for additional, contextinformed analyses. Future research could consider a number of topics relevant for understanding the measurement of innovative performance. An obvious item for further research is to investigate the usefulness of the current indicators in other industries than these high-tech sectors. We expect that in a number of industries with little R\&D, indicators based on patents and new products could still be used although the actual distribution for these measures might be different. As part of the continuous effort to build better theories and improved models to understand innovative performance, it is appealing to focus on the effect that the strategic behavior of companies has on their innovative performance, explaining how this might influence the different measurements of innovative performance. Also, the inclusion of other indicators might be useful for analyzing high-tech industries, although it appears as if the current line-up of measures is quite exhaustive. Furthermore, it should be clear that the measurement of innovative performance in non-manufacturing sectors is in need of a rather different set of indicators. Obviously, future research should consider some alternative measures of innovation that are more appropriate in the context of a wide range of service industries. 



\section{MERGERS AND ACQUISITIONS: THEIR EFFECT ON THE INNOVATIVE PERFORMANCE OF COMPANIES IN HIGH-TECH INDUSTRIES}

\subsection{Introduction}

Given the long-standing history of M\&As, it is no surprise that many researchers from a number of academic disciplines have studied various aspects of M\&As, such as the motives of firms for entering into M\&As, their implementation process, the economic impact of M\&As on the firms involved, different sectoral outcomes, and the effect on society at large. From the 1980 s onward, researchers in industrial organization (e.g. Caves, 1989; Mueller, 1986 a and b; Ravenscraft and Scherer, 1989), corporate control (e.g. Barney, 1988; Hitt et al., 1996), finance (e.g. Healy et al., 1992; Jensen, 1984), and strategic management (e.g. Lubatkin, 1987; Seth, 1990; Shelton, 1988) have made considerable progress in analyzing the effects of M\&As. However, the conclusions of these various studies present a mixture of results and often predict a negative effect of M\&As on a firm's post-M\&A performance. Therefore the aim of this thesis is to take the debate of the effect of M\&A activity somewhat further by studying the long-term implications of M\&As. After ascertaining a generally accepted set of innovation indicators in chapter 3, we can now analyze the effect of M\&As on a firm's post-M\&A innovative performance.

A number of elements in the resource-based view of the firm, in combination with some related contributions that stress the importance of organizational learning and innovation, provide some useful insights and a preliminary explanation why M\&As continue to be a popular growth strategy of many companies (World Investment Report, 2000). The resource-based view of the firm describes the firm as a unique collection of difficult-to-imitate resources, competencies and capabilities (Barney, 1986; Grant, 1996; Wernerfelt, 1984). To create a competitive advantage and capture above-normal rate of returns (i.e. rents), these resources must, by definition, be scarce, valuable and reasonably durable (Barney, 1991). The emerging knowledgebased view is an outgrowth of the resource-based view to the extent that it focuses upon knowledge as the strategically most important resource of the firm (Conner and Prahalad, 1996; Grant, 1996; Nonaka, 199॥; Spender, 1989). Knowledge is also a central issue in several other research traditions that stress the importance of both organizational learning and the transfer and diffusion of innovative capabilities within the firm (e.g. Boisot, 1995; Grant, 1996; Huber, 1991; Levitt and March, 1988). In the context of the subject of this paper, the opportunities for organizational learning increase when a firm is exposed to new and diverse ideas based on differences in technological capabilities between the acquiring and the acquired firm (Goshal, 1987; 
Hitt et al., 1996). Acquiring diverse external knowledge bases and making proper use of this new knowledge are found to be relevant contributions to a firm's post-M\&A innovative performance (Cohen and Levinthal, 1989; Pakes and Griliches, 1984).

Our current study is clearly linked to recent research that has already made some progress in analyzing critical success factors that have a significant influence on a firm"s post M\&A innovative performance. For instance, Ahuja and Katila (2001) studied the impact of the absolute and relative size of acquired knowledge bases on the innovative performance of firms in the chemicals industry. They argue that the absolute size of the acquired knowledge base enhances innovative performance of the acquirer, while relative size dissimilarities reduce the innovative performance of companies. Hagedoorn and Duysters (2002a) analyzed the effect of M\&As on the patent intensity growth of firms in the international computer industry. They find that, given a proper strategic and organizational fit, M\&As can contribute to an improved post-M\&A innovative performance. Building on insights developed in the literature on technological innovation, organizational learning and the resource-based view, we seek to provide an understanding of the post-M\&A innovative performance that focuses on the size and the relatedness of the knowledge bases of the M\&As of hightech firms.

Our study can be characterized as an extended replication of the analysis by Ahuja and Katila (2001). We realize that, contrary to the applied sciences, replication studies are not very popular in most of the social sciences, with the possible exception of applied econometrics and some fields in psychology. For instance, Hubbard and Vetter (1992 and 1997) and Fuess (1996) found that leading journals in economics, management and finance publish relatively few extended replication studies. From a purely methodological point of view, this comes as quite surprising because so far the management literature has generated a slightly confusing body of literature, to say the least. For many basic questions in the literature, the reader will find contradictory findings, different measurements, unclear international implications, and the use of a range of partly overlapping constructs. See, for instance, the literature on the effects of M\&As on several aspects of company performance as discussed in the above.

The aloofness regarding replication studies is remarkable if we realize that even in an almost perfect setting, there are methodological arguments in favour of replication. In such a setting, replication studies would measure the dependent variable and the independent variables following exactly the same procedures, and all studies would draw samples from the same population. Still for this seemingly redundant setting, it can be argued that replication studies are meaningful because each individual study with a limited sample size will contain sampling errors that affect its results. Apart from the fact that related empirical studies in the management literature do not seem to use the same population, the sample size of the average management study is relatively small compared to what would be adequate from a purely statistical point of view (Hunter, 2001).

Replication studies of the kind mentioned in the above might be necessary but they are somewhat short on creativity indeed. A more interesting approach to 
replication studies, followed below, advocates the use of equivalent measurements, i.e. similar but not necessarily identical measurements. Also, such a more extended replication study will take duplication as a starting point but then widen the research by using some alternative methods or using other samples and a different time period (Hamermesh, 1997; Hubbard and Vetter, 1997). Compared to simple replications studies, replication studies with extension, such as undertaken below, do not concern the internal validity of the research design but their main focus is on the external validity or generalization of previous research findings.

The Ahuja and Katila (2001) study concentrated on the effect of M\&As in a single medium-tech industrial context: the chemicals sector. Their contribution invites subsequent research by others to consider a wider range of industries, in particular high-tech industries. Our study extends the work by Ahuja and Katila analyzing the post-M\&A innovative performance of companies by means of a large sample of firms operating in four high-tech sectors consisting of aerospace and defense, computers and office machinery, pharmaceuticals, and electronics and communications as defined by the OECD (1997). These high-tech sectors are selected for two main reasons. First, these industries are primarily knowledge-driven industries (OECD, 1997). Technological learning is expected to be a key determinant in creating and sustaining a competitive advantage for many of the sample firms in these industries (Bierly and Ckakrabarti, 1996). Second, for each of these industries we can measure innovative performance through the same indicator, i.e. patents. It is well known that particularly in these industries, patents play a significant role in indicating important aspects of innovative performance (Hagedoorn and Cloodt, 2003; OECD, 1997).

The chapter is organized as follows. In section 4.2 we first present the theoretical background and the four hypotheses that stipulate the expected effect of non-technological $M \& A s$ and technological $M \& A s$ on post-M\&A innovative performance. The research methodology is discussed in section 4.3. This is followed by a presentation of the results of our study (section 4.4). In the last section, we discuss the main findings, we draw some conclusions from this research and we briefly present some topics for future research.

\subsection{Theory and hypotheses}

According to the resource-based theory of the firm and the knowledge-based view, differences in innovative performance between firms are a result of dissirnilar knowledge sources and different capabilities (Bierly and Chakrabarti, 1996). In the context of M\&As, it is the firm's ability to acquire additional knowledge bases and capabilities, its integration skills, and its capacity to generate new knowledge through M\&As that create a sustainable competitive advantage (Barney, 1986). Therefore, one of the main objectives of M\&As, from an innovation perspective, is to transfer and integrate the acquired firm's knowledge base into the knowledge base of the acquiring firm. However, we do realize that not all acquisitions are undertaken for technological 
reasons with the sole intent to learn (Hamel, 1991). M\&As might also be motivated by market-entry and market-structure related considerations. Firms can enter an international market or attempt to create new markets by merging with another firm. Furthermore, acquisitions can be motivated by the desire to expand the firm's product range internationally (Berkovitch and Narayanan, 1993; Chakrabarti et al., 1994; Hagedoorn and Sadowski, 1999; Trautwein, 1990). These considerations motivate firms to undertake non-technological acquisitions that are less likely to provide technological knowledge to the acquiring firm.

If M\&As involve no or only a few technological components, they are expected to have little or no effect on the innovation routines of the firm and thus little or no impact on the innovative performance of the acquiring firm (Ahuja and Katila, 2001). However, if M\&As create a disruption of the established routines of both the acquiring and the acquired firm, thereby consuming significant managerial time and energy, they can have a negative impact on the post-M\&A innovative performance. (Ahuja and Katila, 2001; Haspeslagh and Jemison, 1991; Hitt et al., 1996). In particular, acquisitions motivated by non-technological incentives, such as short-term profit growth, can require that much managerial attention that this objective leads to a lower managerial commitment to long-term investments and other objectives such as innovation (Hitt et al., 1996). In summary, we expect that non-technological M\&As either contribute little to the innovative output of the acquiring firm, or that there might be a negative impact on the post-M\&A innovative performance. Hence,

Hypothesis 1: Non-rechnological acquisitions will have either a negative or a nonsignificant effect on the post-M\&A innovative performance of the acquiring firm.

The possible positive impact of technological M\&As on innovative performance depends on a number of characteristics of these M\&As. A first critical dimension in the technological unification of two firms concerns the size or the quantity of the acquired knowledge bases (Ahuja and Katila, 2001). The effect of M\&As depends on whether M\&A targets have a similar or preferably higher R\&D input and other higher or similar innovative activities. It appears that R\&D intensive firms, motivated by the opportunity to reach synergies in future $R \& D$, aim at M\&As with firms from other R\&D intensive sectors (Hall, 1990; MacDonald, 1985). The unification of two knowledge bases can provide these synergies or economies of scale and scope, while reducing redundant or duplicate R\&D efforts, providing a larger research base to finance its costs (Hall, 1990).

Another positive effect of the increased size of knowledge bases through M\&As, besides economies of scale and scope, is found in the potential for aggregation (Grant, 1996). The transfer of knowledge from the acquired firm to the acquiring firm involves both transmission and receipt (Grant, 1996). Receipt can be analyzed in terms of a firm's absorptive capacity, which plays a dual role in improving innovative performance (Cohen and Levinthal, 1989 and 1990). When a firm increases its internal knowledge base by bringing in knowledge from an outside source via acquisition, it 
can use this knowledge to generate new product and process innovations. In addition, the expansion of the internal knowledge base also increases the firm's ability to recognize the value of new external information, to transmit and assimilate this information and to further exploit this external knowledge for commercial ends (Cohen and Levinthal, 1989).

Hence, by undertaking $M \& A s$, firms are not only confronted with the internally created knowledge base of the acquired firm. By taking over the acquired firm's knowledge base, the firm will be able to view some issues from a different perspective and recognize the value of new external knowledge, which can help the acquirer develop a richer knowledge base (Ahuja and Katila, 2001; Bierly and Chakrabarti, 1996; Levinthal and March, 1993; Vermeulen and Barkema, 2001). Several studies mention the advantages of creating a richer or broader knowledge base, such as increased strategic flexibility, sustainable competitive advantage, and increased performance (Bierly and Chakarabarti, 1996; Henderson and Cockburn, 1994; Reed and DeFillipi, 1990; Volberda, 1996). We expect that the acquisition of external available knowledge will lead to increased economies of scale and scope and a broader knowledge base, that can both have a positive effect on the post-M\&A innovative performance.

Hypothesis 2. There is a positive relationship between the absolute size of the acquired knowledge base and the post-M\&A innovative performance of the acquiring firm.

The challenge for companies is not just to acquire knowledge bases but also to integrate them in order to improve the post-M\&A innovative performance (Ahuja and Katila, 2001; Child, Faulkner, and Pitkethly, 2001; Haspeslagh and Jemison, 1991). This integration process forms the second critical dimension in the unification of two firms. The success of R\&D integration can be influenced significantly by several acquisition management interventions such as open information exchange between employees, empowerment and team-based structures (Child, et al., 2001; Gerpott, 1995; Grant, 1996). The integration of a knowledge base that is of a relatively large size can disrupt existing innovative activities and render the different integration stages more complex, more time consuming and full of risks (Capron and Mitchell, 2000; Chakrabarti, et al., 1994; Gerpott, 1995; Haspeslagh and Jemison, 1991). Besides the disruption of the existing innovation processes, a problematical integration of the acquired knowledge base can even become an excuse for discontinuing the use of the newly acquired knowledge (Szulanski, 1996; Zaltman, Duncan and Holbeck, 1984). Due to such problems, integrating a relatively large knowledge base requires additional resources to be devoted to integration activities, leaving fewer resources for the actual innovative endeavor (Ahuja and Katila, 2001).

What this part of the literature suggests is that if the acquired firm's knowledge base is large relative to the acquiring firm, this has some serious consequences for the integration of the innovative activities of its M\&A partners. In other words, simply adding up research and other technological knowledge of a large partner to the already 
existing knowledge of the acquiring firm, assuming that the integration process will take place rather smoothly, overestimates a firm's organizational flexibility. Thus, we expect that with the integration of a relatively large knowledge base, fewer resources will be available for innovation, having a negative impact on the acquirer's post-M\&A innovative performance.

Hypothesis 3. There is a negative relationship between the relative size of the acquired knowledge base and the post-M\&A innovative performance of the acquiring firm.

A third important factor in the merger of two firms is their relatedness in terms of particular fields of technology that the acquiring firm shares with the acquired firm (Hagedoorn and Duysters, 2002a). While the relatedness of M\&As in terms of product-markets concerns the industry-aspect, the technological relatedness refers to firm-specific aspects such as technological disciplines and engineering capabilities. The positive effect of relatedness in technological knowledge on the success of M\&As is found by several studies that emphasize the effects of economies of scale and scope of R\&D, such as a shorter innovation lead-time and the possibility to engage in larger combined projects (Gerpott, 1995, Hagedoorn and Duysters, 2002a; Mowery et al., 1996).

From an organizational learning perspective, this positive effect lies in the ability to better evaluate and utilize related externally acquired knowledge than unrelated externally acquired knowledge (Cohen and Levinthal, 1990). This is based on the idea that a firm's absorptive capacity depends to a large degree on its level of knowledge in a specific field (Cohen and Levinthal, 1990; Dodgson, 1993; Duysters and Hagedoorn, 2000; Mowery et al., 1996). If the knowledge base of the acquirer is not sufficiently adapted to the newly acquired knowledge, the absorption process becomes very difficult (Duysters and Hagedoom, 2000). Therefore we can argue that, unrelated technologies often require a radical change in the way of organizing research (Kogut and Zander, 1992) and such a major modification can easily be counterproductive (Ahuja and Katila, 2001; Dosi, 1988).

However, technological knowledge and engineering capabilities that are too similar to the already existing knowledge of the acquiring company will contribute little to the post-M\&A innovative performance. Some degree of differentiation in technological capabilities between the acquiring and acquired firm may entich the acquiring firm's knowledge base and create opportunities for learning (Goshal, 1987; Hitt et al., 1996). A richer or broader knowledge base increases the acquiring firm's potential of realizing the full combinatory capabilities of the firm's knowledge base (Bartlett, 1993; Kogut and Zander, 1992, Sanchez and Mahoney, 1996). This enrichment of the acquiring firm's knowledge base and a proper use of the acquired external knowledge are relevant contributions to a firm's innovative performance (Cohen and Levinthal, 1989; Griliches, 1990; Pakes and Grilliches, 1984). In other words, we expect that one has to strive for moderate relatedness between knowledge bases. On the one hand, the acquired knowledge has to show enough overlap with the 
acquirer's already existing knowledge base to facilitate the absorption process. On the other hand, the combination of knowledge bases requires enough diversity between existing and acquired technological knowledge to make a substantial contribution to the post-M\&A innovative performance. M\&As with the abovementioned moderate degree of overlap between the knowledge bases will likely have the most positive effect on the post-M\&A innovative performance of the acquiring firm. Hence,

Hypothesis 4. The technological relatedness of the acquired knowledge base will be curvilinearly related to the post-M\&A innovative performance of the acquiring firm.

\subsection{Methods}

\subsubsection{Model}

As discussed in the next section, our dependent variable is a non-negative integervalued count variable for post-M\&A innovative performance, measured by patent counts. Non-negative integer-valued count variables violate one of the main assumptions of the classical linear regression model as this dependent variable cannot be normally distributed. For such data, count models provide a methodological improvement over the classical linear (OLS) regression models (Cameron and Trivedi, 1986; Gourieroux, Montfort and Trognon, 1984a and b; Hausman, Hall and Griliches, 1984). The Poisson model is the simplest and more restricted count data model that assumes equality of the conditional mean and variance. However, a large number of empirical distributions of count data have a variance greater than the mean and are thus over-dispersed relatively to the Poisson case (Cameron and Trivedi, 1986; Wooldridge, 2002). The negative binomial regression is an extension of the Poisson model and provides a mechanism for incorporating overdispersion while allowing the variance of the process to differ from the mean (Cameron and Trivedi, 1986; Gourieroux et al., 1984a and b; Hausmann et al., 1984).

Following Ahuja and Katila (2001) we specifiy the following regression model:

$P_{i t}=\exp \left(X_{i t-1} \gamma+A_{i t-1} \beta_{1}+A_{i t-2} \beta_{2}+A_{i t-3} \beta_{3}+A_{i t-4} \beta_{4}\right)$

where $P_{i t}$ is the number of patents achieved by firm $i$ in year $t, X_{i t-1}$ is a vector of control variables affecting $\mathbb{P}_{\text {iit }}$ (e.g. firm size, industry, nationality, cultural distance, time and unobserved heterogeneity), $A_{\text {it-year } j}$ is the lagged vector of the independent variables for year $j=1$ to $4, \gamma$ is a vector of regression coefficients for the control variables, and the $\beta$ s are the vectors of regression coefficients for the $j$ th period lagged independent variables. We include unobserved heterogeneity as an additional covariate in the model. To control for unobserved heterogeneity, we gathered pre-sample 
information of the unobserved differences in knowledge stocks between the sample firms.

We use a distributed lag model since the effect of a change in the independent variables will probably only gradually affect the dependent variable (Judge, Hill, Griffiths, Lutkepohl and Lee, 1988). By including lagged effects we can subsequently test the effect of acquisitions for up to 4 years after the year the $\mathrm{M} \& \mathrm{~A}$ was originally made (Ahuja and Katila, 2001). The total impact of an M\&A across time can be analyzed by summing the regression coefficients on the distributed lags. By calculating t-statistics we can test the hypothesis that the total impact of acquisitions, summed across all years, is zero and check whether it is statistically significant (Ahuja and Katila, 2001; Greene, 1993; Gujarati, 1988). In that case:

$t=\left(\beta_{1-1}+\beta_{1-2}+\beta_{i-3}+\beta_{1-4}\right) / \sqrt{ }$ Variance $\left(\beta_{1-1}+\beta_{1-2}+\beta_{4-3}+\beta_{l-4}\right)$

where the $\beta s$ are the regression coefficients for the $j$ th period lagged independent variable (Judge et al., 1988). The variance for the summed coefficients can be computed using the following relation (Gujarati, 1988):

Variance $\left(\beta_{t-1}+\beta_{t-2}+\beta_{t-3}+\beta_{t-4}\right)=\left[\operatorname{Var}\left(\beta_{t-1)}+\operatorname{Var}\left(\beta_{t-2}+\operatorname{Var}\left(\beta_{t-3)}+\operatorname{Var}\left(\beta_{t-4}\right)+\right.\right.\right.\right.$

$2 \operatorname{Cov}\left(\beta_{t-1} \beta_{t-2}\right)+2 \operatorname{Cov}\left(\beta_{i-1} \beta_{t-3}\right)+2 \operatorname{Cov}\left(\beta_{t-1} \beta_{t-4}\right)+2 \operatorname{Cov}\left(\beta_{t-2} \beta_{t-3}\right)+$

$\left.2 \operatorname{Cov}\left(\beta_{1-2} \beta_{t-4}\right)+2 \operatorname{Cov}\left(\beta_{1-3} \beta_{1-4}\right)\right]$.

This study uses a panel dataset model that combines time series and crosssections to analyze our data and test the hypotheses. Mathematically such a model can be represented as:

$E\left(Y_{i t} / X_{i t}, C_{i}\right)=\beta_{i 0}+X_{i t} \beta+C_{i}+U_{i t}, i=1 \ldots N_{y} t=1 \ldots T$ and $X_{i t} \beta=\beta_{1} X_{i}+\ldots \beta_{k} X_{t k}(4.4)$

with $i$ denoting firms and $t$ denoting time. $\beta_{0}$ is a scallar, $X_{i l}$ is the $i t$ th observation on $K$ explanatory variables, $\beta$ is $K \times 1, C_{i}$ denotes the unobservable individual specific effect, and $U_{\text {it }}$ denotes the remainder disturbance.

Panel data make it possible to specify a random effects model or a fixed effects model (Baltagi, 1995; Hsiao, 1986). The key consideration in choosing between a random effects panel approach and a fixed effects panel approach is whether $C_{i}$ and $X_{i t}$ are correlated (Baltagi, 1995; Hsiao, 1986). When $C_{i}$ is allowed to be arbitrarily correlated with the $X_{i \text { in }}$, a fixed effects analysis is appropriate (Wooldridge, 2002). The random effects approach to estimating $\beta$ effectively puts $C_{i}$ into the error term, under the assumption that $C_{i}$ is orthogonal to $X_{i t}$ and then accounts for the implied serial correlation un the composite error $V_{i t}=C_{i j}+U_{i t}$ (Wooldridge, 2002). Obviously, timeconstant variables are not allowed in fixed effects analyses. If $C_{i}$ can be arbitrarily correlated with each element of $X_{\text {it, }}$ there is no way to distinguish the effects of timeconstant observables from the time-constant unobservable $C_{i}$. We use a random effects 
model because our analysis includes variables such as nationality and industry that are time-constant factors in $\mathrm{X}_{\mathrm{it}}$ (Wooldridge, 2002).

\subsubsection{Sample and Data}

The hypotheses are tested on a relatively large international sample of companies covering four high-tech industries: aerospace and defense (SIC-codes 372 and 376), computers and office machinery (SIC-code 357), pharmaceuticals (SIC-code 283) and electronics and communications (SIC-code 36). Our sample consists of 347 companies of which $21(6.05 \%)$ operate in the aerospace and defense industry, $76(21.9 \%)$ are found in computers and office machinery, $77(22.19 \%)$ are active in pharmaceuticals, and $173(49.86 \%)$ operate in the electronics and communications sector. The sample consists of 256 North American companies and 91 companies from other regions (45 from Europe and 46 from Aslia). Some additional details regarding the sectoral and international breakdown of this sample are presented in Appendix 1.

Our sample is also diverse in terms of the distribution of the size of companies (see table 4.1 ). About $18 \%$ of the companies in our sample are relatively small with less than 1000 employees. Almost the same percentage of companies can be characterized as very large with more than 50,000 employees. More than half of the sample $(64 \%)$ can be found in intermediate size-classes.

Table 4.1 Distribution of size classes of companies in the total sample and for industry subsamples (number of employees).

\begin{tabular}{|c|c|c|c|c|c|}
\hline $\begin{array}{l}\text { Size } \\
\text { classes }\end{array}$ & Total & $\begin{array}{l}\text { Aerospace } \\
\text { and defense }\end{array}$ & $\begin{array}{l}\text { Computers } \\
\text { and office } \\
\text { machinery }\end{array}$ & $\begin{array}{l}\text { Pharmacen- } \\
\text { ticals }\end{array}$ & $\begin{array}{l}\text { Electronics } \\
\text { and } \\
\text { commu- } \\
\text { nications }\end{array}$ \\
\hline$<1000$ & $18.30 \%$ & $00.00 \%$ & $12.73 \%$ & $20.84 \%$ & $22.86 \%$ \\
\hline $1000<5000$ & $27.68 \%$ & $06.25 \%$ & $38.18 \%$ & $14.58 \%$ & $31.43 \%$ \\
\hline $5000<10000$ & $09.82 \%$ & $06.25 \%$ & $12.73 \%$ & $14.58 \%$ & $06.67 \%$ \\
\hline $10000<50000$ & $26.34 \%$ & $31.25 \%$ & $23.64 \%$ & $39.58 \%$ & $20.95 \%$ \\
\hline$>50000$ & $17.86 \%$ & $56.25 \%$ & $12.72 \%$ & $10.42 \%$ & $18.09 \%$ \\
\hline Total & $100 \%$ & $100 \%$ & $100 \%$ & $100 \%$ & $100 \%$ \\
\hline & $N=224$ & $N=16$ & $\mathbb{N}=55$ & $N=48$ & $N=105$ \\
\hline
\end{tabular}

In total we identified 2429 M\&A events for our sample firms in the period 1985-1994. To distinguish between technological and nontechnological M\&As, we analyzed if the target firm had any patenting activity in the 5 years preceding the M\&A (see Ahuja and Katila, 2001). Of the total amount of M\&As, 1148 met the above-mentioned 
criterion and they are classified as technological M\&As. The remaining $1281 \mathrm{M} \& \mathrm{As}$ are classifred as non-technological M\&As.

For the firms in the sample we obtained annual patent count data for the period 1980-1994 and acquisition and firm specific data for the years 1980-1993. The final panel for the regression analysis amounts to 7 years from 1989 to $\mathbb{1 9 9 5 .}$

Our sample is taken from the Securities Data databank, which contains information on worldwide M\&As. Within the M\&A database there is information on the year the M\&A was established and company information on the acquirer, the target, the parent acquirer and the parent target firm. The industry information is provided in SIC codes of the acquiree and acquirer. Additional information on size and R\&D expenditures of companies in this sample was identified through various other datasets such as Amadeus, Compustat, and Worldscope. Data on patents and patent citations are taken from the US Patent and Trademark Office database (US Department of Commerce). We use US patent data for both US and non-US firms. Although these US data could imply a bias in favour of US companies against non-US firms, it is mentioned in the literature that, given the importance of the US market, the "real" patent protection offered by US authorities and the level of technological sophistication of the US market, it is often compulsory for non-US companies to file pattents in the US (Patel and Pavitt, 1991). Furthermore, to assert a certain levell of regularity, trustworthiness and similarity it is preferable to choose one patenting system instead of several patenting systems across nations (Ahuja and Katila, 2001).

\subsubsection{Dependent Variable}

The dependent variable, post-M\&A innovative performance of the acquiring firm, is measured by the number of patents granted to each acquiring firm (Ahuja and Katila, 2001). The patent measure, in particular the use of raw patent counts, is subject to a longstanding debate regarding its bias and shortcomings (Archibugi, 1992; Cohen and Levin, 1989, Griliches, 1998). International and sectoral differences, dissimilarity between large and smaller firms, the identical weight given to very important patents as well as to rum-of the-mill patents are shortcomings discussed in the literature. However, it appears that raw patent counts are generally accepted as one of the most appropriate indicators that enable researchers to compare the inventive or innovative performance of companies in terms of new technologies, new processes and new products (Bresmam et al., 1999; Freeman and Soete, 1997; Griliches, 1998; Hagedoom and Cloodt, 2003; Patel and Pavitt, 1995).

In addition, as explained in section 4.2 , technological M\&As lead to a unification of different knowledge bases that enable the combined firm to avould or reduce duplicate $R \& D$ efforts. So, in case we use $R \& D$ expenditures as an indicator of post-M\&A innovative performance, the positive effect of efficiency gains can be wrongly interpreted as a negative effect of M\&As on a firm's post-M\&A innovative performance based on a negative correlation between M\&As and R\&D expenditures. 
Therefore it is better to focus on patent counts as an output indicator of innovative performance. We measure patents $s_{i l}$, as the number of successful patent applications, or patents granted, for the acquiring firm $i$ in year $t$. The dependent variable is based on the number of patents of the acquiring firm obtained during four years after the M\&A.

\subsubsection{Independent Variables ${ }^{1}$}

Number of nontechnological M\&As. M\&As are reported as technological acquisitions if the acquired firm had any patenting activity during the five years preceding the acquisition. ${ }^{2}$ M\&As that did not meet the above-mentioned criterion are considered as nontechnological M\&As.

Absolute size of acquired knowledge base. For each acquiring firm and for each year, a list was made with the number of the patents that a firm and its targets had obtained during the preceding five years before the particular M\&A event. The time period of five years for measuring a firm's knowledge base follows Ahuja and Katila (2001). These patents were then combined with the patents that were cited by these companies. Duplicates were abstracted from the list to ensure that a patent number appears only once. The acquired knowledge base was then calculated as the number of patents (i.e. knowledge elements) on this list.

Relative size of acquired knowledge base. This variable was measured by dividing the absolute size of the acquired knowledge base by the absolute size of the acquiring firm's knowledge base. The absolute size of the acquiring firm's knowledge base was calculated using the same procedure as the absolute size of the acquired firm's knowledge base. In a few cases the acquired knowledge base was larger than the acquiring firm's knowledge base. In these cases we used the larger number as the denominator. As we are interested in the relative proportion of the merged firm's resources that are likely to be occupied with integrative rather than inventive activity, a number greater than one is not meaningful.

Technologically related and technologically unrelated M\&As. To measure the relatedness of the acquired knowledge base, the following procedure was followed. We composed a list of patent numbers that appeared in both the acquired firm's knowledge base and in the acquiring firm's knowledge base. The number of elements on this list was divided by the absolute size of acquired knowledge base.

All independent variables described in the above consist of four lagged versions.

\footnotetext{
${ }^{1}$ For obvious trasons, this section is largely based on the description of the main independent variables in Ahuja and Katila (2001).

2. The variable "number of nontechnological M\&As" is slightly different from the definition used by Alluja and Kavila (2001). 10 distinguish nontechnological acquisitions frorn technological acquisitions we only analyzed the patenting activity of the acquired fum in the live years preceling the M\&A evert. Ahufal and Katila (2001) also included M\&As for which they found press releases that indicated the technological nature of particular M\&As. Since we have no access to these press releases, we could not examine this information to establish whether technoliagy was reported as a motivation for undertaking some M\&As.
} 


\subsubsection{Control Variables}

We control for a number of possible additional effects on the post-M\&A innovative performance of the acquiring firm. Previous research on the effect of cultural distance on post-M\&A performance suggests both positive and negative effects, but the negative effects seem to be dominant (Chatterjee, Lubatkin, Schweiger \& Weber, 1992; Datta, 1991; Haspeslagh \& Jemison, 1991). We use the Kogut and Singh (1988) modified index of Hofstede (1980) to control for international cultural differences between companies involved in M\&As. When calculating this variable we have to make a correction as a zero for an observation in a certain year can represent both a domestic M\&A (no cultural distance) and no M\&A in that particular year. We use a dummy variable to correct for this by setting the values of a dummy variable cultural distance to one, each time no M\&A took place.

Studies by Bound et al. (1984) and Griliches (1998) and Pakes and Griliches (1984) indicate a statistical relationship between $R \& D$ and the number of patents across firms and industries, although patent output appears to gradually decrease with an increase in $R \& D$ expenditures. The control variable for yearly $R \& D$ expenditures is standardized by converting the financial data from mational currencies to US dollars.

Previous studies indicate that the patent activity of companies increases with size (Cohen and Levin, 1989; Mansfield, 1986; Mueller,1986a; Scherer, 1984). The size of the acquiring firm is measured by taking the natural $\log$ of its number of employees. We also control for differences between the four high-tech sectors. All four sectors are high-tech industries but there is still considerable dissimilarity in their R\&D and patenting-intensity (OECD, 1992). We included sector dummies to control for these differences. Given the international differences in patenting behavior between companies from the USA, Europe and Japan (OECD, 2001), we control for the nationality of the acquiring firm. A National Science Foundation (1998) study shows that the number of patents granted increased significantly during the period of our study. To control for this development we included year dummies.

Pre-sample differences in the number of patents of the sample firms should have a positive influence on the innovative performance of the acquiring firm after the M\&A. Firms that achieve high levels of innovativeness have, according to Dosi (1988), also a higher chance of maintaining or increasing their level of innovativeness. The firm heterogeneity control variable pre-sample patents is measured as the sum of patents obtained by a firm in the 3 years prior to the firm's entry into the sample.

As already mentioned in the previous section, the relative size of the acquired knowledge base is calculated by dividing the absolute size of the acquired knowledge base by the size of the acquiring firm's knowledge base. However, in a few cases the acquiring firm's knowledge base is zero for some of the years in the panel data set. In order to calculate the relative size correctly, we follow Hausman et al. (1984) and set these specific values to one instead of zero and use a dummy variable, called dummy absolute size acquirers, to correct for this solution. 
Finally, two variables from the study of Ahuja and Katila (2001), one indicating the number of technological M\&As where information on patents is unavailable and another variable for firm diversification, are not be included in this study. The reason for this is that we do not have information on both the possible technological nature of M\&As with target firms that do not have patents and the firm sales per standardized business segment.

\subsection{Results}

Appendix $J$ provides the descriptive statistics for all variables. ${ }^{3}$ There is little correlation between the main independent variables, with the expected exception of relatedness of the acquired knowledge base with its squared term. There is also little correlation between the independent variables and the control variables. Only the correlation between pre-sample patents and R\&D is rather high (0.784), although lower than reported by Ahuja and Katila (0.89). Since we have to control for unobserved heterogeneity and also because we prefer to follow the Ahuja and Katila (2001) model, we will keep both variables in our model.

In order to choose between the Poisson model and the negative binomial model we tested the equality of the conditional mean and variance, which is the most important distributional assumption of the Poisson regression model. The calculated chi-square of the test for equality of the conditional mean and variance of the Poisson model is 3123.746 and statistically significant. The test shows that our data are overdispersed, the variance exceeds the mean, understating the computed standard errors in the Poisson regression. In that case we can use the negative binomial regression model.

Table 4.2 displays the estimation results of the negative binomial model with distributed lag analysis for the post-M\&A innovative performance of the sample firms. We will use the full model (model 4), including both individual and summed coefficients, to discuss the results.

Hypothesis 1 argues that non-technological M\&As contribute little to the innovative output of the acquiring firm or that there might even be a negative impact on the post-M\&A innovative performance. The individual coefficients of the variable for the number of non-technological acquisitions are significant and three out of four show a negative sign. The summed coefficient, reflecting the total impact, is negative and significant. Together this provides strong support for hypothesis $\mathbb{l}$.

We also anticipate that the acquisition of the target firm's knowledge base will lead to increased economies of scale and scope and a broader knowledge base. Both are expected to have a positive effect on the post-M\&A innovative performance (hypothesis 2). The individual coefficients of the four variables for absolute size of acquired knowledge base are all significant but they show a diverse picture.

\footnotetext{
We do not report the extensive correlation statistics, this information is avallable from the authors.
} 
Table 4.2 Negative binomial regression with distributed lag analysis.

\begin{tabular}{|c|c|c|c|c|}
\hline Variable & 1 & 2 & 3 & 4 \\
\hline \multirow[t]{2}{*}{ Intercept } & $-2.992 * *$ & $3.317 * *$ & $3.467 *$ & $3.44 * * *$ \\
\hline & $(0.248)$ & $(0.137)$ & $(0.160)$ & $(0.148)$ \\
\hline No. of nontechnological & & $-0.114 * *$ & $-0.106 * * *$ & $-0.174 * * * *$ \\
\hline Acquisisitions $(\mathrm{tu} \mid)$ & & $(0.009)$ & $(0.0139)$ & $(0.012)$ \\
\hline No. of nontechnological & & $-0.061 * *$ & $-0.075^{* * * * *}$ & $-0.081^{* * * *}$ \\
\hline Acgunisitions (c-2) & & $(0.008)$ & $(0.015)$ & $(0.008)$ \\
\hline No. of nontechnological & & -0.009 & -0.007 & $0.069 * * * *$ \\
\hline Acquisitions $(t-3)$ & & $(0.009)$ & $(0.011)$ & $(0.007)$ \\
\hline No. of nontechnological & & -0.017 & $-0.041 *$ & $-0.088^{* * * *}$ \\
\hline Acquisitions $(t-4)$ & & $(0.011)$ & $(0.016)$ & $(0.012)$ \\
\hline Albsolute size of acquired & & $0.000005^{*}$ & $-0.000019 * *$ & $0.000025^{* * * *}$ \\
\hline knowledge base $(t-1)$ & & $(0.000002)$ & $(0.000003)$ & $(0.000002)$ \\
\hline Absolute size of acquired & & $0.000016 * *$ & $0.000007^{*}$ & $0.000028 *$ \\
\hline knowledge base (t-2) & & $(0.000002)$ & $(0.000004)$ & $(0.000003)$ \\
\hline Absolute size of acquired & & $-0.000248 * * *$ & $-0.000094 *$ & $-0.000228 * * *$ \\
\hline knowledge base (t-3) & & $(0.000006)$ & $(0.000009)$ & $(0.000008)$ \\
\hline Absolute size of acquired & & $-0.000034 * * * *$ & $-0.000083^{* * * *}$ & $-0.000032^{* * *}$ \\
\hline knowledge base $(t-4)$ & & $(0.000002)$ & $(0.000007)$ & $(0.000005)$ \\
\hline Dummy absolute size & & $-0.394 * *$ & $-0.487 * * *$ & $-0.496^{* * * * *}$ \\
\hline acq. knowledge base (t-1) & & $(0.155)$ & $(0.178)$ & $(0.149)$ \\
\hline Dummy absolute size & & $-0.423^{* *}$ & $-0.482^{* *}$ & $-0.483^{* * * * *}$ \\
\hline acq. knowledge base ( $(-2)$ & & $(0.201)$ & $(0.199)$ & $(0.145)$ \\
\hline Dumnny absolute size & & 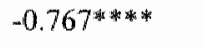 & $-0.777 * * * *$ & $-0.747 * * * *$ \\
\hline acq. knowledge base (t-3) & & $(0.199)$ & $(0.191)$ & $(0.161)$ \\
\hline Dummy absolute size & & 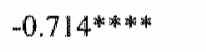 & $-0.698 * * *$ & $-0.727^{*} * * * *$ \\
\hline acq. knowledge base (t-4) & & $(0.182)$ & $(0.195)$ & $(0.169)$ \\
\hline Relative size of acquired & & & -0.249 **水* & $-0.253 * * * *$ \\
\hline knowledge base (t-1) & & & $(0.035)$ & $(0.027)$ \\
\hline Relative size of acquired & & & $-0.144 * * *$ & $-0.073^{*}$ \\
\hline knowledge base $(t-2)$ & & & $(0.038)$ & $(0.039)$ \\
\hline Relative size of acquired & & & 0.013 & $-0.069 *$ \\
\hline knowledge base (t-3) & & & $(0.029)$ & $(0.028)$ \\
\hline Relative size of acquired & & & -0.006 & $-0.091 * * *$ \\
\hline knowledge base (t-4) & & & $(0.036)$ & $(0.031)$ \\
\hline Relatedness of acquired & & & $0.204 * *$ & $0.797 *$ \\
\hline knowledge base (t-1) & & & $(0.099)$ & $(0.237)$ \\
\hline Relatedness of acquired & & & $0.261 * *$ & $1.069 * * * *$ \\
\hline knowledge base (t-2) & & & $(0.130)$ & $(0.197)$ \\
\hline Relatedness of acquired & & & 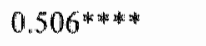 & $1.084 * * *$ \\
\hline knowledge base $(t-3)$ & & & $(0.138)$ & $(0.364)$ \\
\hline
\end{tabular}


Relatedness of acquired knowledge base ( $\mathrm{t}-4$ )

Relatedness of acquired knowledge base $\mathrm{sq}(\mathrm{t}-1)$ Relatedness of acquired knowledge base sq $(\mathrm{t}-2)$ Relatedness of acquired knowledge base sq ( $\mathrm{t}-3)$ Relatedness of acquired knowledge base sq ( $(-4)$

Cultural distance (t-1)

Cultural distance $(\mathrm{t}-2)$

Cultural distance $(t-3)$

Cultural distance (t-4)

Dummy

cultural distance $(\mathrm{t}-\mathrm{l})$

Dummy

cultural distance $(\mathrm{t}-2)$

Dumimy

cultural distance $(\mathrm{t}-3)$

Dumny

cultural distance $(t-4)$

R\&D ( $(-1)$

Logemployees (t-1)

Computers and

office machinery

Pharmaceuticals

Electronics and

Communications

European fïrms

Presample patents (t-1)

$$
\begin{aligned}
& -0.003 \\
& (0.028)
\end{aligned}
$$

$-0.002$

$$
(0.035)
$$

$-0.026$

$$
(0.029)
$$

-0.052 *

(0.0265)

$-0.037$

$(0.042)$

$-0.022$

(0.043)

$-0.057$

(0.038)

$-0.128 * * * *$

(0.035)

$-0.000002$

(0.000044)

\subsection{3 ****}

(0.021)

$0.724 * *$

$(0.119)$

$1.472 * * *$

(0.109)

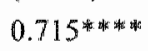

(0.083)

$-1.693 * *$

$(0.097)$

$0.063 * * *$

(0.005)

$\begin{array}{ll}0.556 * * * & 0.591 * * \\ (0.104) & (0.237) \\ & -0.658 * * \\ & (0.251) \\ & -0.967 * * * \\ & (0.226) \\ & -0.727 * \\ & (0.406) \\ & -0.117 \\ & (0.297)\end{array}$

$0.099 * *$

$0.087^{* * * *}$

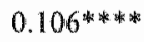

$(0.014)$

$(0.041)$

$(0.0111)$

0.0952 * 水非

0.098 ****

0.007

$(0.016)$

$(0.040)$

$(0.014)$

0.032 *

0.057 ***

0.022 *

$(0.016)$

$(0.016)$

(0.013)

$0.070^{* * * * * * *}$

$0.046^{* *}$

$0.115^{\text {* * * * * * }}$

(0.008)

(0.015)

(0.009)

-0.177 * * * *

$-0.295^{*}$ ****

-0.247 ****

(0.028)

$(0.034)$

(0.031)

-0.136 * * * *

-0.193 ; * *** * *

$-0.119 * * *$

$(0.0258)$

(0.040)

(0.038)

-2.668 * * * * *

-0.243 *⿻一未火

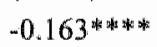

$(0.0247)$

$(0.037)$

$(0.028)$

$-0.427 * * * *$

$-0.378 * * * *$

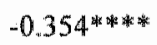

$(0.01998)$

$(0.036)$

$(0.027)$

$-0.001291 *$ *

$-0.002062$

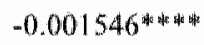

$(0.000026)$

$(0.000039)$

$(0.000022)$

$-0.042^{* * * *}$

$-0.0 \$ 7$

$0.022^{*}$

(0.013)

$(0.0 \Perp 4)$

(0.013)

-0.0344 * 水永

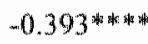

$-0.437 *$

$(0.059)$

(0.080)

$(0.066)$

$-0.045$

$-0.062$

$-0.099 *$

(0.073)

(0.093)

(0.059)

$-0.386 * *$

-0.390 ****

$-0.378 * *$

$(0.041)$

(0.054)

$(0.042)$

$-0.044$

$-0.056$

$-0.054$

(0.071)

(0.079)

(0.052)

$0.314^{4}$

0.347 秋的的

0.293 *** * *

$(0.003)$

(0.004)

(0.003) 


\begin{tabular}{|c|c|c|c|c|}
\hline N & 2429 & 2429 & 2429 & 2429 \\
\hline Log Likelihood & -5160.595 & -9052.857 & -7510.249 & -9217.112 \\
\hline \multicolumn{5}{|l|}{ Summed coefficients } \\
\hline No. of nontechnological & & & & $-0.273^{* * * *}$ \\
\hline Acquisitions & & & & $(0.015)$ \\
\hline Absolute size of acquired & & & & $-0.000208^{* * * *}$ \\
\hline knowledge base & & & & $(0.000009)$ \\
\hline Relative size of acquired & & & & $-0.486 * * * *$ \\
\hline knowledge base & & & & $(0.050)$ \\
\hline Relatedness of acquired & & & & $3.542 * *$ \\
\hline knowledge base & & & & $(0.474)$ \\
\hline Relatedness of acquired & & & & $-2.469 * * * *$ \\
\hline knowledge base sq & & & & $(0.551)$ \\
\hline \multirow[t]{2}{*}{ Cultural distance } & & & & $0.249 * * *$ \\
\hline & & & & $(0.015)$ \\
\hline
\end{tabular}

$* p<0.10 ; \quad * 0<0.05 ; \quad * * * 0.01 ; \quad * * * *<<0.001$

Standard errors are in brackets, Year dummies are included but not shown

The absolute size of acquired knowledge base contributes to improved post-M\&A innovative performance during the first two years, but thereafter it has a negative influence. The summed coefficient is significant and negative, which also provides no support for hypothesis 2 .

In hypothesis 3 we predict a negative relationship between the relative size of the acquired knowledge base and the post-M\&A innovative performance of the acquiring firm. The individual and summed coefficients are all significant and negative, which clearly supports this hypothesis.

Hypothesis 4 states that the acquired knowledge base has to show enough overlap with the acquirer's already existing knowledge base to facilitate the absorption process. Yet, the relatedness of the acquired knowledge base needs enough diversity to make a substantial contribution to the post-M\&A innovative performance. The individual and summed coefficients for the variable relatedness of acquired knowledge base are significant and positive. The summed coefficient of the squared term is negative and significant. The individual coefficients for its squared term are negative and significant, with the exception of the last lagged period (t-4). Overall, we find support for this hypothesis, indicating that the technological relatedness of M\&As has a curvilinear impact on the post-M\&A innovative performance of the acquiring firm.

As far as the controll variables are concemed, most of our findings are quite straightforward. As expected, size of the companies and pre-sample differences in the knowledge bases of the sample firms both have a significant positive impact on post$M \& A$ innovative performance. The region and industry of the acquiring firm have a negative influence on post-M\&A innovative performance, although the region variable reflecting the acquiring firm's nationality is not significant. The year dummy for 1989 
is not significant and negative. In addition, the year dummies for 1990-1994 are all significant and negative, relative to the omitted year 1995. This result shows that, compared with the previous years, patenting has significantlly increased in 1995 .

Somewhat surprisingly, cultural distance has a significant positive impact on the post-M\&A innovative performance of the acquiring firm, although the individual 2-year lagged variable is not significant. This finding supports some less well-known work that indicates that international M\&As can have a positive impact on innovative performance because it might force a company to rethink its innovation strategy in a more international context (e.g. Hoecklin, 1995). Higher R\&D efforts have a significant negative influence on patent output, which supports studies by Bound et al. (1984), Hagedoom and Duysters (2002a) and Hausman et al. (1984) who also found that higher $\mathbb{R} \& D$ inputs do not necessarily lead to higher patenting ouput.

\subsection{Discussion and Conclusions}

Our study does indeed replicate many of the findings by Ahuja and Katila (2001) in an alternative context of high-tech industries such as aerospace and defense, computers and office machinery, pharmaceuticals, and electronics and communications. Following their analysis we made a critical distinction between the effect of nontechnological M\&As and technological M\&As on the post-M\&A innovative performance of the acquiring firm. Obviously, not all M\&As are undertaken for technological reasons with the intent to learn (Hamel, 1991). These non-technological M\&As do not create additional technological learning or make any other contribution to the post-M\&A innovative performance. Apparently, they even have a negative influence on this performance. As explained by Hitt et al. (1996) such M\&As can have a disruptive effect on a range of activities and established organizational routines of the integrating firm. Managing the repair of these disruptions requires additional resources which otherwise could have been invested in long-term innovative projects.

Through technological acquisitions that are formed with the intent to learn in this high-tech context, firms both acquire new knowledge and they learn how to use their existing knowledge under new competitive conditions (Capron and Mitchell, 2000). Since these technological M\&As provide new knowledge to the acquiring firm, we can expect that they will improve the acquiring firm's post-M\&A innovative performance. However, the positive impact of these M\& As depends on a firm"s ability to integrate this knowledge and to alter existing routines in the organization of its research. In other words, there are limits to a firm's ability to acquire unfamiliar new knowledge with the goal of increasing its innovativeness: more is not always better.

Our results clearly demonstrate that the acquisition of a large absolute knowledge base contributes to improved innovative performance during the first couple of post-M\&A years, but thereafter it appears to have a negative influence. The latter finding, which contradicts the results of Ahuja and Katila (2001), may seem somewhat surprising and deserves further attention. We think that this phenomenon 
can be explained by the different roles played by tacit knowledge, as the implicit and non-codifiable accumulation of skils and knowledge, and codified knowledge that is transmittable through formal language such as patents (Nonaka, 1991; Reed and Defillippi, 1990). Bresman al. (1999) argue that the more time elapsed after an M\&A, the less patents are transferred from the target firm to the acquiring firm. They suggest that in the period shortly after the M\&A, management is primarily focused on the identification of opportunities to combine knowledge and reach economies of scale and scope in the stock of codified knowledge. However the gradual creation of a single organization facilitates the transfer of tacit knowledge (Kogut and Zander, 1992 ) and this transfer is also preferable from a strategic viewpoint since it involves knowledge that is more difficult to copy (Bresman et all., 1999). Over time the two firms, involved in an $M \& A$, are steadily transformed into a single organization thereby facilitating a larger transfer of tacit knowledge at the expense of the transfer of codified knowledge.

The above also explains why the analysis of Ahuja and Katila (2001), for the chemical industry, shows a positive contribution of the absolute size of the acquired knowledge base during a longer post-M\&A period. Firms in the chemical industry have a relatively high degree of codified knowledge through their patents and a relatively low degree of tacit knowledge (Cohen, Nelson and Walsh, 2000). Therefore, firms in this industry can also take a longer post-M\&A time period to evaluate and identify the opportunities for combining and integrating their crucial codified knowledge. For companies in the group of high-tech industries that we study tacit knowledge plays a larger role in the innovation process than it does in the chemical industry (see also Winter, 1987). Hence, in these high-tech industries the transfer of codified knowledge plays a role for only a limited period of time after an M\&A has taken place.

Another limitation to the potentially positive effect of the acquisition of new knowledge lies in the actual unification of two firms. During the different stages of their integration, both firms have to deal with a disruption of their existing organizational processes and routines (Gerpott, 1995; Haspeslagh and Jemison, 1991). The management of the company has to devote a large amount of resources, such as time and financial means, to the integration of a relatively large knowledge base, leaving fewer resources for the innovation process itself (Ahuja and Katila, 2001; Hitt et al., 1996). This implies that if the acquired firm's knowledge base is relatively large compared to the acquiring firm, this can have serious consequences for the integration of the innovative activities of both M\&A partners with a negative mpact on the acquirer"s innovative performance.

In addition to the absolute size and the relative size of the acquired knowledge base, the relatedness of the acquired knowledge base is a third important factor in the unification of two knowledge bases. In the previous paragraph we mentioned that the acquiring firm is constrained by its ability to integrate a knowledge base of a certain size. However, in acquiring new external knowledge, the firm also tends to be constrained by its own existing knowledge base and past routines (Nelson and Winter, 
1982). This means that it is advantageous to the acquiring firm to obtain unfamiliar knowledge in areas that are still somewhat closely related to its existing activities (Dosi, 1988; Teece, 1986). The advantage of this relatedness in technological knowledge is found in the rather smooth absorption process of the acquired knowledge base while changes in the organization of research will be incremental (Kogut and Zander, 1992). With the acquisition of related knowledge, fewer resources are needed to alter organizational structures and routines in which the acquired knowledge is embedded (Capron and Mitchell, 2000). In addition, the acquisition of related knowledge provides opportunities for economies of scale and scope (Gerpott, 1.995; Hagedoorn and Duysters, 2002a; Mowery et al., 1996). The expected smoothness of the absorption process and the economies of scale and scope will leave the acquiring firm with more available resources to invest in the innovation process.

The previous argumentation suggests that, in general, the acquisition of related knowledge will have the most positive impact on a firm's post-M\&A innovative performance. However, the acquisition of knowledge that is too similar to the already existing knowledge base of a company is disadvantageous, as the acquiring firm will have to bear the costs of obtaining and transferring external knowledge without any relevant enrichments of its existing knowledge base (Bartlett, 1993). Some degree of differentiation in knowledge between the acquiring and acquired firm may enrich the acquiring firm's knowledge base, creating opportunities for learning and improvement of a firm's innovative performance (Bartlett, 1993; Kogut and Zander, 1992). This suggests that, in order to increase the innovative performance of companies through M\&As, companies have to target other firms with moderately related knowledge bases. They should avoid acquiring firms with knowledge bases that are either too unrelated or too closely related.

The current study concentrated on the integration of firms in high-tech industries and the resulting impact of this integration on the acquirer's post-M\&A innovative performance. Future research could extend this study by examining the long term post-M\&A economic performance of the acquiring firm, which would enable a thorough assessment of the total impact of technologically related M\&As with other high-tech firms. As this study replicates some of the results of the work by Ahuja and Katila (2001) in the context of several high-tech manufacturing industries, it could be worthwhile to also conduct future research in other industries. This research could for instance focus on non-manufacturing industries with alternative measures of innovation and technological relatedness that are more appropriate for firms in service industries. 


\section{THE EFFECT OF INTERNAL LEARNING, EXTERNAL LEARNING, AND PRIOR M\&A EXPERIENCE ON THE CHOICE BETWEEN RELATED AND UNRELATED TECHNOLOGICAL M\&As}

\subsection{Introduction}

Chapter 4 shows that firms can increase their post-M\&A innovative performance by undertaking technological M\&As and acquiring external knowledge bases that are moderately related to their existing knowledge bases. In that context, it is interesting to analyze which factors determine the direction of a firm's technological relatedness by means of M\&As. In other words, what determines the acquiring firm's choice between undertaking a related technological M\&A and undertaking an unrelated technological M\&A.

The central topic of this chapter concerns the possible impact of internal learning, external learning and the M\&A experience of companies on their diversification behavior by means of related or unrelated technological mergers and acquisitions. Researchers in the field of industrial economics, finance and strategic management have already discussed several concepts of diversification assigned to different lines of thought (Bruche, 2000; Datta, Pinches, Narayanan, 1992; Palepu, 1985; Park, 2002, 2003). The majority of these studies focus on two types of diversification, namely product diversification and international diversification. However, to create and sustain a competitive advantage a firm should not only decide which product markets or particular regions it should target, but also in which technological fields it should make future investments (Geringer et al., 1989). Especially high-tech firms have to spread out their technological competencies over a wide number of technological fields to keep up with the rapid pace of technological change and the increasing complexity of technologies (Fai, 2001; Granstrand, Patel and Pavitt, 1997).

However, to our knowledge technological diversification and its determinants are rather underrepresented in the diversification literature and only a few authors (e.g. Breschi, Lissoni and Malerba, 2003; Hagedoorn and Duysters, 2002a; Jaffe, 1986) have put this topic on the research agenda. We will use the conceptual definition of Breschi et al. (2003) and Hagedoorn and Duysters (2002a) to define a technological diversified firm, as a firm that spans its innovative activities over more than one field of technology. In addition, we attempt to fill the existing gap in the diversification literature, by examining three determinants of the direction of a firm's technological diversification by means of M\&As. 
To start, we argue that both internal learning and external learning are important determinants of technological diversification. Some authors have made a distinction between internal learning processes (internal knowledge) and external learning processes (external knowledge) and their impact on innovation within the firm (e.g. Ahuja and Katila, 2001; Hemmert, forthcoming; Prabhu, Chandy and Ellis, forthcoming): Others have examined the relationship between technological diversification and performance (e.g. Gambardella and Torrisi, 1998; Granstrand, 1998; Hagedoorn and Duysters, 2002a). More recently, Breschi et al. (2003) were the first (to our knowledge) who examined the impact of a firm's learning process on its technological diversification. While each of these studies has certainly advanced our understanding of organizational learning and technological diversification, linking both internal learning and external learning to a firm's choice of undertaking related or unrelated technological M\&As, has not yet been undertaken. So, instead of examining the direct relationship between organizational learning or technological diversification and performance, we argue that internal and external learning are also important determinants of a firm's technological diversification (see figure 5.1).

Figure 5.1 An overview of the contribution of our study to prior research.

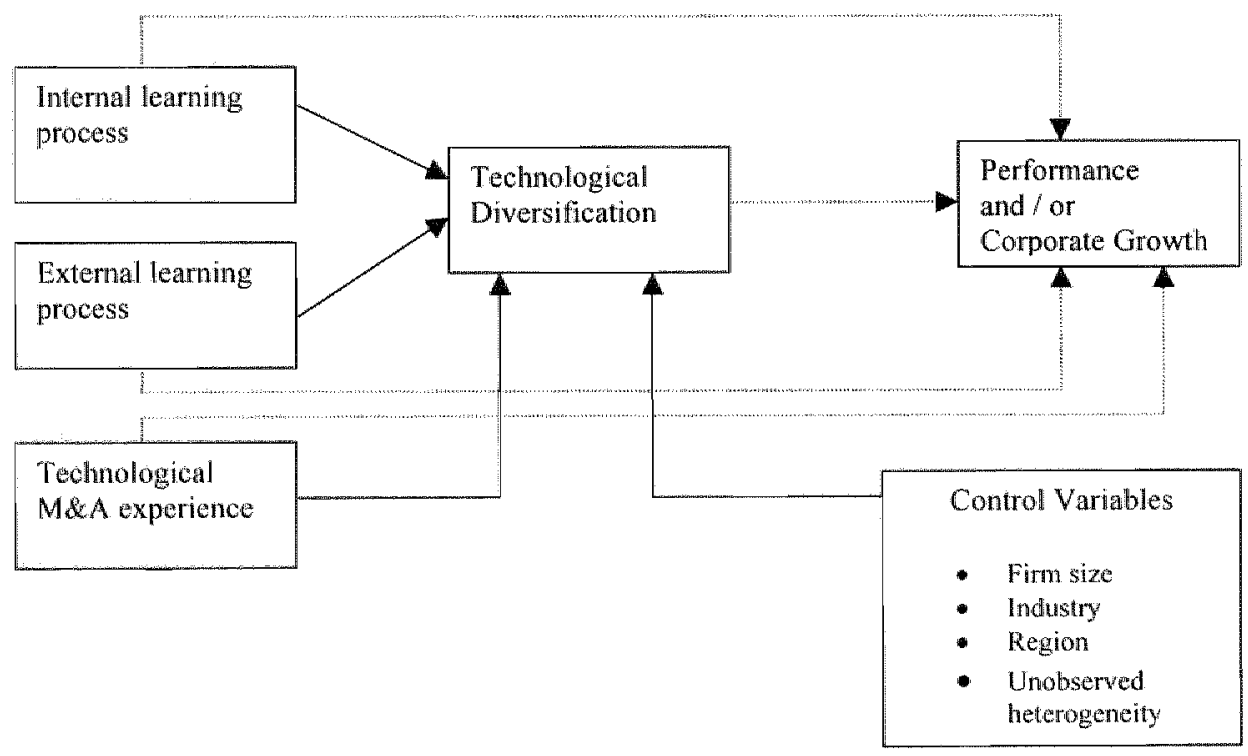

Focus of prior research

Focus of this research 
Internal learning occurs when firms' scientists and engineers create and distribute new technological knowledge within the boundaries of the firm (i.e. internal R\&D activities) (Chesbrough and Teece, 1996). External learning occtirs when the company acquires new technological knowledge that originates from an external target firm (i.e. mergers and acquisitions) (Bierly and Chakrabarti, 1996). Besides the internal and external learning process, the past experience of firms in undertaking M\&As is, in our opinion, a third important determinant of their current choice for related or unrelated technological M\&As.

In the following section we first present the theoretical background and the three hypotheses that stipulate the expected effect of internal and external learning and technological M\&A experience on the relatedness in technological diversification. The research methodology is discussed in section 5.3. This is followed in section 5.4 by a presentation of the results of our study. In the last section, we discuss the main findings, we draw some conclusions from this research and we briefly present some topics for future research.

\subsection{Theory and hypotheses}

We define innovative performance as the output of a firm's underlying knowledge base and a firm's underlying dynamic capabilities by which companies alter their existing knowledge base (Eisenhardt and Martin, 2000; Grant, 1996; Griliches, 1984, 1990). This definition is clearly embedded in the knowledge-based view, which identifies the primary rationale for the high-tech firm as the development and application of technological knowledge (Conner and Prahalad, 1996; Grant, 1996; Nonaka, 1991; Spender, 1989). Knowledge is also a central issue in several other research traditions that stress the importance of both organizational learning and the transfer and diffusion of innovative capabilities within the firm (e.g. Boisot, 1995; Grant, 1996; Huber, 1991; Levitt and March, 1988). Particularly in rapidly changing environments, such as high-tech industries, organizational learning and technological diversification are very important for effective innovative performance and the creation of a sustainable competitive advantage (Eisenhardt and Martin, 2000; Granit, 1996).

Basic differences in the ability of high-tech firms to successfully diversify their technological core by means of M\&As is the result of both their internal and external learning processes. Internal learning processes focus on the idea that a firm can recombine its existing knowledge base and innovate on its own (Blonigen and Taylor, 2000; Capron and Mitchell, 2000). In addition, a firm can acquire the needed technological knowledge and support its continuous search for new technological capabilities through external learning processes such as M\&As (Cohen and Levinthal, 1989). Internal and external learning are mutually dependent, complementary processes that both are necessary within the overall diversification process of hightech firms. In that context, it is interesting to analyze the impact of both the internal 
and the external learning processes on the direction of a firm's technological diversification by means of M\&As.

Besides the internal and external learning processes, we argue that the direction of a firm's technological diversification by means of related or unrelated technological M\&As is also largely influenced by a firm's past experience in undertaking technological M\&As. The rationale for hypothesizing that a firm's accumulation of experience in M\&A activity will affect the direction of its technological diversification behavior, is based on the learning theory and the evolutionary economics school. We are interested in the application of these theoretical insights to the analysis of the probability that lessons learned from previous experiences will be applied in a similar context (related teclanological areas) or a more diverse (unrelated technological areas) context by means of technological M\&As (Zollo, Reuer and Singh, 2002).

In sum, we want to contribute to the stream of diversification research by offering a theoretical framework and an empirical analysis of the direction of a firm's technological diversification influenced by its internal learning process, its external learning process, and its experience with undertaking technological M\&As.

\subsubsection{Internal learning process}

Firms can develop strong knowledge bases internally by investing heavily in R\&D activities (Park, 2002). These R\&D activities will enable the firm to develop its own core capabilities in new technological fields that form the basis of possible "first mover advantages' (Chesbrough and Teece, 1996). However, building up a strong internal knowledge base is a long and costly process. Especially, sunk costs and switching costs related to $R \& D$ expenditures, $R \& D$ equipment and human capital, may restrict firms to exploit their existing knowledge and capabilities in a limited number of related technological areas (Breschi et.al., 2003).

Given the fact that it is a long and costly process to build a profile of technological foundations, it is also very difficult to change this profile over time (Breschi, Lissoni and Malerba, 1998; Giuri, Hagedoom and Mariani, 2004; Granstrand et al., 1997). When firms' scientists and engineers create and distribute new technological knowledge within the boundaries of the firm, this knowledge is retained in routines (March and Sevon, 1984) that are embedded in the individual scientists and their organization (Zollo and Leschinskii, 1999). According to the evolutionary economics school, firms replicate and adapt their routine behavior over time, leading to a stable pattern of diversification in related technological areas that fit their current innovation routines (Nelson and Winter, 1982). Since these routines are based on the firm's own experience, they are also highly firm specific and idiosyncratic in nature (Fai, 2001). Consequently, changing a firm's technological profile built up by internal learning processes becomes a difficult task. Hence, even as firms diversify their knowledge base by taking over target firms' knowledge bases, the search process is restricted to familiar technological areas. 
As a result of the incremental, cumulative, and path-dependent nature of its internal learning process a firm will not spread out its competencies over a wide number of unrelated fields. By means of technological M\&As, it will rather focus on target firms present in a limited number of related technological areas. In sum, we argue that companies will diversify their internally developed technological core by undertaking technological M\&As with target firms in related technological areas.

Hypothesis 1: The stronger the internat learning process of a high-tech company the more likely it will pursue related technological M\&As over whrelated techmological MdeAs.

\subsubsection{External learning process}

As mentioned earlier, a firm's technological profile, developed by internal learning processes, is highly idiosyncratic in nature and constrained by past routines, which makes it difficult for the organization to diversify into unrelated technological areas (Fai, 2001). To break away from existing routines, a firm can use external learning processes (i.e. M\&As) and overcome the path-dependency of internal learning processes to make use of the many new ideas that are generated outside of the firm (Capron and Mitchell, 2000; Karim and Mitchell, 2000).

By undertaking M\&As a firm can add new externally acquired knowledge to its already existing knowledge base, and in that way develop a richer and broader knowledge base (Ahuja and Katila, 2001; Bierly and Chakrabarti, 1996; Levinthal and March, 1993; Vermeulen and Barkema, 2001). A richer or broader knowledge base, in its turn, increases the acquiring firm's potential of realizing the full combinatory capabilities of the firm's knowledge base and creates new opportunities for learning (Bartlett, 1993; Goshal., 1987; Hitt et al., 1996; Kogut and Zander 1992, Sanchez and Mahoney, 1996).

We argue that these new leaming opportunities will mainly be directed at the exploration of a firm's technological knowledge by taking over target firms in unrelated technological areas. This is based on the idea that a diverse or heterogeneous knowledge base developed by extemal learning will enable the firm to view particular issues from different perspectives and enhances its capacity to search for novel solutions in unrelated technological areas (Reuer, Min Park and Zollo, 2002). In sum, external learning will enrich the technological knowledge within a firm, thereby increasing the likelihood that the firm will diversify into unrelated technological areas by means of M\&As.

Hypothesis 2: The stronger the external learning process of a high-tech company, the more likely it will pursue unrelated technological M\&As over related technological MdAs. 


\subsubsection{Technological M\&A Experience}

Besides the internal learning process and the external learning process, we argue that technological M\&A experience is a third important antecedent of technological diversification by means of M\&As. When taking over the knowledge base of another firm, acquiring firms are laced with several complex and interdependent stages during the whole acquisition process (Singh and Zollo, 1998). Of these stages, the two most important ones are ex ante assessing the value and fit of the potential target firm's knowledge base and ex post the integration of the acquired knowledge base and the acquiring firm's knowledge base into a single entity (Ahuja and Katila, 2001).

The non-routiness of the acquisition process increases the riskiness (i.e. uncertainty and unpredictability) of the takeover for an inexperienced firm, thereby consuming significant managerial time and energy (Haspeslagh and Jemison, 1991; Hitt et al., 1996; Pablo, Sitkin and Jemison, 1996). To diminish the riskiness or nonroutiness of the acquisition process it is important for the acquiring firm to persist in the same type of activity over time (Chang and Rosenzweig, 2001; Cyert and March, 1963). Only by undertaking the same types of mergers and acquisitions over time, firms are able to apply learning experiences from the past to acquisitions in the present (Chang and Rosenzweig, 2001). This repetitive momentum (Amburgey and Miner, 1992) will eventually lead to behavioral persistence, given that acquisition experiencebased knowledge is embedded in routines, and organizations behave consistently with these routines (Feldman, 1989).

Based on this considerable homogeneity in the M\&A decision-making processes (Haleblian and Finkelstein, 1999), we argue that firms will diversify their existing technological core by acquiring firms in related technological areas. So, to diminish the uncertainty regarding knowledge acquisition, transfer and integration, the inexperienced firm should identify a proper technological fit between itself and the target firm (Pablo et al., 1996). In that way it can create a reliable and predictable search process of target firms in the neighborhood of current technologies, a reduced likelihood of errors, and a deeper understanding of the possibilities of the acquired knowledge elements via repeated usage (Levinthal and March, 1981; Katila and Aliuja, 2002).

However, in time, the acquisition process can be facilitated by technological M\&A experience as companies develop certain routines about the identification, valuation and integration of the acquired technological knowledge (Hagedoom and Duysters, 2002b; Hitt, Harrison, Ireland and Best, 1998; Oster, 1999; Kogut and Zander, 1992). This would suggest that the undertaking of a technological M\&A becomes more and more routine, thereby decreasing the uncertainty and the use of managerial time and energy. The fact that firms become more competent in acquiring technological knowledge externally enables them to go one step further and use their idle managerial time and energy to undertake unrelated technological M\&As.

Another reason why we expect that a firm, which is experienced in undertaking technological M\&As, is more likely to pursue unrelated technological M\&As over 
time, is based on the nature of a technological M\&A. By undertaking an increasing amount of technological M\&As the acquiring frm creates a richer and broader wariety of technological knowledge within the firm. Because of this enrichment of the existing knowledge base, firms become more creative and are able to explore and experiment with new technologies in unrelated technological areas for possible future use (Fai, 2001; Granstrand et al., 1997).

In sum, we argue, that an inexperienced firm will try to reduce the acquisition riskiness by undertaking $M \& A s$ in related technological areas. In time, based on an increased technological M\&A experience, firms decide that they can afford to take some risk in their diversification behavior, and start searching for novel solutions by taking over target firms with more exploratory research projects in unrelated technological areas (Bartlett, 1993; Goshal, 1987; Hitt et al., 1996; Reuer et al., 2002).

Hypothesis 3: The stronger the technological M\&A experience of a high-tech company, the more likely it will pursue unrelated technological M\&As over related technological M\&As.

\subsection{Methods}

\subsubsection{Model}

As discussed in the next section, our dependent variable, technological diversification, is measured as the proportion of three-digit patent classes owned by the M\&A partners that are new to the acquiring firm (Hagedoorn and Duysters, 2002a; Katila, 2002). The variable was constructed by comparing the patent classes of the acquiring firm and the patent classes of its targets during the preceding five years before the particular M\&A event. The period of five years is chosen because knowledge depreciates after a certain period of time (Katila, 2002). The actual measure for each company is the share of related patent classes acquired as a percentage of all patent classes acquired.

After exploring the data it was noticed that the dependent variable was not normally distributed. This means that the classical linear tegression models based on the principle of ordinary least square would provide an incomplete description of the data. Therefore we decided to multiply the dependent variable and the independent variables with the denominator (all patent classes acquired). The dependent variable then becomes a non-negative integer-valued count variable for technological diversification, measured by the number of related patent classes acquired. In that way, we can use a methodological improvement over the classical linear (OLS) regression models based on a discrete probability distribution (Cameron and Trivedi, 1986; Gourieroux et al., 1984a and b; Hausman et al., 1984).

The Poisson model is the simplest and more restricted model for the analysis of cross-section discrete data that assumes equality of the conditional mean and variance. 
However, a large number of empirical distributions of count data have a variance greater than the mean and are thus over-dispersed relatively to the Poisson case (Cameron and Trivedi, 1986; Wooldridge, 2002). The negative binomial regression is an extension of the Poisson model and provides a mechanism for incorporating overdispersion while allowing the variance of the process to differ from the mean (Cameron and Trivedi, 1986; Gourieroux, et al., 1984a and b, Hausmann, et al., 1984). Standard methods to test the failure of the variance-mean equality restriction are the likelihood ratio test and the Wald test. We use a likelihood ratio test to examine the adequacy or failure of the equal mean-variance restriction of the Poisson distribution.

\subsubsection{Sample and Data}

The hypotheses are tested on a relatively large international sample of companies covering four high-tech industries: aerospace and defense (SIC-codes 372 and 376), computers and office machinery (SIC-code 357), pharmaceuticals (SIC-code 283) and electronics and communications (SIC-code 36). Our sample consists of 301 companies of which 17 operate in the aerospace and defense industry, 67 are found in computers and office machinery, 66 are active in pharmaceuticals, and 151 operate in the electronics and communications sector. The sample consists of 218 North American companies and 83 companies from other regions ( 41 from Europe and 42 from Asia). Some additional details regarding the sectoral and international breakdown of this sample are presented in Appendix K.

Our sample is also diverse in terms of the distribution of the size of companies (see table 5.1 ). About $16 \%$ of the companies in our sample are relatively small with less than 1,000 employees. Almost $20 \%$ of the companies can be characterized as very large with more than 50,000 employees. Finally, $64 \%$ of the sample can be found in intermediate size-classes.

This study analyses the influence of internal learning processes, external learning processes, and a firm's M\&A experience on its direction of technological diversification by means of related and unrelated technological M\&As. As mentioned earlier, we define our dependent variable, technological diversification, as the proportion of three-digit patent classes owned by the M\&A partners that are new to the acquiring firm (Hagedoom and Duysters, 2002a; Katila, 2002). To measure this proportion we can only analyze the technological M\&As undertaken by each firm and not its nontechnological M\&As. Reason for this is that nontechnological M\&As are classified as those M\&As where the target firm had no patenting activity in the 5 years preceding the M\&A (see Ahuja and Katila, 2001). No patent activity of the target firm means that there can also be no overlap or distinction between the patent classes of the acquiring firm and the patent classes of the target firm. Technological diversification is measured for the period 1989-1994 and the independent variables and control variables are measured for the period 1985-1988. In total we identified 964 technological M\&A events for our sample firms in the period 1989-1994. 
Table 5.1 Distribution of size classes of companies in the total sample and for industry subsamples (number of employees).

\begin{tabular}{llllll}
\hline $\begin{array}{l}\text { Size } \\
\text { classes }\end{array}$ & Total & $\begin{array}{l}\text { Aerospace } \\
\text { and defense }\end{array}$ & $\begin{array}{l}\text { Computers } \\
\text { and office } \\
\text { machinery }\end{array}$ & $\begin{array}{l}\text { Pharmaceu- } \\
\text { ticals }\end{array}$ & $\begin{array}{l}\text { Electronics } \\
\text { and commi- } \\
\text { nications }\end{array}$ \\
\hline$<1000$ & $15.66 \%$ & $00.00 \%$ & $10.42 \%$ & $15.91 \%$ & $20.43 \%$ \\
$1000<5000$ & $28.79 \%$ & $07.69 \%$ & $39.59 \%$ & $18.18 \%$ & $31.18 \%$ \\
$5000<10000$ & $11.11 \%$ & $00.00 \%$ & $14.58 \%$ & $15.91 \%$ & $08.60 \%$ \\
$10000<50000$ & $24.75 \%$ & $30.77 \%$ & $20.83 \%$ & $40.91 \%$ & $18.28 \%$ \\
$>50000$ & $19.69 \%$ & $61.54 \%$ & $14.58 \%$ & $09.09 \%$ & $21.51 \%$ \\
Total & $100 \%$ & $100 \%$ & $100 \%$ & $100 \%$ & $100 \%$ \\
\hline & $\mathrm{N}=198$ & $\mathrm{~N}=13$ & $\mathbb{N}=48$ & $\mathrm{~N}=44$ & $\mathrm{~N}=93$ \\
\hline
\end{tabular}

Our sample is taken from the Securities Data databank, which contains information on worldwide M\&As. Within the M\&A database there is information on the year the M\&A was established and company information on the acquirer, the target, the parent acquirer and the parent target firm. The industry information is provided in SIC codes of the target and acquirer. Additional information on size and R\&D expenditures of companies in this sample was identified through various other datasets such as Amadeus, Compustat, and Worldscope. Data on patents and patent citations are taken from the US Patent and Trademark Office database (US Department of Commerce). We use US patent data for both US and non-US firms. Although these US data could imply a bias in favor of US companies against non-US firms, it is mentioned in the literature that, given the importance of the US market, the 'real' patent protection offered by US authorities and the level of technological sophistication of the US market, it is often compulsory for non-US companies to file patents in the US (Patel and Pavitt, 1991).

\subsubsection{Dependent Variable}

The dependent variable, technological diversification, is measured as the proportion of three-digit patent classes owned by the M\&A partners that are new to the acquiring firm (Hagedoorn and Duysters, 2002a; Katila, 2002). The actual measure for each company is the share of related patent classes acquired as a percentage of all patent classes acquired. 


\subsubsection{Independent Variables}

Internal learning process. The variable internal leaming process is measured by the R\&D expenditures of the acquiring firm. Investments in R\&D expenditures are measured yearly and standardized by converting the financial data from national currencies to US dollars.

External learning process. For each acquiring firm and for each year, a list is made with the number of patents that a firm's targets have obtained during the preceding five years before the particular M\&A event. The time period of five years for measuring a firm's knowledge base follows Ahuja and Katila (2001). These patents are then combined with the patents that are cited by these companies. Duplicates are abstracted from the list to ensure that a patent number appears only once. The acquired knowledge base is then calculated as the number of patents (i.e. knowledge elements) on this list.

Technological M\&A experience. Experience with technological M\&As is measured by the share of a firm's technological M\&As as a percentage of all its M\&As made during the four years period from 1985 to 1988 .

\subsubsection{Control Variables}

Size of the firm. Literature analyzing the effect of the size of the firm on technological diversification presents rather mixed results. Breschi et al. (2003) state that larger firms use more related technological diversification than smaller firms. Other studies indicate that unrelated technological diversification of companies increases with size (Pavitt, Robson and Townsend, 1989). The size of the acquiring firm is measured by taking the natural log of its number of employees.

Industry. All four sectors are high-tech industries, but there is still considerable dissimilarity in their R\&D and patenting intensity (OECD, 1992). We include sector dummies to control for these differences.

Region. According to Gerybadze and Stephan (2002), there exist considerable differences in the technological diversification of companies from different regions. To control for these differences we include a dummy variable for Europe, North Anerica and Asia.

Unobserved heterogeneity. Pre-sample differences in the direction of technological diversification have an influence on a firm's current strategy of technological diversification. According to Park (2002) a firm will create a certain technological profile over time. In other words, if firms undertake technological M\&As to diversify mainly into related technological areas, there is an increased likelihood that the firm will use the same strategy in the future. The firm heterogeneity control variable is measured as a firm's technological diversification behavior three years prior to the firm's entry into the sample. 


\subsection{Results}

Table 5.2 provides descriptive statistics and correlation coefficients for all variables. There is little correlation between the main independent variables. There is also little correlation between the independent variables and the control variables. One exception is the correlation between the variables Europe and the pharmaceutical industry and the variables North America and the electronics and communication industry. This collinearity does not affect the coefficient estimates but it can affect the stability of the estimated coefficients (Ahuja and Katila, 2001). To ensure that our estimated coefficients are stable, we omitted one of the two correlated variables from our analysis. The results of the sensitivity analysis stayed the same for all but the omitted variable. In other words, the sign and the significance of the affected variables did not change and we can conclude that our results are robust. Therefore, we decided to include both control variables (region and sector) in our model since they represent theoretically different constructs.

Table 5.3 displays the estimation results of the negative binomial model. In order to choose between the Poisson model and the negative binomial model we tested the equality of the conditional mean and variance, which is the most important distributional assumption of the Poisson regression model. The calculated chi-square of the test for equality of the conditional mean and variance of the Poisson model is 112.478 and statistically significant. The test shows that our data are over-dispersed, the variance exceeds the mean, understating the computed standard errors in the Poisson regression. In that case we have to use the negative binomial regression model for our analysis.

Hypothesis 1 argues that acquiring firms as a result of the incremental, cumulative, and path-dependent nature of their internal learning process, diversify into related technological fields instead of exploring new and unrelated technological areas. The coefficient of the variable internal learning process is significant and positive. This provides strong support for hypothesis 1.

In hypothesis 2 we predict that firms use their external learning process to enrich their existing knowledge base. This broader knowledge base will open up opportunities for a firm to explore and experiment with new technologies for possible future use and diversify into unrelated technological areas. In other words, we predict a negative relationship between the external learning process and the choice for related technological M\&As over unrelated technological M\&As. The coefficient of the external learning process is indeed significant and negative, which clearlly supports this hypothesis.

Hypothesis 3 states that inexperienced firms diversify into related technological areas, based on considerable homogeneity in their M\&A decision-making processes. In time, as these firms become more experienced they are more likely to pursue unrelated technological M\&As over related technological M\&As, driven by a broader and richer knowledge base and an increased ability to take some risk in their 


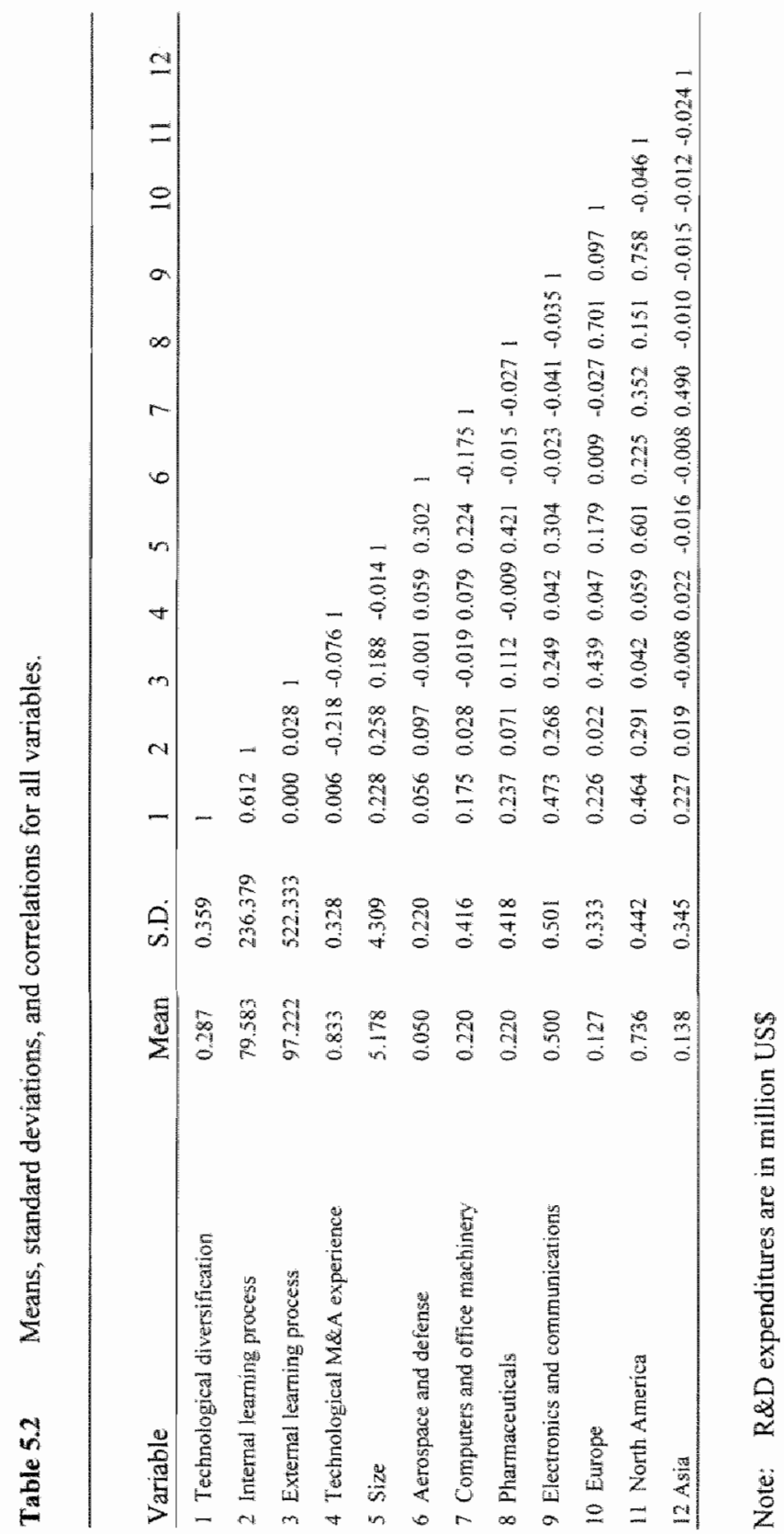


Table 5.3 Results for the Negative Binomial Model $(\mathrm{N}=301)$

\begin{tabular}{ll}
\hline Variable & $3.107^{* *}$ \\
\hline Constant & $(0.410)$ \\
Internal learning process & $0.006^{\circ{ }^{\circ}}$ \\
& $(0.002)$ \\
External learning process & $-0.002^{* *}$ \\
& $(0.0006)$ \\
Technological M\&A experience & -0.034 \\
& $(0.448)$ \\
Size & 0.00003 \\
& $(0.00002)$ \\
Pre-sample differences & $0.001^{*}$ \\
& $(0.0007)$ \\
Aerospace and defense & -0.00005 \\
& $(0.0003)$ \\
Computers and office machinery & $0.0003^{* 0}$ \\
Electronics and communications & $(0.0001)$ \\
Europe & 0.0002 \\
& $(0.0001)$ \\
Asia & $0.0003^{*}$ \\
& $(0.0002)$ \\
a & 0.0002 \\
& $(0.0004)$ \\
&
\end{tabular}

"Significant at 5\%-level: Significant at 10\%-level. Standard errors are in parentheses.

diversification behavior. So, we argued that technological M\&A experience and a firm's choice of related technological M\&As over unrelated technological M\&As have a negative relationship. The coefficient for the variable technological M\&A experience is indeed negative but insignificant, thereby providing no support for hypothesis 3 .

As far as the control variables are concerned, we can say the following. The size of the firm has a positive influence, although the coefficient is nonsignificant. Presample differences in the direction of technological diversification have a significant positive impact on the relatedness of technological M\&As. In other words, companies create a certain technological profile and use the same diversification strategy in the 
future. With respect to differences between the regions, we can state that European and Asian firms undertake more related technological M\&As than firms from North America, although the difference between Asia and North America is nonsignificant. Finally, companies in the computer industry undertake significantly more related technological M\&As than pharmaceutical companies. The difference between the other sectors is nonsignificant.

\subsection{Discussion}

Technological diversification is very important for effective innovative performance of technology-based firms and their creation of a sustainable competitive advantage (Eisenhardt and Martin, 2000; Grant, 1996). According to Granstrand (1998), in hightech industries, the multitechnology corporation (a firm that diversifies its knowledge base into a wide range of technologies) is now the rule rather than the exception. Through the combination and recombination of a wide range of technologies, firms are better able to generate and take advantage of technological opportunities (Granstrand and Sjölander, 1990; Granstrand, 1998). In this study, we analyzed the antecedents of the direction of a firm's diversification into a range of technological areas by means of M\&As. Prior research provided evidence for the notion that a firm's learning process has an impact upon its technological diversification (Breschi et al., 2003). Therefore, we argued that two important determinants of a firm's technological diversification behavior are its internal learning process and its external learning process.

Internal learning is important for a firm in order to build up a strong coherent knowledge base that forms the basis of possible 'first mover advantages' (Chesbrough and Teece, 1996; Rosenkopf and Nerkar, 2001). In addition, internal learning not only generates new information but it also increases a firm's absorptive capacity (Cohen and Levinthal, 1989). By building up a strong internal knowledge base a firm will be better able to assimilate and exploit outside knowledge. As already explained in chapter 4 , this is based on the idea that a firm's absorptive capacity depends to a large degree on its stock of prior knowledge in a specific lield (Cohen and Levinthal, 1990; Dodgson, 1993; Duysters and Hagedoorn, 2000; Mowery et al., 1996). Especially in the case of external learning by means of M\&As, the internal knowledge base of the acquirer should be sufficiently adapted to the newly acquired knowledge to facilitate the M\&A absorption process (Duysters and Hagedoorn, 2000).

Besides building up a strong internal knowledge base, there is also the need for high-tech firms to be open to new external sources of knowledge and ideas that lie outside a firm's current technological areas. Several researchers stress the importance that the gains associated with the internal development of technology are not sustainable unless the organization is able to integrate external developments from across different fields (Henderson and Cockburn, 1994; Pisano, 1994; Rosenkopf and Nerkar, 2001: p292). Others argue that external learning is absolutely necessary for high-tech firms in order to survive in a rapidly changing and technologically complex 
environment, where it becomes more and more important to rely much less on existing knowledge and much more on fast developed new knowledge (e.g. Eisenhardt and Martin, 2000). Especially in these high-tech environments, firms are used to undertake aggressive acquisition behavior (external learning) and focus on extensive knowledge recombination (Capron and Mitchell, 2000).

In short, previous research shows that internal and external learning are mutually dependent, complementary processes. In that context, it is interesting to see if internal learning and extemal learning lead to convergence or divergence in the direction of a firm's technological diversification. Our findings suggest that internal learning and external learning have a divergent effect on the relatedness of new technological fields entered by means of M\&As. Results clearly indicate that firms will use their internal learning process to acquire target firms in related technological areas, mainly driven by the long and costly process that firms have to go through when building up a strong internal knowledge base. Given the fact that it is such a long and costly process to develop a technological profile over time, it is also very difficult to change this profile. When new knowledge is created and distributed internally, it is embedded in organizational routines that are highly firm-specific in nature. According to the evolutionary economics school, firms replicate these idiosyncratic organizational routines over time (Nelson and Winter, 1982). Following this logic, we argue that this replication of routines will lead to a stable pattern of diversification into related technological areas.

To break away from existing innovation routines, a firm can undertake external learning processes (M\&As) to overcome the threats of the path-dependency created by internal learning processes (Capron and Mitchell, 2000; Karim and Mitchell, 2000). By adding the new externally acquired knowledge to its already existing knowledge base, the firm can develop a richer and broader knowledge base (Ahuja and Katila, 2001; Bierly and Chakrabarti, 1996; Vermeulen and Barkema, 2001). This broader knowledge base, in its turn, enables the firm to view particular issues from different perspectives and it creates new opportunities for learning. To take advantage of these learning opportunities, high-tech firms can start searching for novel solutions and explore knowledge bases in unrelated technological areas (Reuer et al., 2002).

Thus, our research indicates two important findings, knowledge that is originated from within the firm is used to diversify into related teclinological areas and knowledge that is acquired externally by the firm is used to diversify into distant technological areas. The fact that internal knowledge is used for related technological diversification implies several advantages, such as a reliable and predictable search process, a reduced likelihood of errors, and a deeper understanding of the possibilities of the acquired knowledge elements via repeated usage (Levinthal and March, 1981; Ahuja and Katila, 2001). Despite the above-mentioned advantages, it is important especially for high-tech firms to move beyond related technological areas and to recombine their knowledge to successfully compete over time (Henderson and Cockburn, 1994; Kogut and Zander, 1992; Rosenkopf and Almeide, 2003; Teece, Pisano and Shuen, 1997). Rosenkopf and Nerkar (2001) for example, argue that 
diversification into related technological areas will lead to short-term gains within the existing technological domain. However, diversification into unrelated technological areas suggests the possibility of entering new technological platforms with longer-term gains. All told, the complementary processes of internal learning and external learning result in a mixture of related and unrelated diversification, thereby creating a true multitechnology corporation.

\subsection{Conclusion}

This chapter has proposed that internal and external learning processes are two key factors in affecting a firm's technological diversification by means of M\&As. Hightech firms use their internal learning process in combination with related technological diversification, to focus on small improvements of technologies, as an essential condition for the effective development of a strong and coherent technological profile. In addition, firms use their external learning process in combination with unrelated technological diversification, to access and monitor all the necessary technologies embedded in a broad range of unrelated technological areas that are important for their core products. Thereby, increasing the flexibility of the firm in volatile environments (Grant, 1996).

For future research, it would be interesting to analyze the role of other external learning processes (i.e. alliances) besides M\&As to explore the technological diversification behavior of companies. As mentioned before, given the complexity of technologies and the rapid pace of technological change, companies can only concentrate on a few R\&D projects internally (Duysters and Hagedoom, 2000) and use alliances as an important vehicle for monitoring external knowledge (Duysters and Hagedoorn, 2000; Hagedoorn, 1995). Since our analysis shows that technological M\&A experience has a nonsignificant influence on a firm's technological diversification by means of $M \& A s$ it would also be interesting to analyze this relationship in more detail. Another suggestion would be to conduct future research in other industries, such as low-tech or medium-tech industries. In comparison with hightech industries, these industries have more stable operating processes, which rely much more on existing knowledge (Eisenhardt and Martin, 2000). Related technological diversification is probably a more preferable strategy for firms in these industries than a mixture of related and unrelated technological diversification. Finally, we think that our results pave the way for further research in terms of a better understanding of the determinants of a firm's technological diversification strategy and eventually the influence of this strategy on a firm's innovative and economic performance. 


\section{CHAPTER 6}

\section{CONCLUSIONS}

\subsection{Introduction}

The aim of this thesis was to examine the impact of mergers and acquisitions on the post-M\&A innovative performance of high-tech firms. More in particular, we analyzed the role of fit in explaining innovative performance differentials between high-tech firms in terms of strategic fit through technological complementarities and organizational fit through matches in relative size of the acquired knowledge base. Our results showed that $M \& A s$ contribute to an improved innovative performance when they support both aspects of fit. However, too much fit between the acquiring and acquired firm can diminish a firm's flexibility towards its ever-changing environment. Especially for high-tech firms, increased flexibility is absolutely necessary to take advantage of technological opportunities that rely on fast developed new knowledge (Eisenhardt and Martin, 2000; Granstrand and Sjölander, 1990; Granstrand, 1998). This implies that acquiring firms have to deal with an important paradox, namely the tension between fit (strategic and organizational) on the one hand and flexibility on the other hand. This paradox creates a strategy tension in which companies have to try to find novel ways to combine both opposites of the paradox at the same time and benefit from this as much as possible (Wit and Meyer, 1998). Only then, a firm is able to create and capture the maximum value of its post-M\&A innovative performance.

A number of elements in the resource-based view of the firm, in combination with some related contributions that stress the importance of knowledge and organizational learning, provided some useful insights about the conditions under which M\&As contribute to an improved post-M\&A innovative performance. The resource-based view argues that the importance of possessing specific resources, competencies and capabilities lie at the core of a firm's existence (Wernerfelt, 1984). Those resources, which are scare, valuable and reasonably durable, will eventually lead to a competitive advantage (Barney, 1991). In general, strategy researchers argue that mainly intangible assets such as knowledge generate value, because they are socially complex and more difficult to understand and imitate (Hitt, Ireland, Camp, Sexton, 2001; Liebeskind, 1996; Spender, 1994; Grant, 1996). This is based on the idea that tangible resources such as raw materials or labor are positioned outside the firm and assuming an efficient market therefore generate less rents than intangible resources. So, competitive advantage in today"s economy is mainly based on firmspecific knowledge that enables a firm to add value to its production factors, rather than by having access to raw materials or cheap labor (Liebeskind, 1996; Spender, 1996). This perspective is clearly linked to the knowledge-based view of the firm, which is an outgrow of the resource-based view to the extent that it focuses upon 
knowledge as the strategically most important resource of the firm (Conner and Prahalad, 1996; Grant, 1996; Nonaka, 1991; Spender, 1989).

Knowledge is also a central issue in several other research traditions that stress the importance of organizational learning (e.g. Boisot, 1995; Grant, 1996; Huber, 1991; Levitt and March, 1988). In rapidly changing and technologically complex environments, such as high-tech industries, the value of a firm's current knowledge is quickly reduced (Hitt et al., 2001) and it becomes more and more important to rely on fast developed new knowledge (Eisenhardt and Martin, 2000; Hitt et al., 2001). One important tactic for acquiring new knowledge, mentioned in the organizational learning literature, is the use of a merger or an acquisition. More in particular, it is expected that the firm's ability to acquire additional knowledge bases and capabilities, its integration skills, and its capacity to generate new knowledge through M\&As, can create a sustainable competitive advantage (Barney, 1986).

Consequently, acquiring new technological knowledge by means of M\&As with the aim of increasing innovation is critical for high-tech firms to compete effectively within their dynamic environment. Therefore the general research question of this thesis was: "To what extent contribute M\&As in high-tech industries to the post-M\&A innovative performance of acquiring firms ?". However, before we were able to analyze the effect of M\&As on a firm's innovative performance, we first had to establish a better understanding of the concept and measurement of innovative performance. Once we had ascertained a generally accepted set of innovation. indicators we could analyze the effect of M\&As on a firm's post-M\&A innovative performance.

In the next section we will discuss the main results of this study within the context of the paradox, and provide an overall answer to the general research question of this thesis. Then, in section 6.3 we outline the methodological, theoretical and managerial implications of this thesis. Finally, section 6.4 discusses the limitations of our study and provides some suggestions for future research.

\subsection{Some major findings of this thesis}

We stress the importance of understanding the conditions under which M\&As might have a positive effect on the innovative performance of the acquiring firm. In that context we emphasize the role of fit in explaining innovative performance differentials. The search for fit (and more in particular synergy) has always been an important rationale for $M \& A$ activity in many of the existing analyses of M\&As and economic performance (e.g. Hitt, et al., 1998; King et al., 2004; Lubatkin, 1987; Mukherjee, Kiymaz and Baker, 2004). With respect to innovative performance, Hagedoorn and Duysters (2002) show that M\&As undertaken by high-tech firms contribute to an improved innovative performance when they support major aspects of strategic fit between the acquiring and the acquired firm. This finding is confirmed by 
other research, which argues that synergy is perhaps the most important motive for acquiring firms to undertake M\&As (Mukherjee et al.., 2004; King et al., 2004).

Synergy occurs when firms are ablle to share resources among their businesses, thereby increasing the value of the combined firm (Cooke, 1988; Wit de and Meyer, 1998; Seth, 1990). Examples include, using each others' distribution networks or sharing the same production facilities (Hitt et al., 1997; World Investment Report, 2000). Besides these tangible resources, intangible resources such as firm-specific knowledge may be shared as well. With respect to M\&As, realizing synergies implies that one has to unify the acquiring firm's resources with the resources of the acquired firm. The concept of unification within an M\&A entails the idea of fit between the resources. Fit in this context is defined in terms of strategic fit through product-market and technological complementarities (Hagedoorn and Duysters, 2002a) and organizational fit through matches in relative size of the acquired resources.

However, fit (strategic and organizational) comes with a price tag. Unification of resources that fit to the already existing resources of a firm with the purpose of increasing synergetic benefits or improving the absorption process can diminish a firm's flexibility towards its ever changing environment. Especially for high-tech firms it becomes more and more important to access and monitor all the necessary technologies embedded in a broad range of unrelated technological areas (increased flexibility) instead of doing more of the same (decreased flexibility). Therefore, firms can improve their innovative performance the most, by undertaking M\&As in which they are able to find a balance between the opposites of fit (synergy and unification) on the one hand and flexibility on the other hand.

Although the improvement of innovation is such an important component of a high-tech firm's strategy (Hamel, 2000), the management and applied economics literature have a long history of struggling with the concept and its measurement. Hence, it was necessary to get a better understanding of the measurement of innovative performance before we could analyze the effect of M\&As on the acquiring firm"s innovative performance.

\subsubsection{How to measure innovative performance}

The management and applied economics literature on innovation shows a long history of struggling with the measurement of the innovative performance of companies, Many studies use a single indicator ( $R \& D$, patents, patent citations, or new product announcements) arguing that the specific indicator that is applied has fewer shortcomings than the other indicators. Some studies use two or more indicators to generate one construct, based on an intermediate statistical association between a number of measures. Other studies suggest that, given the rather high correlation between some indicators, any of these correlated measures could be used as a partial or overall indicator of performance. 
Our understanding of the literature, as outlined in the above, led to a number of research questions. First, is there a systematic disparity between different indicators such as $R \& D$ inputs, patent counts, patent citations and new product announcements? Second, is there a statistical communality between two or more indicators, indicating that a composite construct can capture a latent variable? Third, is the statistical association between two or more indicators of such a nature that each of these indicators can be applied as a representative indicator of innovative performance?

The outcome of our research showed that there is no major systematic disparity amongst R\&D inputs, patent counts, patent citations and new product announcements. Second, the statistical communality of the four indicators of innovative performance was high, indicating that a composite construct clearly catches a latent variable "innovative performance". However, our results also indicated that the statistical overlap between each of the four indicators was that strong that future research might also consider using any of these indicators to measure the innovative performance of companies in high-tech industries.

\subsubsection{Fit (synergy and unification) versus flexibility}

The most common motive for acquiring firms to undertake M\&As is the search for synergy (King et al., 2004; Mukherjee et al., 2004). Synergy by means of M\&As can be reached in terms of their international nature, in terms of the product-markets involved, and in terms of the technological knowledge involved. By undertaking international M\&As, firms can recover investments from large scale research projects (Franko, 1989; Kobrin, 1991). These returns can then be used to re-invest in new innovation projects (Barkema and Vermeulen, 1998). Although, in general we witnessed an enlarged importance of international M\&As during the period of our analysis, we found some significant differences with respect to the high-tech sectors. Both the aerospace and defense sector and the computers and office machinery sector showed a preference for domestic M\&As. This can be explained by a need for military independence and national prestige in the former case (Texier, 2000), and a rapid maturation of the industry in the latter case (Duysters, 1995). The pharmaceutical sector, however, showed a disproportionate importance of international M\&As, driven by the desire to recoup the large investments in $R \& D$ projects that are required to develop new generations of drugs (DiMasi, 1995; Fildes, 1990; Kang and Johansson, 2000; Pisano and Wheelwright, 1995; Sharp et al., 1997).

With regard to the product-markets involved in an M\&A transaction, we can make a distinction between horizontally or vertically related M\&As and conglomerate or unrelated M\&As. A substantial part of the existing M\&A literature expects that related M\&As should show superior performance because of value created by economies of scale and scope that ought to generate more synergetic benefits than in the case of unrelated M\&As that have no relationship other than being held together by an overarching system of corporate control (Healy et al., 1992; Hoskisson and 
Johnson, 1992; Hoskisson and Hitt, 1994; Kranenburg van et al., 2001; Porter, 1987; Shelton, 1988; Sing and Montgomery, 1987). Although previous studies focus mainly on economic performance instead of innovative performance, Hagedoorn and Duysters (2002a) show that there is a positive relationship between the relatedness of M\&As (in terms of product-markets) and the post-M\&A innovative performance. For example, horizontally related M\&As can provide economies of scale and scope, such as complementary innovation programs, that by generating new products and technologies contribute to an improved post-M\&A innovative performance of the acquiring firm (Hagedoorn and Duysters, 2002a). With respect to vertically related M\&As, economies of scale and scope such as cost reductions of integrating previously separate activities, will generate savings that can be reinvested in innovative programs (Hagedoorn and Duysters, 2002a).

Although, synergy is an important motive for a firm to acquire a target company, we witnessed for the period of our analysis that two-third of all M\&A deals were so called unrelated M\&As and one-third were related M\&As. This large number of unrelated M\&As can be explained by an accelerated technological convergence apparent on the product-market level during the mid 1980s and early 1990s (Duysters and Hagedoorn, 1998). When previously unrelated technologies converge, firms with initially different technological trajectories, face the challenge of quickly obtaining the knowledge necessary to compete in emerging product markets (Lee, 2004, p.1). In addition, the convergence process causes the blurring of traditional technological and sectoral boundaries thereby increasing the need for companies to master many different technologies at the same time (Tulder van and Junne, 1988). Subsequently, this means that firms in high-tech sectors have to broaden their existing knowledge base and do this as quickly as possible to keep up with the pace of technological change.

In order to gain access to the essential technological knowledge and thereby broaden the existing knowledge base, companies can develop the required technological knowledge themselves (internal learning) or undertake M\&As with technologically sophisticated companies (external learning)'. Internal learning occurs when firms" scientists and engineers create and distribute new technological knowledge within the boundaries of the firm (Chesbrough and Teece, 1996). This knowledge will enable the firm to develop its own core capabilities in technological fields that form the basis of possible 'first mover advantages' (Chesbrough and Teece, 1996; Rosenkopf and Nerkar, 2001). However, building up a strong internal knowledge base is a long and costly process. Given the fact that it is a long and costly process to build a profile of technological foundations, it is also very difficult to change this profile over time (Breschi et al., 1998; Giuri et al., 2004; Granstrand et al., 1997). When firms' scientists and engineers create and distribute new technological knowledge within the boundaries of the firm, this knowledge is retained in routines

\footnotetext{
'We do realize that between these two extremes, intemal development or M\&As, several other options (i.e. joint research pact, joint dewelopment agreement, joint ventures and research corporations) are open lo a company (Hagedoorn, Cloodt and van Kranenburg, forthcoming).
} 


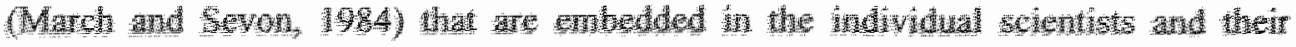

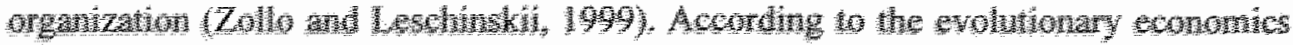

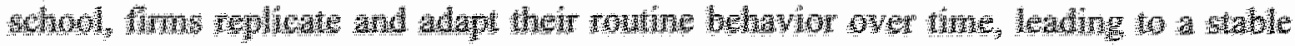

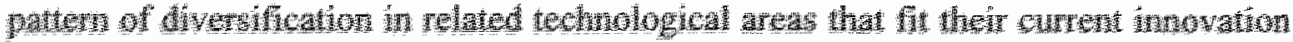

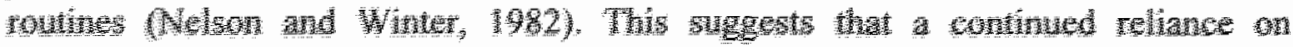

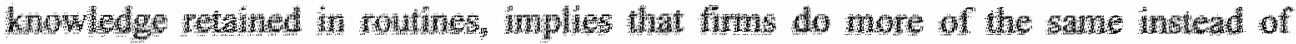

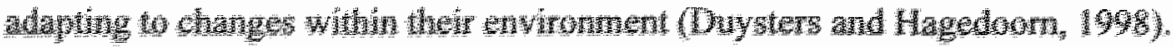

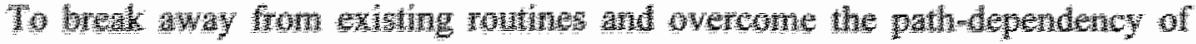

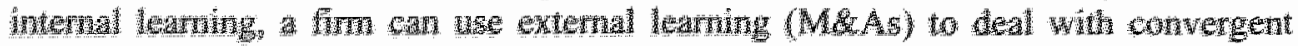

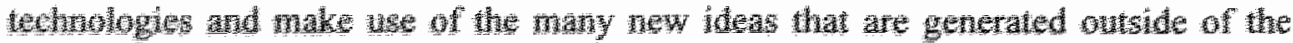

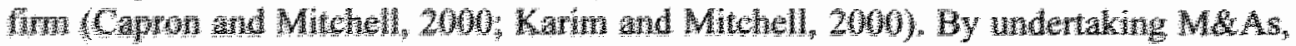

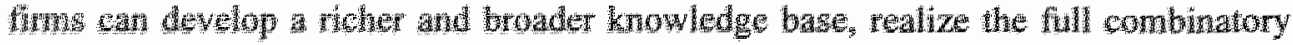

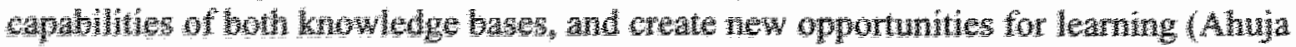

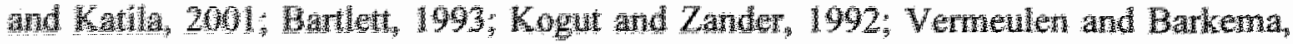

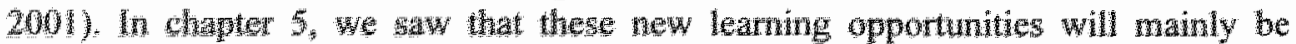

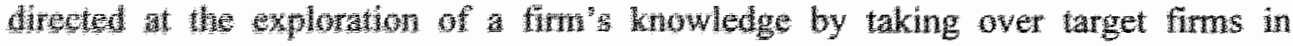

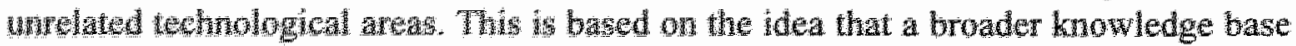

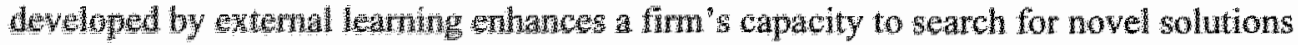

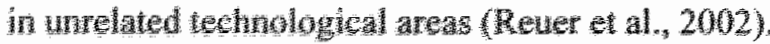

Contequenty, Mres are armpontan means to quickly adapt and brouden a

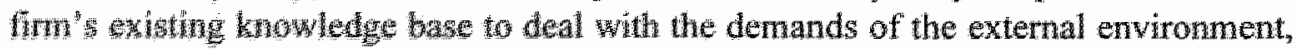

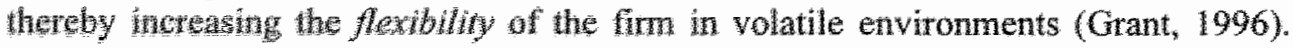

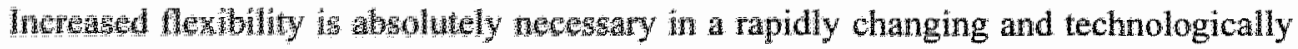

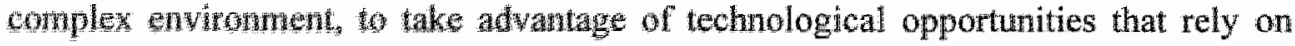
fant developel new snowledge (Evemhard and Martin, 2000; Granstrand and Sjolduder, $1990^{\circ}$ Gramtrand, 1998). In addion, Rosenkopf and Nerkar (2001) argue that diversitution into related techological areas will lead to short-term gains (aynergetic benefits) within the existing technological domain. However, diversification into unrelated technological areas suggests the possibility of entering new technological platforms (flexibility) with longer-term gains.

Hence, from the viewpoint of flexibility it is preferable for an acquiring firm to have access to a broad range of knowledge in unrelated technological areas, to deal with the technological convergence apparent on the product-market level and the rapid. pace of technological change. Although acquiring knowledgeable companies in new technological areas seems to be an attractive option for companies to create a broad spectrum of knowledge, these technological M\&As are hampered by the fact that the challenge for companies is not just to acquire knowledge bases but also to unify them (Ahuja and Katila, 2001; Child et al., 2001; Haspeslagh and Jemison, 1991).

From an organizational learning perspective, an acquiring firm is better able to evaluate and utilize related externally acquired knowledge than unrelated externally acquired knowledge (Cohen and Levinthal, 1990). This is based on the idea that a firm's absorptive capacity depends to a large degree on its level of knowledge in a specific field (Cohen and Levinthal, 1990; Dodgson, 1993; Duysters and Hagedoorn 
2000; Mowery et al., 1996). Acquiring knowledge in unrelated technological areas, often requires a radical change in the way of organizing research (Kogut and Zander, 1992) and such a major modification can easily be counterproductive (Ahuja and Katila, 2001; Dosi, 1988). Thus, if the knowledge base of the acquirer is not sufficiently adapted to the newly acquired knowledge, the unification process becomes very difficult (Duysters and Hagedoorn, 2000).

Another important factor in the unification of knowledge bases is the relative size of the acquired knowledge base. We argue that the unification of a knowledge base that is of a relatively large size compared to the already existing knowledge base, disrupts the existing innovative activities and renders the different integration stages more complex, time consuming and full of risks (Capron and Mitchell, 2000; Chakrabarti et al., 1994; Haspeslagh and Jemison, 1991). Due to such problems, integrating a relatively large knowledge base requires additional resources to be devoted to the integration task, leaving fewer resources for the actual innovative endeavor (Ahuja and Katila, 2001).

\subsubsection{Answer to the general research question}

The answer to the general research question: "To what extent contribute M\&As in high-tech industries to the post-M\&A innovative performance of acquiring firms", lies in the ability of high-tech firms to find a proper balance between the tension of fit (synergy and unification) versus flexibility. One of the most conmon topics studied in strategic management is the importance of synergy for improved firm performance. Although previous research shows that synergy can be realized by undertaking international M\&As and related product-market M\&As, Hitt et al. (1998) argue that the identification of resource complementarities is the key to success. According to them, both related and unrelated M\&As (in terms of product-markets) can enable merged firms to exploit positive synergy as long as firms are able to identify complementarities between their resources.

By undertaking both nontechnological and technological M\&As, firms can acquire complementary resources and exploit synergetic benefits. An important reason for firms in the high-tech sectors to undertake nontechnological M\&As, is the fact that high-tech firms are often rapidly growing, which creates a shortage of managerial and / or financial resources (McGowan, 1971). This motivates them to acquire targets that can offer these complementary resources, even if they cannot make a significant contribution to the existing knowledge base of the acquiring firm.

Although nontechnological M\&As provide acquiring firms with complementary managerial and/or financial resources, we saw in chapter 4 that these M\&As have a negative impact on the firm's post-M\&A innovative performance. The main reason for their negative impact on innovative performance, is the fact that they disrupt the established innovation routines of both firms (Hitt et all, 1996). Thus, the 
short-term benefits of increased managerial and/or financial resources do not outweigh the long-term organizational effects of a disruption of the innovation process.

With respect to technological M\&As, our study focused on the complementarity between intangible resources of the acquiring and the acquired firm and more in particular between the knowledge bases of both firms. As discussed in section 6.2.2, the unification of the acquiring firm's knowledge base and the acquired firm's knowledge base can provide synergies or economies of scale and scope, such as a shorter innovation lead-time and the possibility to engage in larger combined projects, while reducing redundant or duplicate R\&D efforts (Gerpott, 1995; Hagedoom and Duysters, 2002a; Hall, 1990; Mowery et al., 1996). In addition, hightech firms undertake technological M\&As as a means to increase their flexibility. Increased flexibility of high-tech firms is needed in order to deal with their fast changing and complex technological environment.

Hence, from a strategic viewpoint firms should try to capture the benefits of synergy on the one hand and flexibility on the other hand. However, from an organizational viewpoint, as explained in section 6.2.2, there are limits to the acquisition of a large amount of unrelated technological knowledge. Acquiring knowledge in unrelated technological areas, often requires a radical change in the way of organizing research (Kogut and Zander, 1992) and such a major modification can easily be counterproductive in terms of innovative performance (Ahuja and Katila, 2001; Dosi, 1988).

All told, companies have to target firms with moderately related knowledge bases that are relatively equal in size to their existing knowledge base. In that way they can profit from synergetic benefits between both knowledge bases, a smooth absorption process of the acquired knowledge base, and enough enrichment of their existing knowledge base to create flexibility and opportunities for an improved postM\&A innovative performance.

\subsection{Methodological, theoretical and managerial implications}

In this study we conducted a quantitative assessment of the acquiring firm's postM\&A innovative performance, its measurement, and its antecedents. Our international, large-scale, multi-sectoral sample of high-tech firms allowed a detailed statistical analysis of the impact of nontechnological and technological M\&As on the acquiring firm's innovative performance. In addition, we aimed to establish the generalisability of the analysis of critical success factors and processes that had a significant influence on a firm's post-M\&A innovative performance, highlighted in previous research. 


\subsubsection{Methodological implications}

From the viewpoint of research methods, this thesis provides two important contributions. First, the management and applied economics literature on innovation has a long history of struggling with the measurement of the innovative performance of companies. The results of many studies have not yet led to a generally accepted indicator of innovative performance or a common set of indicators. Therefore we decided in chapter 3 to establish a better understanding of the innovative performance of companies. This chapter was purely methodological in nature as it did not outline a theory or a model explaining differences in the innovative performance of companies, but focused purely on the measurement of innovative performance. Our findings have some important implications for future research, since we found that the statistical overlap between the indicators (R\&D expenditures, patents, patent citations, and new product announcements) is that strong that any of these indicators can be used to measure the innovative performance of companies in high-tech industries.

Second, looking at the research methods used in the post-M\&A performance literature we observed that there is hardly any overlap between the variables used to explain performance (King et al., 2004). Therefore, King et al. (2004) stimulate researchers to build on past models instead of continuously seeking new effects and create new models. More specific, we decided not only to build on a past model but we performed an extended replication study of the analysis of Ahuja and Katila (2001). We took duplication as a starting point but then widened the research by using other sample firms from different sectors and a different time period. In other words, the main focus of our study was the external validity or generalization of previous research findings, instead of the internal validity of the research design. Our study both replicated and falsified some of the findings from the single medium-tech sector study of Ahuja and Katila (2001), extending into an alternative multi-sectoral context of high-tech industries. All in all, from a methodological point of view, our extended replication study made an important contribution in ensuring the validity and reliability of previous research thereby facilitating knowledge accumulation and theory building in post-M\&A performance research.

\subsubsection{Theoretical implications}

Changes to theory about post-M\&A research are needed, since a meta-analysis of variables frequently used in existing empirical research (i.e. whether or not the $M \& A$ was undertaken by a conglomerate firm, whether or not the acquired firm was a related firm, differences in the method of payment, whether or not the acquiring firm had prior M\&A experience) showed no significant effect on post-M\&A performance (King et al., 2004). To find an explanation for the ongoing M\&A activity in most of the industries, King et al. (2004) encourage additional theorizing of nonfinancial motives to undertake M\&As, since these are rather under-represented in the existing M\&A 
literature. In addition, complementary resources between the acquiring and the acquired firm become, according to them, one of the most promising theoretical foundations for M\&A research in the future.

Our study contributes to both of the abovementioned suggestions leading to some important theoretical improvements of post-M\&A research. First of all, we analyzed several nonfinancial motives of undertaking M\&As, for example the pursuit of growth in case of nontechnological M\&As or the management of technological uncertainty in case of technological M\&As. Second, we tried to take the debate of post-M\&A research one step further by looking at the long-term effects of M\&As on nonfinancial performance (innovative performance) instead of financial performance.

Focusing on technological M\&As, we also included the suggestion of an analysis of complementary resources between the acquiring and the acquired firm in our study. This is important because existing research often uses product relatedness as a proxy for resource complementarity and in addition focuses only on tangible resources (Hitt et al., 1998). In chapter 4, we analyzed the degree of complementarity between the knowledge bases (intangible resources) of the acquiring and the acquired firm. Results of this study suggested that a moderate complementarity between the knowledge bases of both firms leads to the highest post-M\&A innovative performance. In chapter 5 we analyzed the complementarity of the acquiring firm's existing technological areas and the newly entered technological areas. This study implied that the more firms acquire knowledge externally instead of developing knowledge internally, the more they will diversify into unrelated technological areas by means of M\&As. This suggests that the creation of a broader or richer knowledge base by means of M\&As will lead to a search for more unrelated (less complementary) knowledge instead of an exploitation of existing knowledge. The outcome of these two studies enriches our understanding of post-M\&A performance research and paves the way for future theory building within this area.

Besides taking a new perspective (nonfinancial motives, innovative performance, complementary resources) in the analysis of post-M\&A performance research our study also has some clear theoretical implications with respect to the diversification literature. To our knowledge, technological diversification and its determinants are rather underrepresented in the diversification literature and only a few authors have put this topic on the research agenda. More in particular, linking internal learning and external learning to a firm's choice of undertaking related or unrelated technological M\&As, as we did in chapter 5 , has not yet been undertaken (see figure 5.1). Our findings showed that internal learning and external learning have a significant divergent effect on the relatedness of new technological fields entered by means of M\&As. This result has some important implications for a firm's technological diversification strategy by means of M\&As and opens the way for a further development of a very promising area of research. 


\subsubsection{Managerial implications}

Appropriating innovation vallue from undertaking mergers and acquisitions is possible as long as managers understand that they have to clearly examine how and when the acquisition of target firms can strengthen their post-M\&A innovative performance. This thesis provides managers with a guidance by addressing several important characteristics of M\&As that have a positive impact on the acquiring firm's innovative performance. With respect to technological M\&As, managers should focus on those target firms that are in possession of a knowledge base which, is more or less of an equal size and moderately related to their own knowledge base. Concerning the absolute size of the acquired knowledge base no clear-cut answer can be given. Chapter 4 demonstrated that a large absolute size of the acquired knowledge base improves the innovative performance for the first couple of post-M\&A years but thereafter has a negative effect.

Although the direct effect over time is negative there is a possibility that the absolute size of the acquired knowledge base indirectly contributes to an improved post-M\&A innovative performance of the acquiring firm. That is to say, chapter 5 illustrated that the acquisition of a large absolute knowledge base will lead to technological M\&As with target firms in unrelated technological areas. This is based on the idea that by acquiring a large absolute knowledge base, the acquiring firm can create a richer and broader variety of knowledge within the firm. Because of this enrichment of the existing knowledge base, firms become more creative and are able to explore and experiment with new technologies in unrelated technological areas (Fai, 2001; Granstrand et al., 1997). A positive effect of the acquisition of technologies embedded in a broad range of unrelated technological areas is that it increases the flexibility of high-tech firms (Grant, 1996). In addition, several researchers argue that diversification into unrelated areas is absolutely necessary for high-tech firms to create long-term gains in their rapidly changing and technologically complex environment (e.g. Eisenhardt and Martin, 2000; Rosenkopf and Almeida, 2003; Rosenkopf and Nerkar, 2001). However, the question remains if the acquiring firm is able to absorb the external knowledge present in unrelated technological areas. As chapter 4 proved, managers have to make sure that there is still some relatedness between the technological areas newly entered by means of M\&As and the technological areas in which they are already present.

\subsection{Limitations and suggestions for future research}

Limitations of each of the studies have been discussed in detail at the end of each chapter. Therefore, we will only discuss those limitations that cover all chapters and provide some general directions for future research. A first limitation of our study is the fact that we analyzed the acquiring firm's post-M\&A innovative performance within the context of the high-tech sector. The high-tech sector (aerospace and 
defense, computers and office machinery, pharmaceuticals, and electronics and communications) was selected as the primary context of our analysis for several reasons. First, M\&As are important sources of innovation for all companies in the most technologically oriented industries (Link, 1988). Second, these high-tech industries are primarily knowledge-driven industries and they were selected because it is known that particularly in these industries, there is an abundance of reliable innovation indicators. Finally, the high-tech environment is also a field, which has become highly internationalized and characterized by global competition (OECD, 1992). This allowed us to study the impact of M\&As on a firm"s innovative performance within an international setting.

For future research, it is however important to analyze the effect of M\&As on the acquiring firm's post-M\&A innovative performance in other industries as well. Just as the manufacturing high-tech industry, the service industry for example has to deal with similar environmental threats, such as a high speed of technological developments, shortened life cycles of services, and intensified competition. In that context, M\&As could help service firms to improve their innovative performance and introduce successfully new services as a source of competitive advantage.

In addition, when analyzing the post-M\&A innovative performance within the service sector, one has to consider some alternative measures of innovation that are more appropriate in the context of a wide range of service industries. The measurement of innovative performance in our thesis, as discussed in chapter 3 , is based on indicators that more effectively capture some aspects of technical innovation rather than of service innovation (Kleinknecht, 1999).

A second limitation of our study is the fact that we focused our analysis on the post-M\&A innovative performance and not on the economic value of this innovative performance. Examining the economic value of the post-M\&A innovative performance would be a natural extension of the work in this thesis. For example, there is already some empirical work that shows a positive relationship between high innovation and superior economic performance (Roberts, 1999). In that way, future research will be able to provide a thorough assessment of the long-term implications of nontechnological and technological M\&As.

Finally, the results of this thesis can be useful for research in the area of alternate modes of sustaining or improving inmovative performance, such as internal organic growth or alliances. Although the focus of our study was on mergers and acquisitions as a strategic tool for increasing a firm's innovative performance, findings of our study could play an important role for these governance modes as well. 


\section{APPENDIX A}

\section{The Securities Data M\&A database}

The databank that provided information on M\&As is property of the firm Securities Data and can be used via on-line access. For a limited period of time this database has been accessed and a specific data sample has been extracted. Our sample contains information on about 121.000 worldwide M\&As for the period 1985-1994. This information is arranged in several data files. Within the M\&A database there is information on the year the M\&A got established and company information on the acquirer, the target, the parent acquirer and the parent target firm. The industry information is provided in SIC codes of the acquirer and acquiree. 


\section{APPENDIX B}

\section{The U.S. Patent and Trademark Office Database (USPTO)}

The USPTO is an intellectual property organization of the US Department \& Commerce who registers patent applications and patent citations from all over the world. The database we used includes patent information during the period 1963 to December 1999. In the database we have information about the patent number, the name of the company, the country, the application year, the issue year, the primary classification in the US patent classification system, and the individual SIC codes for the primary classifications. 


\section{APPENDIX C}

Distribution of companies in the sample, numbers and $\%$ distribution for sectors and regions

\begin{tabular}{llll}
\hline Industry & North America & Others & Total \\
\hline Aerospace & 38 & 21 & 59 \\
and defense & $(4.55 \%)$ & $(5.87 \%)$ & $(4.94 \%)$ \\
& $(64.41 \%)$ & $(35.59 \%)$ & $(100 \%)$ \\
Computers & 227 & & \\
and office & $(27.15 \%)$ & $(14.81 \%)$ & 280 \\
machinery & $(81.07 \%)$ & $(18.93 \%)$ & $(23.45 \%)$ \\
Pharmaceuticals & 152 & & $(100 \%)$ \\
& $(18.18 \%)$ & 92 & 244 \\
& $(62.30 \%)$ & $(25.70 \%)$ & $(20.44 \%)$ \\
Electronics and & 419 & $(37.70 \%)$ & $(100 \%)$ \\
communications & $(50.12 \%)$ & 192 & 611 \\
& $(68.58 \%)$ & $(53.62 \%)$ & $(51.17 \%)$ \\
& & $(31.42 \%)$ & $(100 \%)$ \\
& & & $(10 \% \%)$ \\
Total & 836 & 358 & $(100 \%)$ \\
& $(100 \%)$ & $(100 \%)$ & $(29.98 \%)$ \\
\hline
\end{tabular}




\section{APPENDIX D}

\section{Correlations}

\section{North America}

\begin{tabular}{lccccc}
\hline Variables & Total & $\begin{array}{l}\text { Aerospace } \\
\text { and defense }\end{array}$ & $\begin{array}{l}\text { Computers } \\
\text { and office } \\
\text { machinery }\end{array}$ & $\begin{array}{l}\text { Pharma- } \\
\text { ceuticals }\end{array}$ & $\begin{array}{l}\text { Electronics } \\
\text { and commun- } \\
\text { cations }\end{array}$ \\
\hline $\begin{array}{l}\text { Patents and } \\
\text { patent citations }\end{array}$ & 0.951 & 0.793 & 0.985 & 0.792 & 0.897 \\
$\begin{array}{l}\text { Patents and } \\
\text { R\&D expenditures }\end{array}$ & 0.822 & 0.902 & 0.921 & 0.833 & 0.898 \\
$\begin{array}{l}\text { Patents and } \\
\text { new products }\end{array}$ & 0.769 & 0.482 & 0.786 & 0.554 & 0.752 \\
$\begin{array}{l}\text { Patent citations and } \\
\text { R\&D expenditures }\end{array}$ & 0.778 & 0.879 & 0.905 & 0.562 & 0.870 \\
$\begin{array}{l}\text { Patent citations and } \\
\text { new products }\end{array}$ & 0.782 & 0.770 & 0.777 & 0.386 & 0.811 \\
$\begin{array}{l}\text { R\&D expenditures } \\
\text { and new products }\end{array}$ & 0.796 & 0.659 & 0.925 & 0.864 & 0.828 \\
\hline
\end{tabular}




\section{APPENDIX D continued}

\section{Correlations}

Others

\begin{tabular}{|c|c|c|c|c|c|}
\hline Variables & Total & $\begin{array}{l}\text { Aerospace } \\
\text { and defense* }\end{array}$ & $\begin{array}{l}\text { Computers } \\
\text { and office } \\
\text { machinery }\end{array}$ & $\begin{array}{l}\text { Pharma- } \\
\text { ceuticals }\end{array}$ & $\begin{array}{l}\text { Electronics } \\
\text { and communi- } \\
\text { cations }\end{array}$ \\
\hline
\end{tabular}

$\begin{array}{llllll}\text { Patents and } & 0.964 & 0.859 & 0.987 & 0.827 & 0.968\end{array}$

patent citations

Patents and

$0.764-0.30$

0.980

0.592

0.787

R\&D expenditures

$\begin{array}{llllll}\text { Patents and } & 0.903 & 0.122 & 0.940 & 0.625 & 0.907\end{array}$

new products

Patent citations and

$0.713-0.23$

0.942

0.536

0.747

R\&D expenditures

Patent citations and

0.882

0.154

0.938

0.394

0.889

new products

R\&D expenditures

0.775

0.940

0.933

0.771

0.791

and new products

* Correlation matrix is not positive definite 


\section{APPENDIX E}

\section{Results for the KMO measure and the MSA measure}

KMO measure

\begin{tabular}{ll}
\hline Total & 0.762 \\
Aerospace and defense & 0.721 \\
Computers and office machinery & 0.651 \\
Pharmaceuticals & 0.695 \\
Electronics and communications & 0.804
\end{tabular}

MSA measure

\begin{tabular}{llllll}
\hline Variables & Total & $\begin{array}{l}\text { Aerospace } \\
\text { and defense }\end{array}$ & $\begin{array}{l}\text { Computers } \\
\text { and office } \\
\text { machinery }\end{array}$ & $\begin{array}{l}\text { Pharma- } \\
\text { ceuticals }\end{array}$ & $\begin{array}{l}\text { Electronics } \\
\text { and communi- } \\
\text { cations }\end{array}$ \\
\hline R\&D expenditures & 0.809 & 0.758 & 0.652 & 0.702 & 0.858 \\
Pattent counts & 0.703 & 0.666 & 0.613 & 0.705 & 0.754 \\
Patent citations & 0.703 & 0.788 & 0.679 & 0.671 & 0.750 \\
New products & 0.885 & 0.657 & 0.665 & 0.694 & 0.884
\end{tabular}




\section{APPENDIX F}

\section{Communalities for North America and Others}

North America

\begin{tabular}{llllll}
\hline Variables & Total & $\begin{array}{l}\text { Aerospace } \\
\text { and defense }\end{array}$ & $\begin{array}{l}\text { Computers } \\
\text { and office } \\
\text { machinery }\end{array}$ & $\begin{array}{l}\text { Pharma- } \\
\text { ceuticals }\end{array}$ & $\begin{array}{l}\text { Electronics } \\
\text { and communi- } \\
\text { cations }\end{array}$ \\
\hline R\&D expenditures & 0.834 & 0.921 & 0.963 & 0.897 & 0.917 \\
Patent counts & 0.913 & 0.790 & 0.936 & 0.850 & 0.894 \\
Patent citations & 0.897 & 0.915 & 0.924 & 0.611 & 0.909 \\
New products & 0.807 & 0.633 & 0.829 & 0.656 & 0.810
\end{tabular}

Others

\begin{tabular}{lcclll}
\hline Variables & Total & $\begin{array}{l}\text { Aerospace } \\
\text { and defense }\end{array}$ & $\begin{array}{l}\text { Computers } \\
\text { and office } \\
\text { machinery }\end{array}$ & $\begin{array}{l}\text { Pharma- } \\
\text { ceuticals }\end{array}$ & $\begin{array}{l}\text { Electronics } \\
\text { and communi- } \\
\text { cations }\end{array}$ \\
\hline R\&D expenditures & 0.743 & $*$ & 0.963 & 0.729 & 0.771 \\
Patent counts & 0.946 & $*$ & 0.989 & 0.812 & 0.949 \\
Patent citations & 0.910 & $*$ & 0.969 & 0.661 & 0.921 \\
New products & 0.907 & $*$ & 0.940 & 0.675 & 0.909
\end{tabular}

* The correlation and covariance matrix are not positive definite 


\section{APPENDIX G}

\section{Results of the initial unrotated factor analysis}

North America, component I

\begin{tabular}{|c|c|c|c|c|c|}
\hline Variables & Total & $\begin{array}{l}\text { Aerospace } \\
\text { and defense }\end{array}$ & $\begin{array}{l}\text { Computers } \\
\text { and offece } \\
\text { machinery }\end{array}$ & $\begin{array}{l}\text { Pharma- } \\
\text { ceuticals }\end{array}$ & $\begin{array}{l}\text { Electronics } \\
\text { and } \\
\text { communi- } \\
\text { cations }\end{array}$ \\
\hline R\&D expenditures & 0.913 & $0.95 \%$ & 0.982 & 0.947 & 0.958 \\
\hline Patent counts & 0.956 & 0.889 & 0.968 & 0.922 & 0.945 \\
\hline Patent citations & 0.947 & 0.957 & 0.961 & 0.782 & 0.953 \\
\hline New products & 0.898 & 0.796 & 0.911 & 0.810 & 0.900 \\
\hline Total Eigenvalue & 3.451 & 3.259 & 3.653 & 3.014 & 3.530 \\
\hline \multicolumn{6}{|l|}{$\%$ variance } \\
\hline explained & 86.28 & 81.47 & 91.32 & 75.35 & 88.25 \\
\hline \multicolumn{6}{|c|}{ Others, component I } \\
\hline Variables & Total & $\begin{array}{l}\text { Aerospace } \\
\text { and defense }\end{array}$ & $\begin{array}{l}\text { Computers } \\
\text { and office } \\
\text { machinery }\end{array}$ & $\begin{array}{l}\text { Pharma- } \\
\text { ceuticals }\end{array}$ & $\begin{array}{l}\text { Electronicis } \\
\text { and } \\
\text { communi- } \\
\text { cations }\end{array}$ \\
\hline R\&D expenditures & 0.862 & $*$ & 0.981 & 0.854 & 0.878 \\
\hline Patent counts & 0.973 & * & 0.994 & 0.901 & 0.974 \\
\hline Patent citations & 0.954 & $*$ & 0.984 & 0.813 & 0.960 \\
\hline New products & 0.952 & $*$ & 0.970 & 0.822 & 0.954 \\
\hline Total Eigenvalue & 3.506 & * & 3.861 & 2.877 & 3.550 \\
\hline $\begin{array}{l}\text { \% variance } \\
\text { explained }\end{array}$ & 87.66 & * & 96.51 & 71.92 & 88.75 \\
\hline
\end{tabular}




\section{APPENDIX H}

\section{Ratios for the different indicators in the sample as a whole and for sub-samples}

\begin{tabular}{|c|c|c|c|c|}
\hline Industry & $\begin{array}{l}\text { Patent counts / } \\
\text { R\&D } \\
\text { expenditures }\end{array}$ & $\begin{array}{l}\text { Patent citations } \\
\text { R\&D } \\
\text { expenditures }\end{array}$ & $\begin{array}{l}\text { New products / } \\
\text { R\&D } \\
\text { expenditures }\end{array}$ & $\begin{array}{l}\text { New products } \\
\text { Patent counts }\end{array}$ \\
\hline Total & 0.216 & 1.072 & 0.062 & 0.287 \\
\hline $\begin{array}{l}\text { Aerospace and } \\
\text { defense }\end{array}$ & 0.062 & 0.251 & 0.012 & 0.192 \\
\hline $\begin{array}{l}\text { Computers and } \\
\text { office machinery }\end{array}$ & 0.327 & 1.759 & 0.126 & 0.385 \\
\hline Pharmaceuticals & 0.086 & 0.257 & 0.026 & 0.304 \\
\hline $\begin{array}{l}\text { Electronics and } \\
\text { communications }\end{array}$ & 0.258 & 1.326 & 0.060 & 0.233 \\
\hline
\end{tabular}

Note: R\&D expenditures are in millions of US\$ 


\section{APPENDIX I}

Distribution of companies in the sample, numbers and $\%$ distribution for sectors and regions

Industry

$\begin{array}{llll}\text { Aerospace } & 18 & 3 & 21 \\ \text { and defense } & (7.03 \%) & (3.30 \%) & (6.05 \%) \\ & (85.71 \%) & (14.29 \%) & (100 \%) \\ \text { Computers } & 65 & 11 & 76 \\ \text { and office } & (25.39 \%) & (12.09 \%) & (21.90 \%) \\ \text { machinery } & (85.53 \%) & (14.47 \%) & (100 \%) \\ \text { Pharmaceuticals } & 45 & 32 & 77 \\ & (17.58 \%) & (35.16 \%) & (22.19 \%) \\ & (58.44 \%) & (41.56 \%) & (100 \%) \\ \text { Electronics and } & 128 & 45 & 173 \\ \text { communications } & (50.00 \%) & (49.45 \%) & (49.86 \%) \\ & (73.99 \%) & (26.01 \%) & (100 \%) \\ & & & \\ \text { Total } & & 91 & 347 \\ & 256 & (100 \%) & (100 \%) \\ & (100 \%) & (26.23 \%) & ( \pm 0 \% \%)\end{array}$




\section{APPENDIX J}

\section{Means and standard deviations for all variables}

\begin{tabular}{|c|c|c|}
\hline Variable & Mean & S.D. \\
\hline 1 Patents & 46.490 & 139.880 \\
\hline $2 \mathrm{Na}$. of nontechnological acquisitions $\mathrm{t}-1$ & 0.400 & 1.030 \\
\hline $3 \mathrm{No}$ of nontechnological acquisitions $\mathrm{t}-2$ & 0.350 & 0.970 \\
\hline $4 \mathrm{No}$. of nontechnological acquisitions $\mathrm{t}-3$ & 0.320 & 0.900 \\
\hline $5 \mathrm{No}$. of nontechnological acquisitions $\mathrm{t}-4$ & 0.310 & 0.880 \\
\hline 6 Absolute size of acquired knowledge base $t-1$ & 443.200 & 2303.190 \\
\hline 7 Absolute size of acquired knowledge base $1-2$ & 371.210 & 2032.950 \\
\hline 8 Absolute size of acquired knowledge base $\mathrm{t}-3$ & 338.090 & 1943.130 \\
\hline 9 Absolute size of acquired knowledge base $t-4$ & 323.580 & 1887.560 \\
\hline 10. Dummy absolute size acq.knowledge base t-1. & 0.026 & 0.160 \\
\hline I Dummy absolute size acq.knowledge base $\mathrm{t}-2$ & 0.027 & 0.160 \\
\hline 12 Dummy absolute size acq. knowledge base $1-3$ & 0.027 & 0.160 \\
\hline 13 Dummy absolute size acq. knowledge base $1-4$ & 0.024 & 0.150 \\
\hline 14 Relative size of acquired knowledge base t-1 & 0.181 & 0.354 \\
\hline 15 Relative size of acquired knowledge base $t-2$ & 0.171 & 0.348 \\
\hline 16 Relative size of acquired knowledge base $t-3$ & 0.160 & 0.339 \\
\hline 17 Relative size of acquired knowledge base $t-4$ & 0.157 & 0.336 \\
\hline 18 Relatedness of acquired knowledge base $t-\|$ & 0.012 & 0.084 \\
\hline 19 Relatedness of acquired knowledge base $t-2$ & 0.013 & 0.086 \\
\hline 20 Relatedness of acquired knowledge base t-3 & 0.011 & 0.078 \\
\hline 21 Relatedness of acquired knowledge base t-4 & 0.011 & 0.078 \\
\hline 22 Relatedness of acquired knowledge base $t-1 \mathrm{sq}$. & 0.007 & 0.076 \\
\hline 23 Relatedness of acquired knowledge base $\mathrm{t}-2 \mathrm{sq}$. & 0.008 & 0.078 \\
\hline 24 Relatedness of acquired knowledge base $t-3 \mathrm{sq}$. & 0.006 & 0.070 \\
\hline 25 Relatedness of acquired knowledge base $t-4 \mathrm{sq}$. & 0.006 & 0.070 \\
\hline 26 Cultural distance $t-1$ & 0.227 & 0.687 \\
\hline 27 Cultural distance $t-2$ & 0.216 & 0.674 \\
\hline 28 Cultural distance $\mathrm{t}-3$ & 0.209 & 0.666 \\
\hline 29 Cultural distance $t-4$ & 0.194 & 0.648 \\
\hline 30 Dummy Cultural distance t-1 & 0.620 & 0.490 \\
\hline 31 Dummy Cultural distance t-2 & 0.650 & 0.480 \\
\hline 32 Dummy Cultural distance $t-3$ & 0.680 & 0.470 \\
\hline
\end{tabular}




\section{APPENDIX J continued}

\section{Means and standard deviations for all variables}

\begin{tabular}{lcc}
\hline \multicolumn{1}{c}{ Variable } & Mean & S.D. \\
\hline 33 Dummy Cultural distance t-4 & 0.690 & 0.460 \\
34 R\&D t-1 & 316.159 & 718.358 \\
35 Logemployees t-1 & 8.810 & 1.962 \\
36 North America & 0.740 & 0.440 \\
37 Asia & 0.130 & 0.340 \\
38 Europe & 0.130 & 0.340 \\
39 Aerospace and defense & 0.061 & 0.240 \\
40 Computars and office machinery & 0.220 & 0.410 \\
41 Pharmaceuticals & 0.220 & 0.420 \\
42 Electronics and communications & 0.500 & 0.500 \\
43 Presample patents t-1 & 124.210 & 368.970 \\
44 year 1989 & 0.140 & 0.350 \\
45 year 1990 & 0.140 & 0.350 \\
46 year 1991 & 0.140 & 0.350 \\
47 year 1992 & 0.140 & 0.350 \\
48 year 1993 & 0.140 & 0.350 \\
49 year 1994 & 0.140 & 0.350 \\
50 year 1995 & 0.140 & 0.350 \\
\hline
\end{tabular}




\section{APPENDIX K}

Distribution of companies in the sample, numbers and \% distribution for sectors and regions

Industry

\section{Aerospace}

and defense

Computers

and office

machinery

Pharmaceuticals

$(16.97 \%)$

Electronics and communications

Total

218

$(100 \%)$

$(72.43 \%)$
37

(56.06\%)

Others

1

$(1.20 \%)$

$(5.88 \%)$

10

$(12.05 \%)$

(14.93\%)

29

$(34.94 \%)$

$(43.94 \%)$

43

$(51.81 \%)$

(28.48\%)

(71.52\%)
83

$(100 \%)$

$(27.57 \%)$
Total

17

(5.65\%)

(100\%)

67

(22.26\%)

$(100 \%)$

66

(21.93\%)

(100\%)

151

(50.16\%)

(100\%)

301

(100\%)

$(100 \%)$ 


\section{REFERENCES}

A

Acs, Z.J. and D.B. Audretsch, 1989, Patents as a measure of innovative activity, Kyklos, 4, pp. 171-180.

Adams, L., 1998, Merger mania returns with a vengeance, http/www.iswonline.com /archives/wood/mergers.shtml.

Ahuja, G. and R. Katila, 2001, Technological acquisitions and the innovation performance of acquiring firms: a longitudinal study, Strategic Management Journal, 22, pp. 197-220.

Albert, M.B., Avery, D., Narin, F. and P. McAllister, 1991, Direct validation of citation counts as indicators of industrially important patents, Research Policy, 20, pp. $251-259$.

Amburgey, T. and A.S. Miner, 1992, Strategic momentum: the effects of repetitive, positional, and contextual momentum on merger activities, Strategic Management Jowrnal, 13, pp. 335-348.

Archibugi, D., 1992, Patenting as an indicator of technological innovation: a review, Science and Public Policy, 6, pp. 357-358.

Arundel, A. and J. Kabla, 1998, What percentage of innovations are patented? experimental estimates in European firms, Research Policy, 27, pp. 127-142. Aspden, H., 1983, Patent statistics as a measure of technological vitality, World Patenf Information, 5, pp. 170-173.

Auerbach, A.J., 1988, Mergers and acquisitions, University of Chicago Press, Chicago.

\section{B}

Baltagi, B.H., 1995, Econometric analysis of panel data, J.H. Willey \& Sons inc., New York.

Barkema, H.G. and G.A.M. Vermeulen, 1998, International expansion through start-up or through acquisition: an organizational learning perspective, Academy of Management Journal, 41, pp. 7-26. 
Barney, J.B., 1986, Strategic factor markets: expectations, luck, and business strategy, Management Science, 21, pp. 1231-1241.

Barney, J.B., 1988, Returns to bidding firms in mergers and acquititions: reconsidering the relatedness hypothesis, Strategic Management Journal, 9, pp.71-78.

Barney, J.B., 1.991, Firm resources and sustained competitive advantage, Joumal of Management, 17, pp. 99- 120.

Bartlett, C.A., 1993, Commentary: strategic flexibility, firm organization, and managerial work in dynamic markets, in: Shrivastava, P., Huff, A.S. and J. Dutton (eds.), Advances in Strategic Management, 9, JAl Press, Greenwich. Basberg, B.L., 1987, Patents and the measurement of technological change: a survey of the literature, Research Policy, 12, pp. 227-237.

Berkovitch, E. and P. Narayanan, 1993, Motives for takeovers: an empirical investigation, Journal of Financial and Quantitative Analysis, 28, pp. 347-362.

Bierly, P. and A. Chakrabarti, 1996, Generic knowledge strategies in the U.S. pharmaceutical industry, Strategic Management Journal, 17 winter special issue, pp. 123-135.

Blonigen, B.A. and C.T. Taylor, 2000, R\&D intensity and acquisitions in hightechnology industries: evidence from the U.S. electronic and electrical equipment industries, Journal of Industrial Economics, 48, pp. 47-70.

Boisot, M.H., 1995, Is your firm a creative destroyer? competitive learning and knowledge flows in the technological strategies of firms, Research Policy, 24, pp. 489-506.

Bound, J., Cummins, C., Griliches, Z., Hall, B.H. and A. Jaffe, 1984, Who does R\&D and who patents?, in Z. Griliches, (ed.), R\&D, patents, and productivity, University of Chicago Press, Chicago, pp. 21-54.

Breschi, S., Lissoni, F. and F. Malerba, 1998, Technological diversification and knowledge proximity, mimeo CESPRI, Bocconi University, Milan.

Breschi, S., Lissoni, F. and F. Malerba, 2003, Knowledge-relatedness in firm technological diversification, Research Policy, 32, pp. 69-87. 
Bresman, $\mathrm{H}_{\text {, }}$ Birkenshaw, J. and R. Nobel, 1999, Knowledge transfer in international acquisitions, Joumal of Intemational Busmess Studies, 30, pp. 439-462.

Brouwer, E. and A. Kleinknecht, 1999, Innovative output, and a firm's propensity to patents: an exploration of CIS micro data, Research Policy, 28, pp. 615-624. Bruche, G., 2000, Corporate strategy, relatedness and diversification, working paper no. 13, Business Institute Berlin, Berlin School of Economics, Berlin.

C

Cameron, A.C. and P.K. Trivedi, 1986, Econometric models based on count data: comparisons and applications of some estimators and tests, Jounal of Applied Econometrics, 1, pp. 29-53.

Cantwell, J, and C. Hodson, 1991, Global R\&D and UK competitiveness, in Casson, M. (ed.), Global research strategy and international comperitiveness, Blackwell, Oxford, pp. 133-182.

Capron, L. and W. Mitchell, 2000, Internal wersus external knowledge sourcing: evidence from telecom operators in Europe, Working Paper, INSEAD, France. Carlton, D.W. and J.M. Perloff, 1990, Modenn industrial organization, HarperCollins Publishers, U.S., London.

Carpenter, M. P., Narin, F. and P. Woolf, 1981, Citation rates to technologically important patents, World Patent Information, 3, pp. 160-163.

Caves, R.E., 1989, Mergers, takeovers, and economic efficiency: foresight us. hindsight, International Journal of Industrial Organization, 7, pp.16-30.

Chakrabarti, A., Hauschildt, J. and C. Sueverkruep, 1994, Does it pay to acquire technological firms?, R\&D Management, 24, pp.47-56.

Chang, S. and P.M. Rosenzweig, 2001, The choice of entry mode in sequential foreign direct investment, Strategic Management Joumal, 22, pp. 747-776.

Chatterjee, S., Lubatkin, M.H., Schweiger, D.M. and Y. Weber, 1992, Cultural differences and shareholder value in related mergers: linking equity and human capital, Strategic Management Journal, 13, pp. 319-334.

Chesbrough, H. and D. Teece, 1996, When is virtual virtuous: organizing for innovation, Harvard Business Review, January-February, pp. 65-74. 
Child, J., Faulkner, D. and R. Pitkethly, 2001, The management of intemational acquisitions, Oxford University Press, Oxford.

Cincera, M., 1997, Patents, R\&D, and technological spillovers at the firm level: some evidence from econometric count models for panel data, Journal of Applied Econometrics, 12 , pp. 265-280.

Clark, J.J., Chakrabarti, A.K. and T.C. Chiang, 1988, Trends and stochastic movements in US merger activity, Quarterly Review of Economics and Business, 28, pp. 6-19.

Cohen, W.M. and R.C. Levin, 1989, Empirical studies of innovation and market structure, in: Schmalensee, R. and R. Willig (eds.), 1989, Handbook of industrial organization, 2, Elsevier, Amsterdam, pp. 1059-1107.

Cohen, W.M. and D. Levinthal, 1989, Innovation and learning: the two faces of R\&D, Economic Joumal, 99, pp. 569-596.

Cohen, W.M. and D. Levinthal, 1990, Absorptive capacity: a new perspective on learning and innovation, Administrative Science Quarterly, 35, pp. 128-152.

Cohen, W.M., Nelson, R.R. and J.P. Walsh, 2000, Protecting their intellectual assets: appropriability conditions and why U.S. manufacturing firms patent (or not), National Bureau of Economic Research, working paper 7552, Cambridge MA.

Conner, K. and C.K. Prahalad, 1996, A resource-based theory of the firm: knowledge versus opportunism, Organization Science, 7, pp. 477-501.

Cooke, T.E., 1988, International mergers and acquisitions, Basil Blackwell, Oxford Cyert, R. and J. March, 1963, A behavioral theory of the firm, PrenticeHall: Englewood Cliffs, NJ.

\section{D}

Datta, D.K., 1991, Organizational fit and acquisition performance: effects of postacquisition integration, Strategic Management Joumal, 12, pp. 281-297.

Datta, D.K., Pinches, G.E. and V.K. Narayanan, 1992, Factors influencing wealth creation from mergers and acquisitions: a meta-analysis, Strategic Management Joumal, 13, pp. 67-84. 
Devinney, T.M., 1993, How well do patents measure new product activity?, Economic Letters, 41 , pp. 447-450.

Di Pede, T., 2001, Merger Mania in the pharmaceutical industry, Canadian Treatment action council, 4, pp.4-5.

DiBartolomeo, K., 2000, Mergers and acquisitions, http://www.stfrancis.edu/ba ghkickul/stuwebs/btopics/works/merger.htm.

Dimasi, J., 1995, New drug development: cost, risk, and complexity, Drug Information Journal, 29 , pp. 375-384.

Dodgson, M., 1993, Organizational learning: a review of some literatures, Organization Studies, 14, pp. 375-394.

Dosi, G., 1988, Sources, procedures, and microeconomic effects of innovation, Journal of Economic Literature, 26, pp. 1120-1171.

DuBoff, R.B. and E.S. Herman, 2001, Mergers, concentration, and the erosion of democracy, Monthly Review, 53.

Dunning, J.H., 2000, The eclectic paradigm as an envelope for economic and business theories of MNE activity, International Business Review, 9, pp. 163-190.

Duysters, G., 1995, The evolution of complex industrial systems: the dynamics of major IT sectors, Universitaire Pers Maastricht, Maastricht.

Duysters, G., 2001, Partner or perish, surviving the network economy, Inaugural lecture given on 22 June 2001, Eindhoven University of Technology, Eindhoven.

Duysters, G. and J. Hagedoorn, 1998, Technological convergence in the IT industry: the role of strategic technology alliances and technological competencies, International Journal of the Economics of Business, 5, pp. 335-368.

Duysters, G. and J. Hagedoorn, 2000, Core competences and company performance in the world-wide computer industry, Jowrnal of High Technology Management Research, 11, pp. 75-91.

Duysters G. and J. Hagedoorn, 200』, Do company strategies and structures converge in global markets? evidence from the computer industry, Joumal of International Business Studies, 32, pp. 347-356. 
E

Eisenhardt, K.M. and J.A. Martin, 2000, Dynamic capabilities: what are they?, Strategic Management Joumal, 21, pp. 1105-1121.

Ernst, H., 2001, Patent applications and subsequent changes of performance: evidence from time-series cross-section analyses on the firm level, Research Policy, 30 , pp. 143-157.

\section{F}

Fai, F., 2001, Technological diversification: implications for the firm, Submission for Nelson and Winter conference, DRUID, Denmark.

Farell, C., 2000, Who benefits from merger mania, Business Week online, July 7. Feldman, M.S., 1989, Order without design: information production and policy making, Stanford university Press, Stanford CA.

Fildes, R., 1990, Strategic challenges in commercializing biotechnology, California Management Review, Spring, pp. 63-72.

Franko, L.G., 1989, Global corporate competition: who's winning, who's losing, and the R\&D factor as one reason why, Strategic Management Joumal, 10, pp. 449474.

Freeman, C. and J. Hagedoorn, 1995, Convergence and divergence in the internationalization of technology, in: $\mathbb{J}$. Hagedoorn (ed.), Technical change and the world economy. convergence and divergence in technology strategies, Edward Elgar, Aldershot, pp. 34-57.

Freeman, C. and L. Soete, 1997, The economics of industrial inwovation, Pinter, London.

Fuess Jr., S.M., 1996, On replication in business and economics research: the QJBE case. Quarterly Jound of Business and Economics, 35, pp. 3-13.

G

Gambardella, A. and S. Torrisi, 1998, Does techological convergence imply convergence in markets? evidence from the electronics industry, Research Policy, 27, pp. 455-463. 
Gaughan, P., 2001, Is merger mania still a good thing, The journal of Corporate Accounting \& Finance, 12, pp. 3-8.

Gaughan, P., 2002, What is the outlook for M\&A in an uncertain market, The journal of Corporate Accounting \& Finance, 13, pp. 51-53.

Geringer, J.M., Beamish P.W. and R.C. daCosta, 1989, Diversification strategy and internationalization: implications for MNE performance, Strategic Management Jounal, 10, pp. 109-119.

Gerpott, T.J., 1995, Successful integration of R\&D functions after acquisition: an exploratory empirical study, R\&D Management, 25, pp. 161-178.

Gerybadze, A. and Stephan, M., 2002, Determinants of technological diversification, an analysis of corporate diversification patterns, Discussion Paper 02-01, Center for International Management and Innovation, University of Hohenheim, Stuttgart.

Giuri, P., Hagedoom, J. and M. Mariani, 2004, Technological diversification and strategic alliances, in: Cantwell, J., Gambardella A. and O. Granstrand (eds.), The economics and management of technological diversification, Routledge, London.

Golbe, D.L., and L.J. White, 1988, Mergers and acquisition in the US economy: an aggregate and historical overview, in: A.J., Auerbach (ed.), Mergers and acquisitions, The University of Chicago Press, Chicago, pp. 25-47.

Goshal, S., 1987, Global strategy: an organizing framework, Strategic Management Journal, 8, pp. 425-440.

Gourieroux, C., Montfort A. and A.Trognon, 1984a, Pseudo maximum likelihood methods: theory, Econometrica, 52, pp. 681-700.

Gourieroux, C., Montfort A. and A.Trognon, 1984b, Pseudo maximum likelihood methods: applications to poisson models, Econometrica, 52, pp. 701-720. Granstrand, O., 1998, Towards a theory of the technology-based firm, Research Policy, 27, pp. 465-489.

Granstrand, O., Patel, P. and K. Pavitt, 1997, Multi-technology corporations: why they have distributed rather than distinctive core competences, California Management Review, 39, pp. 8-25. 
Granstrand, O. and S. Sjölander, 1990, Managing innovation on multi-technology corporations, Research Policy, 19, pp. 35-60.

Grant, R.M., 1996, Toward a knowledge-based theory of the firm, Strategic Management Journal, 17 winter special issue, pp. 109-122.

Greene, W., 1993, Econometric analysis, Macmillan, New York. Griliches, Z., 1984, Market value, $R \& D$ and patents, University of Chicago Press, Chicago.

Griliches, $Z_{\text {., }}$ 1990, Patent statistics as economic indicators: a survey, Joumal of Economic Literature, 28, pp. 1661-1707.

Griliches, Z., 1998, R\&D and productivity: the econometric evidence, The University of Chicago Press, Chicago.

Grupp, H., 1994, The measurement of technical performance of innovations by technometrics and its impact on established technology indicators, Research Policy, 23, pp. 175-193.

Gujarati, D., 1988, Basic econometrics, McGraw-Hill, New York.

H

Hagedoorn, J., 1989, The dynamic analysis of innovation and diffusion. Pinter London.

Hagedoorn, J., 1993, Understanding the rationale of strategic technology partnering: inter-organizational modes of cooperation and sectoral differences, Strategic Management Joumal, 14, pp. 371-85.

Hagedoorn, J., 1995, A note on international market leaders and networks of strategic technology partnering, Strategic Management Joumal, 16, pp. 241 -250.

Hagedoorn, J., 2002, Inter-firm R\&D partnerships: an overview of major trends and patterns since 1960, Research Policy, 31, pp. 477-492.

Hagedoorn J., Cloodt D. and H. van Kranenburg, forthcoming, Intellectual property rights and the governance of international R\&D partnerships, Journal of International Business Studies.

Hagedoorn, J. and M. Cloodt, 2003, Measuring innovative performance: is there an advantage in using multiple indicators?, Research Policy, 32, pp. 1365-1379. 
Hagedoorn I. and G. Duysters, 2002a, The effect of mergers and acquisitions on the technological performance of companies in a high-tech environment, Technology Analysis \& Strategic Management, 14, pp. 67-85.

Hagedoorn, J. and G. Duysters, 2002b, External appropriation of innovative capabilities: the choice between strategic partnering and mergers and acquisitions, Joumal of Management Studies, 39, pp.167-188.

Hagedoorn, J. and B. Sadowski, 1999, The transition from strategic technology alliances to mergers and acquisitions: an exploratory study, Joumal of Management Studies, 36, pp. 87-107.

Hair, J.F., Anderson, R.E., Tatham, R. and W. Black, 1995, Multivariate data analysis with readings, Prentice Hall, Englewood Cliffs (NJ).

Haleblian, J. and S. Finkelstein, 1999, The influence of organizational acquisition experience on acquisition performance: a behavioral learning perspective, Administrative Science Quarterly, 44, pp. 29-56.

Hall, B.H., 1990, The impact of corporate restructuring on industrial research and development, Brookings Papers on Economic Activity, 3, pp. 85-135.

Hall, B.H., Griliches, Z. and J. Hausman, 1986, Patents and R\&D, is there a lag?, International Economic Review, 27, pp. 265-283.

Hall, B.H., Jaffe, A. and M. Trajtenberg, 2000, Market value and patent citations: a first look, working paper 7741, NBER working series paper.

Hamel, G., 1991, Competition for competence and interpartner learning within international strategic alliances, Strategic Management Journal, 12, pp. 83-103.

Hamel, G., 2000, Leading the Revolution, Harvard Business School Press, Boston. Hamermesh, D.S., 1997, Some thoughts on replications and reviews, Labour Economics, 4, pp. 107-109.

Harhoff, D., Narin, F., Scherer F.M. and K. Vopel, 1999, Citation frequency and the value of patented inventions, Review of Economics and Statistics, 81, pp. 511 515 .

Haspeslagh P.C. and D.B. Jemison, 1991, Managing acquisitions: creating value through corporate renewal, The Free Press, New York. 
Hausman, J., Hall B.H. and Z. Griliches, 1984, Economerric models for count data with an application to the patents-R\&D relationship, Econometrica, 52, pp. 909-938.

Hay, D.A. and D.J. Morris, 1991, Industrial economics and organization, Oxford University Ptess, Oxford.

Healy, P.M., Pallepu, K.G. and R.S. Ruback, 1992, Does corporate performance improve after mergers?, Joumal of Financial Economics, 31, pp. 135-175.

Hemmert, M., forthcoming, The influence of institutional factors on the technology acquisition performance of high-tech firms: survey results from Germany and Japan, Research Policy.

Henderson, R. and I. Cockburn, 1994, Measuring competence? Exploring firm effects in pharmaceutical research, Strategic Management Journal, 15, pp. 63-84.

Hitt, M.A., Harrison, J.S., Ireland., R.D. and A. Best, 1998, Atributes of successful and unsuccessful acquisitions of U.S. firms, British Jounal of Management, 9 , $\mathrm{pp} .91-1 \| 4$.

Hitt, M.A., Hoskisson, R.E., Ireland R.D. and J.S. Harrison, 1991, Effects of acquisitions on R\&D inputs and outputs, Academy of Management Journal, 34 , pp. 693-706.

Hitt, M.A., Hoskisson, R.E., Johnson R.A. and D.D. Moesel, 1996, The market for corporate control and firm innovation, Academy of Management Journal, 39, pp. 1084-1119.

Hitt, M.A., Hoskisson R.E. and H. Kim, 1997, International diversification: effects on innovation and firm performance in product-diversified firms, Academy of Management Joumal, 40, pp. 767-798.

Hitt, M.A., Ireland, R.D. Camp S.M. and D.L. Sexton, 2001, Guest editors" introduction to the special issue strategic entrepreneurship: entrepreneurial strategies for wealth creation, Strategic Management Journal, 22, pp. 479-491.

Hoecklin, I., 1995, Managing cultural differences: strategies for comperitive advantage, Sage Publications, Workingham.

Hofstede, C., 1980, Culture's consequences: international differences in work-related values, Sage Publications, Canada. 
Hoskisson, R. E., and M. A. Hitt, 1994, Downscoping: how to tame the diversiffed firm, Oxford University Press, Oxford.

Hoskisson, R.E. and R.A. Johnson, 1992, Corporate restructuring and strategic change: the effect on diversification strategy and R\&D intensity, Strategic Mamagement Jounnal, 13, pp. 625-634.

Hsiao, C., 1986, Analysis of panel data, Cambridge University Press, Cambridge. Hubbard, R. and D.E. Vetter, 1992, The publication incidence of replications and critical comments in economics, American Economist, 36, pp. $29-34$.

Hubbard, R. and D.E. Vetter, 1997, Journal prestige and the publication frequency of replication research in the finance literature, Quarterly Jound of Business and Economics, 36, pp. 3-14.

Huber, G.P., 1991, Organizational learning: the contributing processes and literatures, Organization Science, 2, pp. 71-87.

Hunter, J.E., 2001, The desperate need for replications, Journal of Consumer Research, 28, pp. 149-158.

I

Ikeda, K. and N. Doi, 1983, The performance of merging firms in Japanese manufacturing industry: 1964-75, The Jowrnal of Industrial Economics, $X X X \mathrm{X}$, pp. 257-265.

$\mathbf{J}$

Jaffe, A.B., 1986, Technologicall opportunity and spillovers of R\&D: evidence from firms' patents, profits, and market value, American Economic Review, 76, pp. 984-1001.

Jaffe, A., Trajtenberg, M. and R. Henderson, 1993, Geographic localization of knowledge spillovers as evidenced by patent citations, Quarterly Journal of Economics, 108, pp. 577-598.

Jarell, G.A., Brickley, J.A. and J.M. Netter, 1988, The market for corporate control: the empirical evidence since 1980 , Joumal of Economic Perspectives, $2, \mathrm{pp} .49$ 68. 
Jemison, D.B. and S.B. Sitkin, 1986, Corporate acquisitions: a process perspective, Academy of Management Review, 11, pp. 145-163.

Jensen, M.C., 1984, Takeovers: folklore and science, Harvard Business Review, pp. 109-121.

Jensen, M.C. and R.S. Ruback, 1983, The market for corporate control: scientific evidence, Journal of Financial Economics, 11 , pp. 5-50.

Jonquières de G., 1989, The deadly mirage of convergent technology, Financial Times, 24 July.

Judge, G.G., Hill, R.C., Griffiths, W.E., Lütkepohl, H.H. and T. Lee, 1988, Introduction to the theory and practice of econometrics, Wiley, New York.

K

Kang, $\mathrm{N}$. and S. Johansson, 2000, Cross-border mergers and acquisitions: their role in industrial globalisation, STI Working Paper, OECD, Paris.

Karim, S. and W. Mitchell, 2000, Path-dependent and path-breaking change: reconfiguring business resources following acquisitions in the US medical sector 1978-1995, Strategic Management Journal, 21, pp. 1061-1081.

Karki, M.M.S., 1997, Patent citation analysis: a policy analysis tool, World Patent Information, 19, pp. 269-272.

Katila, R., 2002, New product search over time: past ideas in their prime?, Academy of Management Journal, 45, pp. 995-1010.

Katilla, R. and G. Ahuja, 2002, Something old, something new: a longitudinal study of search behavior and new product introduction, Academy of Management Journal, 45, pp. 1183-1194.

Katz, J.P., Simanek, A. and J.B. Townsend, 1997, Corporate mergers and acquisitions: one more wave to consider, Business Horizons, 1, pp. 32-40.

King, D.R., Dalton, D.R., Daily, C.M. and J.G. Covin, 2004, Meta-analyses of postacquisition performance: indications of unidentified moderators, Strategic Management Journal, 25, pp. 187-200.

Kleinert, J. and H. Klodt, 2002, Causes and consequences of merger waves, Kiel Working paper no. 1092, Kiel Institute of World Economics, Kiel. 
Kleinknecht, A., 1999, Measuring product and service innovation: an assessment of alternative indicators, Rotterdam Institute for Business Economic Studies, Erasmus Universiteit Rotterdam, Rotterdam.

Kobrin, S.J., 1991, An empirical analysis of the determinants of global integration, Strategic Management Journal, 12, pp. 17-31.

Kogut, B. and H. Singh, 1988, The effect of national culture on the choice of entry mode, Journal of International Business Studies, 19, pp. 411-432.

Kogut, B. and U. Zander, 1992, Knowledge of the firm, combinative capabilities, and the replication of technology, Organization Science, 3, pp. 383-397.

Kondo, M., 1999, R\&D dynamics of creating patents in the Japanese industry, Research Policy, 28, pp. 587-600.

Kranenburg van H., Cloodt M. and J. Hagedoorn, 2001, An exploratory study of tecent trends in the diversification of Dutch publishing companies in the multimedia and information industries, International Studies of Management and Organization, 31, pp. 64-86.

$\mathbf{L}$

Lanjouw, J.O. and M. Schankerman, 1999, The quality of ideas: measuring innovation with multiple indicators, NBER working paper 7345 .

Lee, G., 2004, The significance of capability distribution in the race to enter emerging markets: telephony communications and computer networking 1989-2001, Working Paper, Haas School of Business University of California, Berkeley.

Levinthal, D.A. and J.G. March, 1981, A model of adaptive organizational search, Journal of Economic Behavior and Organization, 2, pp. 307-333.

Levinthal, D.A. and J.G. March, 1993, The myopia of learning, Strategic Management Journal, 14, pp. 95-112.

Levitt, B. and J.G. March, 198.8, Organizational learning, Annual Review of Sociology, 14, pp. 319-340.

Liebeskind, J.P., 1996, Knowledge, strategy, and the theory of the firm, Strategic: Management Joumal, 17 special winter issue, pp. 93-107. 
Link, A.N., 1988, Acquisitions as sources of technological innovation, Mergers and Acquisitions, 23, pp. 36-39.

Lorell, M.A., Lowell, J., Moore, R.M., Greenfield, V. and K. Vlachos, 2002, Going Global? U.S. government policy and the defense aerospace industry, RAND, Santa Monica.

Lubatkin, M., 1987, Merger strategies and stockholder value, Strategic Management Journal, 8, pp. 39-53.

\section{$\mathbf{M}$}

MacDonald, J.M., 1985, R\&D and the directions of diversification, Review of Economics and Statistics, 47, pp. 538-590.

Mairesse, J. and P. Mohnen, 2002, Accounting for innovation and measuring innovativeness: an illustrative framework and application, paper presented at MERIT-workshop, Maastricht University.

Mansfield, E., 1986, Patents and innovation: an empirical study, Management Science, 32, pp. 173-181.

March, J.G. and G. Sevon, 1984, Gossip, information and decision making, in: Sproul, L.and P. Larkey (eds.), Advances in information processing in organizations, 1 , Hillsdale, NJ: Erlbaum, pp. 95-107.

McGowan, J.J., 1971, International comparisons of merger activities, Journal of Law and Economics, 14, pp. 233-250.

Meeks, G., 1977, Disappointing marriage: a study of the gains from merger, Cambridge University Press, Cambridge.

Mergerstat, 2004, FactSet Mergerstat's M\&A roundup in 2003, www.mergerstat.com

Michel, J. and B. Bettels, 2001, Patent citation analysis: a closer look at the basic input data from patent search reports, Scientometrics, 51, pp. 185-201.

Mohnen P. and M. Dagenais, 2002, Towards an innovation intensity index: the case of CIS1 in Denmark and Ireland, in: Kleinknecht A. and P. Mohnen (eds.), Firm performance: economerric explorations of survey data, Palgrave, New York. 
Mowery, D.C., Oxley, J.E., and B.S. Silverman, 1996, Strategic alliances and interfirm knowledge transfer, Straregic Management Joumal, 17 winter special issue, pp. $77-91$.

Mueller, D.C., 1980, The determinants and effects of mergers, an infernational comparison, Oelgeschlager, Gunn \& Hain, Cambridge.

Mueller, D.C., 1986a, The modern corporation-profits, power, growth and performance, Wheatsheaf Books, Brighton.

Mueller, D.C., 1986b, Profits in the long rum, Cambridge University Press, Cambridge.

Mukherjee, T.K., Kiymaz, H. and H.K. Baker, 2004, Merger motives and target valuation: a survey of evidence from CFOs, paper presented at the Financial Management Association amnual meeting, JEL classification: G34, October, New Orleans.

$\mathbf{N}$

Napolitano, G. and G. Sirilli, 1990, The patent system and the exploitation of inventions: results of a statistical survey conducted in Italy, Technovation, 10, pp. 5-16.

Narin, F., Noma E. and R. Perry, 1987, Patents as indicators of corporate technological strength, Research Policy, 16, pp. 143-155.

National Science Foundation, 1998, Science and engineering indicators, National Science Foundation, Washington D.C.

Nelson, R.L., 1959, Merger movements in American industry, 1895-1956, Princeton University Press, Princeton, N.J.

Nelson, R.R., 1987, Understanding technical change as an evolutionary process, Elsevier Science Publishers, New York.

Nelson, R.R. and S.G. Winter, 1982, The evolutionary theory of economic change, Harvard University Press, Cambridge.

Nonaka, I., 1991, The knowledge creating company, Harvard Business Review, 69, pp. 96-104. 
Norusis, M.J., 1993, SPSS@ for Windows TM, Professional Statistics ${ }^{\text {TM }}$, release 6.0, SPSS inc, Chicago (IL).

\section{O}

OECD, 1992, Technology and the economy, OECD, Paris.

OECD, 1997, Revision of high technology sector and product classification, OECD, Paris.

OECD, 2001, The Science Technology and Industry Scoreboard 2001, OECD, Paris. Olie, R.L., 1996, European Transnational Mergers, Datawyse Maastricht, Maastricht. Oster, S.M., 1999, Modern competitive analysis, Oxford University Press, New York.

$\mathbf{P}$

Pablo, A.L., Sitkin, S.B. and Jemison, D.B., 1996, Acquisition decision-making processes: the central role of risk, Journal of Management, 22, pp. 723-746.

Pakes, A., 1985, On patents, R\&D, and the stock market rate of return, Journal of Political Economy, 93, pp. 390-409.

Pakes, A. and Z. Griliches, 1984, Patents and R\&D at the firm level; a first look, in Z.Griliches (ed.), R\&D, patents and productivity, The University of Chicago Press, Chicago, pp. 55-72.

Palepu, K., 1985, Diversification strategy, profit performance, and entrophy measure, Strategic Management Journal, 6, pp. 239-255.

Park, C., 2002, The effects of prior performance on the choice between related and unrelated acquisitions: implications for the performance consequences of diversification strategy, Journal of Management Studies, 39, pp. 1003-1019.

Park, C., 2003, Prior performance characteristics of related and unrelated acquirers, Strategic Management Journal, 24, pp. 471-480.

Patel, P. and K. Pavitt, 1991, Large firms in the production of the world's technology: an important case of non-globalization, Journal of International Business Studies, 22, pp. 1-21.

Patel, P. and K. Pavitt, 1995, Divergence in technological development among countries and firms, in: J. Hagedoon (ed.), Technical change and the world 
economy: convergence and divergence in technology strategies, Edward EIgar, Aldershot, pp. 147-181.

Patel, P. and K. Pavitt, 1997, The technological competencies of the world's largest firms: complex and path-dependent, but not much variety, Research Policy, 26. pp. $141-156$.

Pavitt, K., 1988, Uses and abuses of patent statistics, in: A.F.J. van Raan (ed.), Handbook of Quantitative Studies of Science and Technology, Elsevier, Amsterdam, pp. 509-536.

Pavitt, K., Robson, M. and J. Townsend, 1989, Technological accumulation, diversification and organization in UK companies $1945-1983$, Management Science, 35, pp. 81-99.

Pfeffer, J., 1972, Merger as a response to organizational interdependence, Administrative Science Quarterly, 17, pp. 382-394.

Pisano, G.P., 1994, Knowledge, integration, and the locus of learning: an empirical analysis of process development, Strategic Management Journal, 15, pp. 85100 .

Pisano, G. and S. Wheelwright, 1995, The new logic of high-tech R\&D, Harvard Business Review, 73, pp. 93-105.

Porter, M.E., 1987, From competitive advantage to corporate strategy, Harvard Business Review, May-June, pp. 43-59.

Prabhu, C.J., Chandy, R.K. and M.E. Ellis, forthcoming, The impact of acquisitions on innovation: poisson pill, placebo, or tonic?, Joumal of Marketing.

PriceWaterhouseCoopers, 2004, Technology sector insights: analysis \& opinions on merger \& acquistion activity 2003, PriceWaterhouseCoopers, England.

$\mathbf{R}$

Ravenscraft, D.J. and F.M. Scherer, 1987, Life after takeover, Journal of Industrial Economics, 36, pp. 147-157.

Ravenscraft, D.J. and F.M. Scherer, 1989, The profitability of mergers, International Journal of Industrial Organization, 7, pp. 101-117. 
Reed, R., DeFillipi, R.J., 1990, Causal ambiguity, barriers to imitation, and sustainable competitive advantage, Acadewy of Management Review, 15, pp. 88-102.

Reuer, J.J., Min Park. K. and M. Zollo, 2002, Experiential learning in international joint ventures: the roles of experience heterogeneity and venture novelty in: $F$. Contractor and P. Lorange (eds.), Cooperative strategies and alliances, Pergamon, Ox ford, pp. 321-344.

Roberts, P.W., 1999, Product innovation, product-market competition and persistent profitability in the US pharmaceutical industry, Strategic Management Journal. 20, pp. $655-670$.

Roijakkers, N. and J. Hagedoorn, 2003, Inter-firm R\&D partnering in high technology industries: pattems in the intemational biotechnology industry since 1975, in J.H. Dunning and G. Boyd (eds.), Alliance capitalism and corporate management, Edward Elgar, Cheltenham, pp. 63-91.

Rosenkopf, L. and P. Almeida, 2003, Overcoming local search through alliances and mobility, Management Science, 49, pp. 751-766.

Rosenkopt, L. and A. Nerkar, 2001, Beyond local search: boundary-spanning, exploration, and impact in the optical disk industry, Strategic Management Joumal, 22, pp. 287-306.

Ross, S.A., Westerfield, R.W. and J. Jaffe, 1996, Corporate Finance, Irwin McGrawHill, Boston.

$\mathbf{S}$

Sanchez, R. and J.T. Mahoney, 1996, Modularity, flexibility, and knowledge management in product and organization design, Strategic Management Journal, 17 winter special issue, pp. 63-76.

Scherer, $\mathbb{F}$ M., 1984, Using linked patent and R\&D data to measure interindustry technology flows, in Z. Griliches (ed.), R\&D, patents and productivity, The University of Chicago Press, Chicago, pp. 417-464.

Scherer, F.M., and D. Ross, 1990, Industrial market structure and economic performance, Houghton Mifflin Company, Boston. 
Seth, A., 1990, Value creation in acquisitions: a re-examination of performance issues, Strategic Managemeni Joumal, 11, pp. 99-115.

Sharp, M., Patel P. and K. Pavitt, 1996, Europe's pharmaceutical industry: an innovation profile, SPRU-University of Sussex, Sussex.

Shelton, L.M., 1988, Strategic business fits and corporate acquisition: empirical evidence, Strategic Management Journal, 9, pp. 279-287.

Shugart II, W.F. and R.D. Tollison, 1984, The random character of merger activity, Rand Journal of Economics, 15, pp. 500-509.

Singh, H. and C.A. Montgomery, 1987, Corporate strategies and economic performance, Strategic Management Journal, 8, pp. 377-386.

Singh $\mathrm{H}$. and M. Zollo, 1998, The impact of knowledge codification experience $^{-}$ trajectories and integration strategies on the performance of corporate acquisitions, Working paper 98-24, The Wharton School, Philadelphia.

Spender, J.C., 1989, Industry recipes: the nature and sources of managerial judgment, Blackwell, Oxford.

Spender, J.C., 1994, Organizational knowledge, collective practice and Penrosian rents, International Business Review, 3, pp. 353-367.

Spender, J.C., 1996, Making knowledge the basis of a dynamic theory of the firm, Strategic Management Journal, 17 winter special issue, pp. 45-62.

Stuart, T. E., 2000, Interorganizational alliances and the performance of firms: a study of growth and innovation rates in a high-technology industry, Strategic Management Joumal, 21, pp. 791-811.

Sutton, C.J., 1980, Economics and corporate strafegy, Cambridge University Press, Cambridge.

Szulanski, G., 1996, Exploring internal stickiness: impediments to the transfer of best practice within the firm, Strategic Management Journal, 17 winter special issue, pp. 27-43.

T

Teece, D.J., 1986, Profiting from technological innovation, Research Policy, 15, pp. 285-305. 
Teece, D.J, Pisano, G. and A. Shuen, 1997, Dynamic capabilities and strategic management, Straregic Management Journal, 18, pp. 509-533.

Texier, F., 2000, Industrial diversification and innovation: an international study of the aerospace industry, Edward Elgar Publishing, Cheltenham.

Thomson Financial Statistics, 2004, Thomson financial worldwide M\&A; mergers unleashed, www.thomson.com.

Trajtenberg, M., 1990, A penny for your quotes: patent citations and the value of innovations, Rand Journal of Economics, 21, pp. 172-187.

Translink, 2003, Translink Deal Review 1999, www.translinkcf.com.

Trautwein, F., 1990, Merger motives and merger prescriptions, Strategic Management Journal, 11, pp. 283-295.

Tulder van R. and G. Junne, 1988, European multinationals in core technologies, Wiley, Chichester.

$\mathrm{V}$

Vanhaverbeke, W., Duysters, G. and N. Noorderhaven, 2002, A longitudinal analysis of the choice between technology based strategic alliances and acquisitions in high-tech industries: the case of the ASIC industry, Organization Science, 13, pp. 714-733.

Vermeulen, F. and H. Barkema, 2001, Learning through acquisitions, Academy of Management Journal, 44, pp. 457-476.

Volberda, H.W., 1996, Toward the flexible form: how to remain vital in hypercompetitive environments, Organization Science, 7, pp. 359-374.

W

Wernerfelt, B., 1984, A resource based view of the firm, Strategic Management Journal, 5, pp. 171-180.

Weston, J.F. and K.S. Chung, 1990, Takeovers and corporate restructuring: an overview, Business Economics, 25, pp. 6-11, in: Cosh, A. and A. Hughes (ed.), 1998, Takeovers, 1, Ashgate Dartmouth, Vermont. 
Weston, J.F, Chung K.S. and S.E. Hoag, 1990, Mergers, restructuring, and corporate control, Prentice-Hall, Inc., New Jersey.

Williamson, O.E., 1975, Markets and hierarchies, anolysis and antitust implications, The Free Press, New York.

Winter, S.G., 1987, Knowledge and competence as strategic assets in: D.J. Teece (ed.)., The competitive challenge: strategies for industrial inmovation and renewal, Ballinger, Cambridge $\mathrm{MA}$.

Wit. B. and R. Meyer, 1998, Strategy: process, content, context, International Thomson Business Press, London.

Wooldridge, J.M., 2002, Econometric analysis of cross section and panel data, The MIT press, Cambridge.

World Investment Report, 2000, Cross-border mergers and acquisitions and development, United Nations, New York and Geneva.

2.

Zaltman, G., Duncan, R. and J. Holbeck, 1984, Innovations and organizations, Wiley, New York.

Zollo, M. and D. Leshchinskii, 1999, Can firms learn to acquire? Do markets notice?, working paper 99/82/SM, INSEAD, France.

Zollo, M., Reuer J.J. and H. Singh, 2002, Interorganizational routines and performance in strategic alliances, Organization Science, 13, pp. 701-713. 



\section{Nederlandse samenvatting (Summary in Dutch)}

\section{Fusies en overnames in de hoogtechnologische industrieën}

\section{Introductie}

Dit proefschrift onderzoekt de mate waarin fusies en overnames binnen de hoogtechnologische sector een positieve bijdrage leveren aan het innovatievermogen van ondernemingen na voltooiing van thet fusie - of overnameproces. Recente metaanalyses laten zien dat de verwachte economische waarde van fusies en overnames in het algemeen gering tot negatief is. Een belangrijke verklaring voor deze bevinding is het feit dat onderzoek naar de prestatie van een bedrijf veelal gericht is op korte termijn effecten. De verbetering van het financieel resultaat wordt vaak gezien als de belangrijkste drijfveer voor het ondernemen van een fusie of overname. Recent onderzoek toont echter aan dat fusies en overnames door bedrijven worden geïnitieerd op basis van een reeks van beweegredenen. Het betreft hier bijvoorbeeld het verhogen van de beheersbaarheid van technologische ontwikkelingen die gepaard gaan met een toenemende onzekerheid en complexiteit.

Een belangrijke doelstelling van dit proefschrift is om het debat betreffende het effect van fusies en overnames te verbreden en te verrijken door de lange termijn effecten van fusies en overnames op de innovativiteit van hoogtechnologische bedrijven te analyseren. Het theoretisch kader van waaruit de onderzoeksvragen worden geinterpreteerd omvat een aantal gerelateerde theorieern die het belang vam kennis voor het creëren van een langdurig concurrentievoordeel benadrukken. Toenemende kennis van producten en processen speelt binnen de hoogtechnologische industrie een belangrijke rol en dat belang is alleen maar toegenomen. Ondennemingen hebben gemerkt dat het moeilijker en kostbaarder wordt om op een veelheid wan terreinen zelfstandig kennis te ontwikkelen en te (blijven) excelleren. Als gevolg hiervan zijn veel bedrijven hun kennis vaak extern gaan verwerven. Een snelle manier voor innovatieve ondernemingen om hun kennis uit te breiden is de overname en integratie van extern aanwezige kennis door middel van fusies en overnames. Deze overnames zijn onder andere gericht op het behalen van synergievoordelen uit de technologische complementariteit van de twee partijen en het vergroten van de flexibiliteit van de desbetreffende organisaties. In de praktijk blijkt echter dat veel van deze fusies en overnames niet kunnen voldoen aan de verwachte voordelen doordat ondernemingen moeite hebben met de daadwerkelijke overdracht en integratie van de verworven kennis. 
De algemene onderzoekswraag die aan dit proefschrift ten grondslag ligt luidt dan ook: "In welke mate dragen fusies en overnames binnen hoogtechnologische industrieèn (ruimtevaart \& defensie, computers, farmacie en elektronica) bij aan een verhoogde innovatie voor het overnemende bedrijf?"

Echter, voordat we antwoord kunnen geven op deze vraag is het van belang dat we een goed beeld krijgen van het concept innovatie en de manier waarop dit concept het beste kan worden gemeten. Alleen indien er een geaccepteerde selectie van individuele innovatie indicatoren en samengestelde constructen is onderzocht kan overgegaan worden tot het meten van innovatie na een fusie of overname.

\section{Het meten van innovatie}

De management - en toegepaste economie literatuur heeft veelal moeite met het concept innovatie en het meten daarvan. Veel studies gebruiken slechts één indicator (onderzoek - en ontwikkelingskosten, patenten, patent citaties of nieuwe producten), gebaseerd op het argument dat deze specifieke indicator minder tekortkomingen heeft dan de overige indicatoren. Andere studies voegen twee of meer indicatoren met een gemiddelde correlatie samen tot één construct. Weer andere studies gaan uit van het idee dat een redelijk hoge correlatie tussen enkele indicatoren voldoende ruimte geeft om elk van deze indicatoren te gebruiken als een allesomvattende indicator van innovatie.

Ons begrip van bovenstaande literatuur heeft geleid tot een aantal onderzoeksvragen (zie hoofdstuk 3). Ten eerste, is er een systematische ongelijkheid tussen verschillende indicatoren zoals uitgaven op het gebied van onderzoek \& ontwikkeling, patenten, patent citaties en nieuwe producten? Ten tweede, is er sprake van een statistische associatie tussen twee of meer indicatoren wat betekent dat een samengesteld construct de latente variabele kan vastleggen? Ten derde, is de statistische associatie tussen twee of meer indicatoren van dien aard dat elke van de desbetreffende indicatoren gebruikt kan worden als een representatieve indicator wan innovatie?

De uitkomst van dit onderzoek toont aan dat er geen significante systematische ongelijkheid bestaat tussen onderzoek - en ontwikkelingskosten, patenten, patent citaties en nieuwe producten. Aanvullend hierop, de statistische associatie tussen de vier indicatoren van innovatie is groot, waaruit we kunnen afleiden dat een samengesteld construct de latente variabele 'innovatie' inderdaad kan vastleggen. Echter, onze resultaten laten eveneens zien dat de statistische overeenkomst tussen elk van de vier indicatoren dermate groot is dat toekomstig onderzoek in principe elk van deze indicatoren kan gebruiken voor het meten van het innovatievermogen van hoogtechnologische ondernemingen. 


\section{Fit (synergie en integratie) versus flexibiliteit}

Het meest voorkomende motief voor bedrijven om over te gaan tot een fusie of overname is de zoektocht naar synergie. Synergievoordelen ontstaan wanneer bedrijven in staat zijn gerelateerde middelen samen te voegen en zodoende de waarde van de gezamenlijke onderneming te verhogen. Een belangrijk synergievoordeel in de hoogtechnologische sector is bijvoorbeeld het feit dat bedrijven door middel van internationale fusies en overnames in staat zijn om investeringen in grootschalige onderzoeksprojecten terug te verdienen. Deze verdiensten kunnen dan weer gebruikt worden voor een herinvestering in nieuwe innovatieve projecten. Met betrekking tot fusies en overnames gericht op bepaalde productmarktern kunnen we een onderscheid maken tussen horizontaal gerelateerde -, verticaal gerelateerde - en ongerelateerde fusies en overnames. Een substantieel deel van de bestaande fusie - en overname literatuur verwacht dat gerelateerde fusies en overnames een grotere bijdrage leveren aan de bedrijfsprestatie dan ongerelateerde fusies en overnames. Dit is gebaseerd op het idee dat gerelateerde fusies en overnames waarde creëren door middel van schaalvoordelen die meer synergie opleveren dan ongerelateerde fusies en overnames die geen enkele relatie hebben ten opzichte van elkaar behalve de omstandigheid dat ze onderdeel uitmaken van één overkoepelende beheerseenheid. Ondanks het feit dat huidig onderzoek voornamelijk gericht is op het financiële resultaat van een bedrijf in plaats van het innovatievermogen, is er wel degelijk een positieve relatie tussen de gerelateerdheid van fusies en overnames (in termen van productmarkten) en de innovatie van de onderneming na het fusie- of overnameproces.

Alhoewel synergievoordelen gericht op complementariteit in productmarkten éen van de belangrijjkste drijfveren zijn voor het aangaan van een fusie of overname, zien we in de periode van onze analyse dat tweederde van alle fusies en overnames ongerelateerd zijn en slechts eenderde deel geclassificeerd kan worden als gerelateerde fusies en overnames (zie hoofdstuk 2). Het grote aantal ongerelateerde fusies en ovemames kan worden verklard door een toenemende technologische convergentie tussen de productmarkten halverwege de jaren " 80 en begin jaren " 90 .

Indien vootheen ongerelateerde technologieen convergeren, zullen bedrijven met verschillende technologische trajecten de utdaging moeten aangaan om zo snel mogelijk de noodzakelijke kennis te vergaren die hen in staat stelt on te concurreren in de nieuw ontstane markten. Daarnaast leidt het convergentie proces tot een vervaging van de traditionele technologische - en sectorale grenzen waardoor de noodzaak van bedrijven on meerdere technologieën tegelijkertijd te hanteren toeneemt. Dit betekent dat hoogtechnologische bedrijven zo snel mogelijk hun bestaand kennisdomein moeten vergroten om gelijke tred te houden met de snelheid waarmee de technologische veranderingen plaatswinden.

Om toegang te krijgen tot de noodzakelijke technologische kennis en aldoende het aanwezige kemnisdomein te vergroten, kunnen bedrijven de relevante kennis zelf ontwikkelen (intern leren) of overgaan tot fusies en overnames met hoogontwikkelde technologische bedrijven (extern leren). Het opbouwers van een breed intem 
kennisdomein is een lang en kostbaar proces, waarbij de intern ontwikkelde kennis wordt vastgelegd in routinematig gedrag. Dit maakt het tevens lastig om het profiel van het aanwezige kennisdomein te veranderen. Bedrijven herhalen hun routinematig gedrag wat leidt tot een stabiel patroon van diversificatie in gerelateerde technologische gebieden. Met andere woorden, het continu vertrouwen op kennis welke is vastgelegd in bedrijfsroutines impliceert dat bedrijven meer van hetzelfde doen in plaats van zich echt aanpassen aan de veranderingen in hun omgeving.

Om zichzelf los te maken van bestaande routines kan een bedrijf overgaan tot extern leren (fusies en overnames), waardoor het beter in staat is om gebruik te maken van convergerende technologieën en de vele ideeën die gegenereerd worden buiten de grenzen van het bedrijf. De onderneming hoeft nu immers niet meer alle technologie zelf te ontwikkelen maar kan gebruik maken van de kennis die al door een ander bedrijf is ontwikkeld. In hoofdstuk 5 zien we dat extern leren door middel van fusies en overnames voornamelijk is gericht op het verkennen van verschillende technologische ontwikkelingen en het verwerven van ongerelateerde kennis. Het idee hierachter is dat een verbreding van het kennisdomein de capaciteit van het bedrijf om nieuwe technologische mogelijkheden te benutten vergroot en de snelheid van innovatie laat toenemen. Op basis van dit hoofdstuk kunnen we concluderen dat fusies en overnames een bedrijf in staat stellen om gebruik te maken van de kansen die zich voordoen in een omgeving die wordt gekenmerkt door technologische convergentie en een hoge mate van dynamiek.

Alhoewel het overnemen van kennisintensieve bedrijven in nieuwe en ongerelateerde technologische gebieden een aantrekkelijke optie is voor bedrijven, worden deze technologische fusies en overnames gehinderd door het feit dat de uitdaging niet alleen ligt in het verwerven van kennis maar ook in het verenigen van twee verschillende kennisdomeinen (zie hoofdstuk 4). Vanuit een strategisch perspectief kunnen er schaalvoordelen ontstaan indien de extern verworven kennis met enige of grotere mate is gerelateerd aan het kennisdomein van het overnemende bedrijf. Vanuit een organisatorisch perspectief, is een bedrijf beter in staat om gerelateerde kennis te evalueren en te integreren dan ongerelateerde kennis. Dit heeft te maken met het feit dat de absorptie capaciteit van een bedrijf in grote mate wordt bepaald door het aanwezige kennisdomein in relevante technologische gebieden. Met andere woorden, indien de kennisbasis van het overnemende bedrijf niet voldoende overeenstemt met de nieuw verworven kennis wordt het lastig om beide kernisdomeinen met elkaar in overeenstemming te brengen. Het overnemen van kennis in ongerelateerde technologische gebieden vereist dan ook een radicale verandering in de manier waarop het innovatieproces wordt georganiseerd en zo'n drastische aanpassing kan al snel een contraproductief effect hebben op de innovatie van het bedrijf.

Vanuit organisatorisch oogpunt is niet alleen de gerelateerdheid van kennisdomeinen zoals hiervoor beschreven van belang maar ook de relatieve grootte van het extern verworven kennisdomein. Overname van een relatief groot kennisdomein verstoort de bestaande innovatie activiteiten en leidt tot een complex, 
tijdrovend en risicovol integratieproces. Hierdoor zal het bedrijf extra energie en managementaandacht moeten inzetten om alle stadia van het integratieproces te doorlopen en te voltooien, wat vervolgens de aandacht zal afjeiden van noodzakelijke innovatie activiteiten. Derhalve presteren ondernemingen met een verschil in relatieve grootte van het kennisdomein slechter op het gebied van innovatie dan ondememingen met een relatief gelijke grootte van het kennisdomein.

\section{Antwoord op de algemene onderzoeksvraag}

In dit proefschrift onderstrepen we het belang van de voorwaarden waaronder fusies en overnames een positief effect hebben op de innovatie van het overnemende bedrijf. Teneinde het verschil in innovatievermogen tussen hoogtechnologische bedrijven te verklaren hebben we gekeken naar de rol van strategische - en organisatorische fit aan de ene kant en de mate van flexibiliteit aan de andere kant. Onze resultaten laten zien dat fusies en overnames bijdragen aan een verhoogd innovatievermogen indien er sprake is van strategische fit door middel van een grote mate van overlap tussen de desbetreffende kennisdomeinen en organisatorische fit door middel van overeenstemming in relatieve grootte tussen het overgenomen kennisdomein en de reeds aanwezige kennisbasis. Een grote mate van overlap tussen de kennisdomeinen leidt tot schaalvoordelen in het gezamenlijk ontwikkelen van nieuwe producten en diensten. Daarnaast is het makkelijker om gerelateerde kennis te integreren vanwege een verhoogd absorptievermogen. Tenslotte zal een overeenstemming in relatieve grootte tussen de desbetreffende kennisdomeinen het gehele integratieproces vergemakkelijken.

Echter een grote mate van strategische - en organisatorische fit heeft ook nadelige gevolgen. Het samenbrengen van gerelateerde bedrijfsmiddelen (kennis) met het doel om synergievoordelen te behalen en het absorptieproces danwel integratieproces te vergemakkelijken vermindert de flexibiliteit van een bedrijf ten opzichte van de omgeving. Vooral voor hoogtechnologische bedrijven is het van belang om een uitgestrekt domein van alle noodzakelijke en vaak ongerelateerde technologieën te verkennen (verhoogde flexibiliteit) in plaats van meer van hetzelfde over te nemen (verminderde flexibiliteit). Alleen dan zijn bedrijven in staat om gebruik te maken van technologische kansen die gebaseerd zijn op nieuwe en snel ontwikkelde kennis.

Dit alles betekent dat organisaties te maken hebben met een belangrijke paradox, namelijk de spanning tussen strategische - en organisatorische fit aan de ene kant en flexibiliteit aan de andere kant. Om beide uiteinden van de paradox tegelijkertijd te benaderen vergt een verhoogde mate van inventiviteit van organisaties, maar alleen op die manier is een bedrijf in staat om optimaal te profiteren van de bijdrage die fusies en overnames leveren aan het innovatievermogen.

Concluderend, de kans op het versterken van het innovatievermogen van ondernemingen lijkt het grootst te zijn in het geval van technologische fusies en 
overnames met bedrijven die qua kennisdomein een middenpositie irnemen tussen volledige overlap en het ontbreken van overlap met de al aanwezige kennis van het overnemende bedrijf. Op die manier is er aan de ene kant voldoende overlap voor het behalen van schaalvoordelen en een soepel verlopend integratieproces en aan de andere kant voldoende diversiteit voor het creëren van een toenemende mate van flexibiliteit. 


\section{Curriculum Vitae}

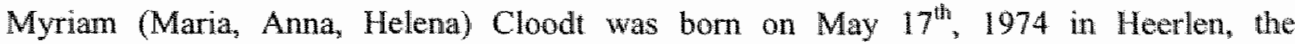
Netherlands. She attended grammar school at the Sintermeerten College in Heerlen, where she graduated in 1992. In the same year she started her study business administration, specializing in marketing and organization, at the Faculty of Economics and Business Administration at the University of Maastricht. During her study, she followed an internship at Oce NVM B.V., were she analyzed the determinants for the functioning of selfmanagement teams, which formed the basis of her Master's thesis.

After her graduation in 1997, she started working as a lecturer at the Faculty of Economics and Business Administration at the University of Maastricht, where she taught courses in the area of Management Science. In September 1999, she started her Ph.D. research at the Maastricht research school of Economics of Technology and Organizations (METEOR) at the department of Organization \& Strategy at the University of Maastricht. In the same year, she also worked as a study counselor for the Faculty of Economics and Business Administration. Since, July $1^{\text {st }} 2004$, she is working as a researcher at the sub-department Organization Science and Marketing at the department of Technology Management at the Eindhoven University of Technology. In this capacity, she is participating in the "Transforum Agro \& Groen" international agrifood networks project. Her research interests include strategic technology alliances, mergers and acquisitions, international strategy, innovation and technological change.

Myriam (Maria, Anna, Helena) Cloodt werd geboren op 17 mei 1974 te Heerlen. Zij doorliep het Lyceum aan het Sintermeerten College in Heerlen, waar zij in 1992 haar diploma behaalde. In hetzelfde jaar begon ze met haar studie bedrijfseconomie, met een specialisatie in marketing en organisatie, aan de Faculteit der Economische Wetenschappen en Bedrijfskunde van de Universiteit Maastricht. Tijdens haar studie liep zij stage bij Oce NVM B.V., waar ze onderzoek deed naar de determinanten van zelfsturende teams. Dit onderzoek vormde de basis van haar doctoraalscriptie.

Na har afstuderen in 1997, trad zij in dienst als docent bij de de Faculteit der Economische Wetenschappen en Bedrijfskunde van de Universiteit Maastricht, waar ze lesgaf in vakken op het gebied van managementwetenschappen. In september 1999, begon zij als assistent-inopleiding, verbonden aan de facultaire onderzoeksschool METEOR, bij de afdeling organisatie en strategie. In hetzelfde jaar werkte ze als studie consulent bij de Faculteit der Economische Wetenschappen en Bedrijfskunde. Sinds 1 juli 2004, is zij werkzaam als onderzoeker bij de vakgroep Organisatiekunde en Marketing aan de Faculteit Technologie Management van de Technische Universiteit Eindhoven. In deze hoedanigheid is zij betrokken bij het Transforum Agro Groen project met een focus op internationale agrifoodnetwerken. Haar onderzoeksinteresses liggen op het terrein van strategische technologie allianties, fusies en overnames, internationale strategie, innovatie en technologische verandering. 